\title{
Development of Carbon-Carbon, Carbon-x bond formation reactions through GoldLewis acid catalysis
}

Yumeng Xi

Follow this and additional works at: https://researchrepository.wvu.edu/etd

\section{Recommended Citation}

$\mathrm{Xi}$, Yumeng, "Development of Carbon-Carbon, Carbon-x bond formation reactions through GoldLewis acid catalysis" (2014). Graduate Theses, Dissertations, and Problem Reports. 7358.

https://researchrepository.wvu.edu/etd/7358

This Thesis is protected by copyright and/or related rights. It has been brought to you by the The Research Repository @ WVU with permission from the rights-holder(s). You are free to use this Thesis in any way that is permitted by the copyright and related rights legislation that applies to your use. For other uses you must obtain permission from the rights-holder(s) directly, unless additional rights are indicated by a Creative Commons license in the record and/ or on the work itself. This Thesis has been accepted for inclusion in WVU Graduate Theses, Dissertations, and Problem Reports collection by an authorized administrator of The Research Repository @ WVU. For more information, please contact researchrepository@mail.wvu.edu. 


\title{
Development of C-C, C-X Bond Formation Reactions Through Gold/Lewis Acid Catalysis
}

\author{
Yumeng Xi \\ Thesis submitted \\ to the Eberly College of Arts and Sciences \\ at West Virginia University \\ in partial fulfillment of the requirements for the degree of \\ Master of Science in \\ Chemistry
}

\author{
Xiaodong Michael Shi, Ph.D.,Chair \\ Björn C. G. Söderberg, Ph.D. \\ Jessica M. Hoover, Ph.D. \\ C. Eugene Bennett Department of Chemistry
}

Morgantown, West Virginia

2014

Keywords: gold, catalysis, alkyne, bond formation, synthesis

Copyright 2014 Yumeng Xi 


\begin{abstract}
All rights reserved
INFORMATION TO ALL USERS

The quality of this reproduction is dependent upon the quality of the copy submitted.

In the unlikely event that the author did not send a complete manuscript and there are missing pages, these will be noted. Also, if material had to be removed,

a note will indicate the deletion.
\end{abstract}

UMI 1554880

Published by ProQuest LLC (2014). Copyright in the Dissertation held by the Author.

Microform Edition (c) ProQuest LLC.

All rights reserved. This work is protected against

unauthorized copying under Title 17, United States Code

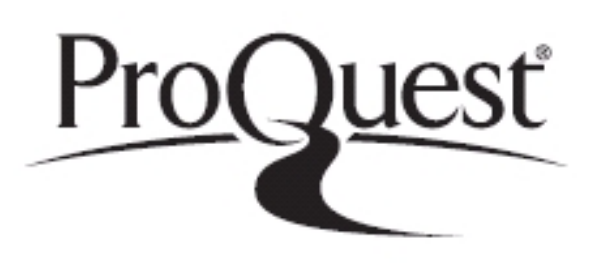

ProQuest LLC.

789 East Eisenhower Parkway

P.O. Box 1346

Ann Arbor, MI $48106-1346$ 


\section{ABSTRACT \\ Development of C-C, C-X Bond Formation Reactions Through \\ Gold/Lewis Acid Catalysis}

\section{Yumeng Xi}

Homogenous gold(I) catalysis has experienced an explosive growth over the past decade. The efficiency towards activation of alkyne, allene, and alkene renders cationic gold complexes unique in the organic synthesis. Despite the great progression, this area still suffers significantly from catalyst decomposition and low reactivity. In the past, our group introduced triazole-gold(I) complex (TA-Au) as a novel class of cationic gold complex with improved thermal stability and unique chemoselectivity. However, it was proved that TA-Au also showed lower reactivity. To overcome this paradox, compatible Lewis acid is used as the compatible additive for improving catalyst performance while maintaining enough stability. This thesis summarizes the development of this novel system and its application to various C-C, C-X bond formation reactions.

Chapter 3 and 4 will discuss the initial discovery of a gallium triflate-assisted TA-Au catalysis in Nakamura reaction. This is the first time that the intermolecular Conia-ene (Nakamura reaction) is achieved and remarkably with catalyst loading as low as 100ppm. Chapter 4 and 5 also contains mechanistic investigation of $\mathrm{Au} / \mathrm{Ga}$ system using various techniques including in situ IR, NMR, MassSpec. It is now clear that this $\mathrm{Au} / \mathrm{Ga}$ system is in dynamic equilibrium and the role of $\mathrm{Ga}$ involves assisting dissociation of triazole ligand for substrate. Chapter 6 is extension of Nakamura reaction, based on which a cyclobutene synthesis is accomplished. Chapter 7 includes the efforts to develop a vinyl ether synthesis from cyclic 1,3-diketone and alkynes. Chapter 8 summarizes the synthesis of $\alpha$-substituted vinyl sulfone, which is the first general synthesis in the literature. The $\mathrm{Au} / \mathrm{Ga}$ system shows higher reactivity one more time. Chapter 9 focuses on the mechanistic aspect of TA-Au catalysis with 3,3rearrangement of propargyl ester. Kinetics experiments show that the rate has first-order dependence on substrate and TA-Au catalyst. Variable temperature experiment determines activation parameter and with TA-Au derivatives Hammett plot is also established. With these results, the associative ligand exchange of substrate with TA-Au is determined as the turnoverlimiting step. 


\section{Acknowledgements}

The past two years have been an amazing and accomplishing two years. I couldn't imagine how my life would be like after two years when I just arrived at WVU. I truly enjoy the time that I spent here at WVU.

First I would like to express my deepest gratitude to my advisor Professor Xiaodong Shi, who has been an amazing mentor and also a friend. I couldn't ask more from him. I have been always deeply impression by his dedication, hard work and enthusiasm for chemistry. I have to say that I truly have enjoyed every discussion with him about chemistry while he is having a 'smoke break'. I will definitely miss it greatly. Many thanks go to his help with my graduate application as well.

I am also thankful to my current committee, Professors Bjorn Soderberg and Jessica Hoover as well as to my past committee members, Professors Jeffrey Petersen and Peter Gannett, though unfortunately I was not able to invite them for my defense.

My experience with the people in the Shi group is invaluable and unforgettable. I have learnt much from the great people both from their personality and chemistry. They are: Qiaoyi, Xiaohan, Rong, Yanwei, Sravan, Yijin, Steve, Haihui, Boliang, Morteza, Siddhita and Lekh Nath. I wish them all the greatest success and very much look forward to the continuation of our friendships. I would like to give my special thank to Boliang, whom I worked with in two projects. Luckily I also have the chance to work with some great undergraduate students: Ed, Tesia and Chris. In addition to the wonderful group members, I very much thank Professor Jeffrey Petersen and Dr. Novruz Akhmedov for their assistance in X-ray and NMR analysis.

Outside of WVU, I am indebted to Prof. Aiwen Lei of Wuhan University, and Prof. Zhen Yang of Peking University, who both have be continuously supportive and helpful over the years. Prof. Lei has been very open to me and luckily I could have a chance to work in his lab and meet great people in his group. It was great experience to be an undergraduate researcher in Prof. Yang's group, where I was firstly introduced to chemical research.

Last but not least, I wish to thank my wonderful parents for their unconditional love through my all twenty-four years. Without them, it is impossible for me to be here today 


\section{Table of Contents}

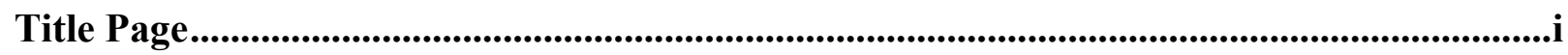

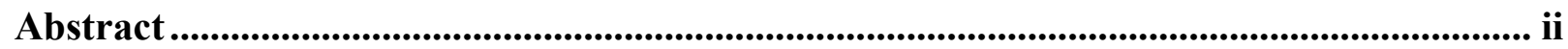

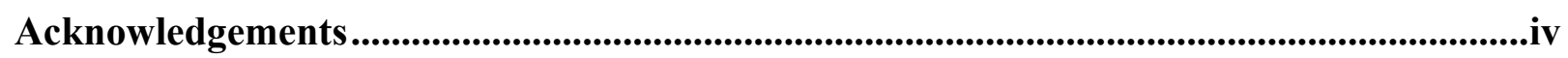

Chapter 1. Homogenous Gold(I) Catalysis ..................................................................................1

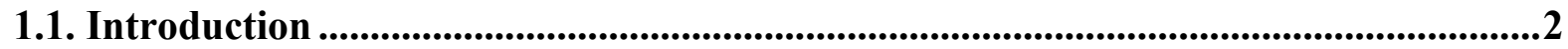

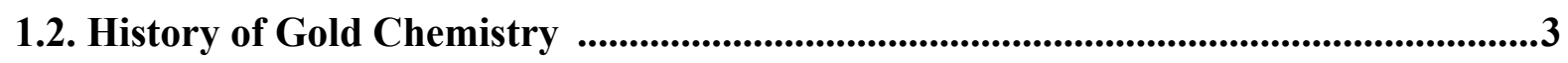

1.3. Elementary Steps in Homogenous Gold Catalysis ..............................................6

Chapter 2. Previous Contribution from Shi Laboratory .................................................10

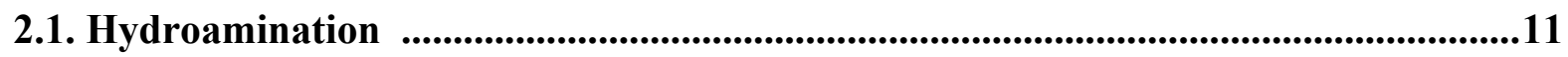

2.2. Propargyl Ester Rearrangement and Thereof ...................................................12

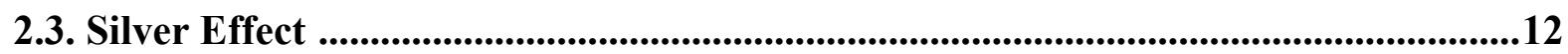

Chapter 3. Development of Gold-Triazole (TA-Au)/Lewis Acid System ..............................13

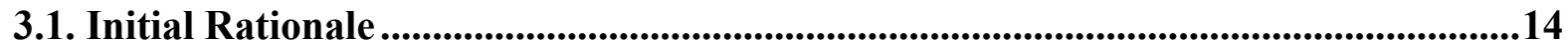

3.2. Lewis Acid Screening .............................................................................................18

3.3. Generality of TA-Au/Lewis Acid System ......................................................................20

Chapter 4. Gold/Gallium-Catalyzed Nakamura Reaction: C-C Bond Formation .............22

4.1. Substrate Scope ........................................................................................................................23

4.2. Development of Low Loading Catalysis..............................................................................25

4.3. Preliminary Mechanistic Investigation ..................................................................................227

4.4. Attempts at Enantioselective Version....................................................................33

Chapter 5. Mechanistic Study of Gold-Triazole (TA-Au)/Lewis Acid System ...................35

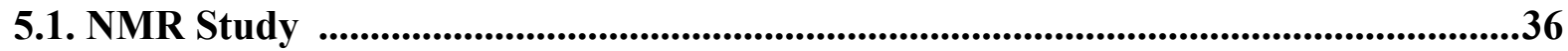

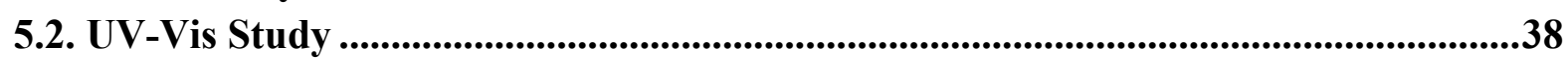

Chapter 6. Gold/Gallium-Catalyzed Cyclobutene Synthesis: C-C Bond Formation .........42

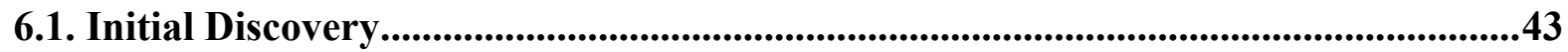

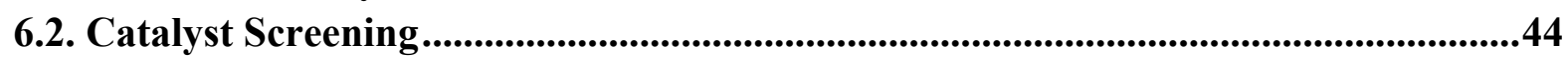

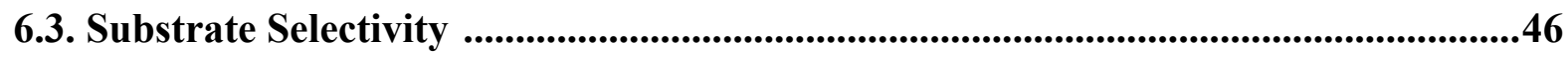

Chapter 7. Gold/Copper-Catalyzed Divinyl Ether Synthesis: C-O Bond Formation ........48

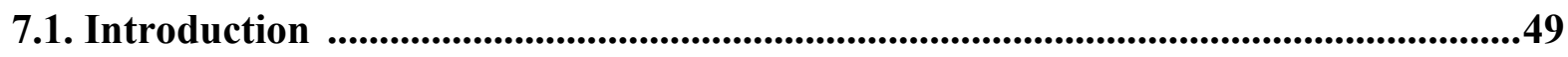

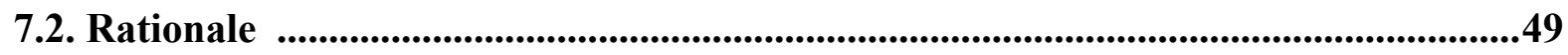

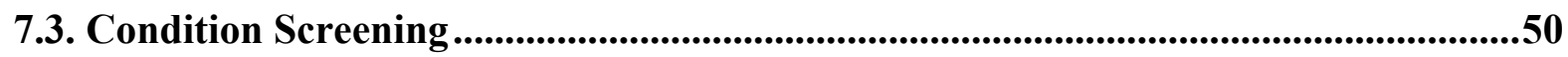

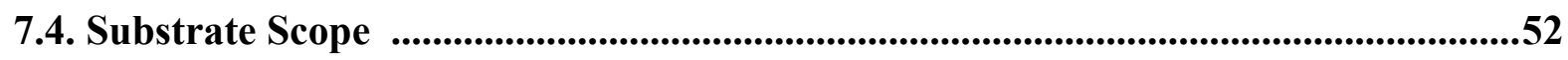

Chapter 8. Gold/Gallium-Catalyzed a-Substituted Vinylsulfone: C-S Bond Formation ...56

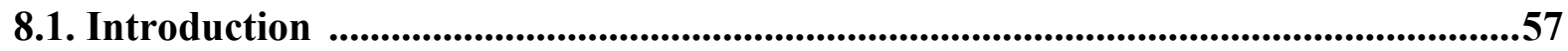

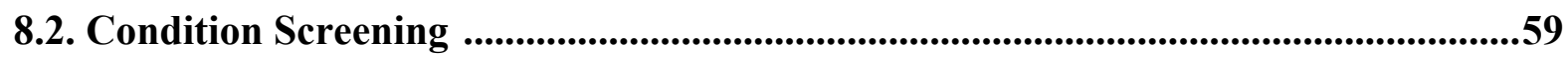

8.3. Substrate Scope ...........................................................................................................................60

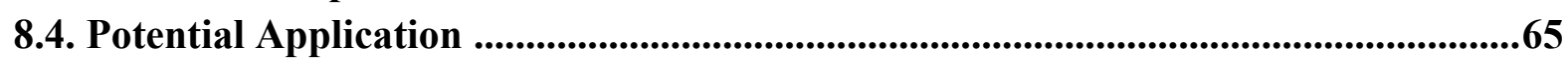

Chapter 9. Mechanistic Study of TA-Au Catalyzed Propargyl Rearrangement .................68 
9.1. Introduction .69

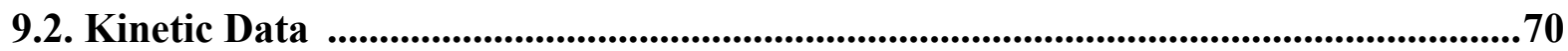

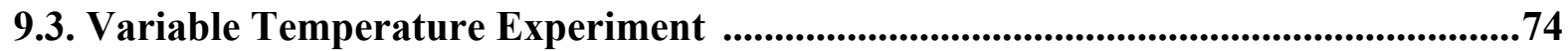

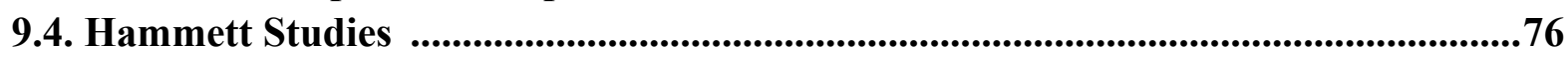

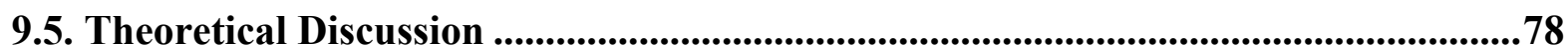

9.6. Implication for Triazole-Gold/Lewis Acid System .................................................79

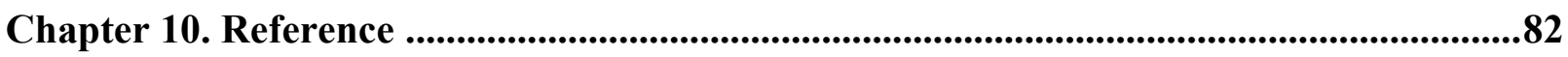

Appendix 1: Publication List at WVU ...................................................................... AP-I

Appendix 2. Supporting Information for Chapter 4 .........................................................AP-II

Appendix 3. Supporting Information for Chapter 7 ................................................. AP-III

Appendix 4. Supporting Information for Chapter 8 .........................................................AP-IV

Appendix 5. Supporting Information for Chapter 9 ......................................................AP-V 


\section{List of Schemes}

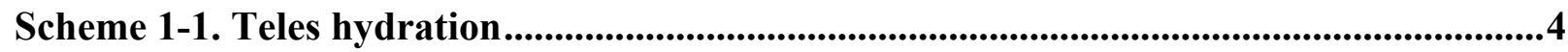

Scheme 1-2. Gold catalysis in total synthesis ................................................................4

Scheme 1-3. Relativistic effect .....................................................................................................5

Scheme 1-4. Dewar-Chatt-Duncanson model for gold-alkyne $\pi$-complex ..............................6

Scheme 1-5. Elementary steps in homogenous gold catalysis.............................................7

Scheme 1-6. Non-typical gold carbenoid reactivity ....................................................................9

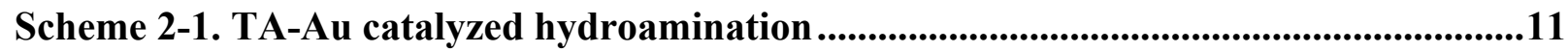

Scheme 2-2. Chemoselectivity of TA-Au ......................................................................12

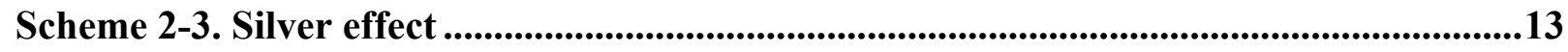

Scheme 3-1. Toste's gold-catalyzed Conia-ene reaction .....................................................15

Scheme 3-2. Nakamura reaction ...........................................................................................16

Scheme 3-3. Gold-catalyzed Nakamura reaction .......................................................................16

Scheme 3-4. Initial screening of gold-catalyzed Nakamura reaction ....................................17

Scheme 3-5. Synergistic catalysis ............................................................................................18

Scheme 3-6. Synergistic catalysis in gold-catalyzed Nakamura reaction ..............................18

Scheme 3-7. Gallium effect on Toste's cycloisomerization ...............................................21

Scheme 3-8. Gallium effect on propargyl ester rearrangement ........................................21

Scheme 4-1. Mechanistic Investigation.........................................................................28

Scheme 4-2. Proposed mechanism ...............................................................................33

Scheme 4-3. Attempted enantioselective Nakamura reaction ................................................34

Scheme 5-1. Two possible pathways ..................................................................................................40

Scheme 6-1. Initial observation .................................................................................43

Scheme 6-2. Substrate chemoselectivity ............................................................................................46

Scheme 6-3. Proposed mechanism for ring expansion .......................................................47

Scheme 7-1. Gold-catalyzed Nakamura reaction ............................................................................49

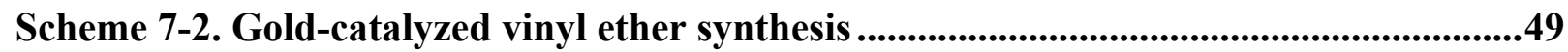

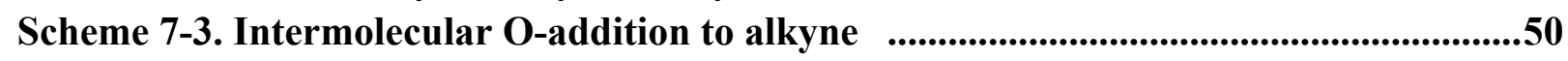

Scheme 7-4. Acid as the critical additive for optimal performance...................................52

Scheme 7-5. Reactions of internal alkyne and other O-nucleophiles .................................55

Scheme 8-1. Rationale for gold-catalyzed C-S bond formation .........................................58

Scheme 8-2. Literature synthesis of vinylsulfone ..........................................................................58

Scheme 8-3. One-pot synthesis of vinyl sulfones starting from bench stable sodium

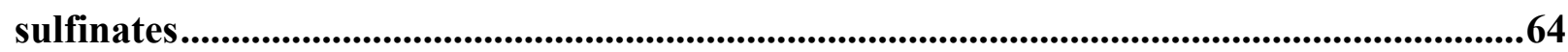

Scheme 8-4. Diels-Alder reaction between 2-sulfonyl diene (33bk) and N-methyl

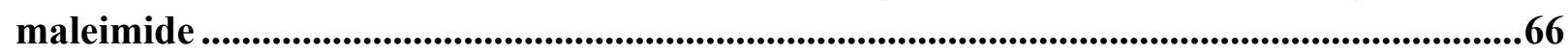

Scheme 8-5. Representative vinylsulfone protease inhibitors .........................................66

Scheme 8-6. Comparison of the aza-Michael addition between secondary amine and $\alpha$ - or

$\beta$-vinyl sulfone $\quad$............................................................................................................667

Scheme 9-1. TA-Au as chemoselective catalyst for alkyne activation...............................69

Scheme 9-2. Proposed Mechanism for TA-Au catalyzed propargyl ester

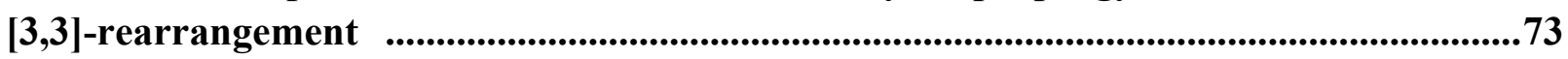

Scheme 9-3. Associative ligand substitution through transient 3-coordinate cationic gold(I) complex 
Scheme 9-4. General mechanism for TA-Au catalysis. 


\section{List of Figures}

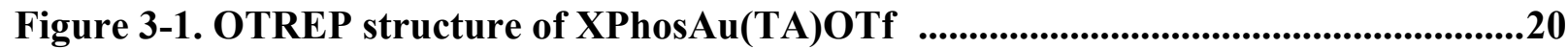

Figure 4-1. In situ IR monitoring of catalytic Nakamura reaction ...................................29

Figure 4-2. ConcIRT spectra of 12a (black curve) and 11a (red curve). Real-time spectra of the catalytic Nakamura reaction $\left(1640-1495 \mathrm{~cm}^{-1}\right.$ region) ............................................29

Figure 4-3. Identification of component $I$......................................................................30

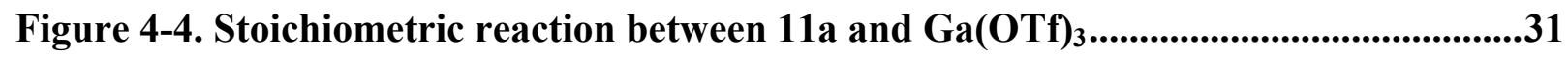

Figure 4-5. Titration of $\mathrm{Ga}(\mathrm{OTf})_{3}$ with XPhosAu(TA)OTf ...........................................32

Figure 4-6. a) Real-time IR spectra of stoichiometric reaction between $\mathrm{Ga}(\mathrm{OTf})_{3}$ and

XPhosAu(TA)OTf. b) Spectra of XPhosAu(TA)OTf given by ConcIRT analysis and authentic XPhosAu(TA)OTf. c) Real-time IR spectra of stoichiometric reaction between

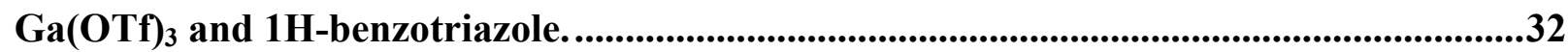

Figure 5-1. ${ }^{31}$ P NMR and ${ }^{19}$ F NMR experiment ................................................................36

Figure 5-2. Stoichiometric Nakamura reaction with ${ }^{31}$ P NMR.............................................37

Figure 5-3. Monitoring catalytic Nakamura reaction with MassSpec ..................................38

Figure 5-4. Color trend of $\mathrm{Cu}(\mathrm{OTf})_{2} / \mathrm{BTA}$ and $\mathrm{Cu}(\mathrm{OTf})_{2} / \mathrm{TA}-\mathrm{Au}$ solutions in different ratio..............................................................................................................................39

Figure 5-5. UV-Vis spectra of $\mathrm{Cu}(\mathrm{OTf})_{2} / \mathrm{BTA}$ and $\mathrm{Cu}(\mathrm{OTf})_{2} / \mathrm{TA}-\mathrm{Au}$ solutions in different

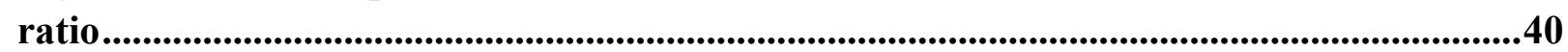

Figure 6-1. ${ }^{1} \mathrm{H}$ and ${ }^{13} \mathrm{C}$ NMR spectra of compound 16 .....................................................44

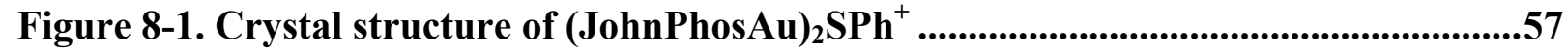

Figure 8-2. Crude ${ }^{1}$ H NMR spectra of optimization for Table 8-2 ..................................61

Figure 8-3. ${ }^{1} \mathrm{H}$ NMR spectrum of the product from benzenesulfinic acid and 4-octyne ....61

Figure 8-4. OTREP structure of $33 \mathrm{bh}$....................................................................63

Figure 9-1. 3D-kinetic profile of rearrangment ConcIRT spectra $\quad$...................................71

Figure 9-2. Dependence of the initial rates on catalyst concentrations for rearrangement

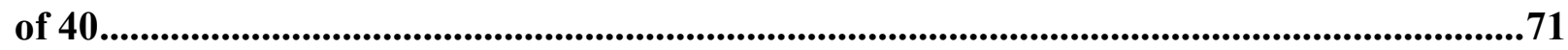

Figure 9-3. Dependence of the initial rates on substrate concentrations for rearrangement

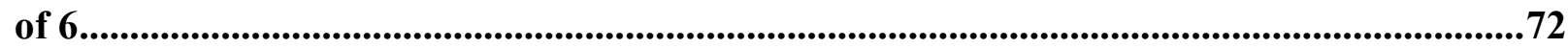

Figure 9-4. ${ }^{31} \mathrm{P}$ NMR monitoring of the reaction progress .............................................73

Figure 9-5. Kinetics profile at different temperatures ...........................................................74

Figure 9-6. Inhibition by external N-Methyl-benzotriazole ..............................................75

Figure 9-7. Kinetics profile using various TA-Au catalysts ...........................................76

Figure 9-8. Hammett plot of substituted TA-Au catalysts .............................................77

Figure 9-9. Kinetics with 2,4-dinitrophenyl substituted TA-Au .......................................78

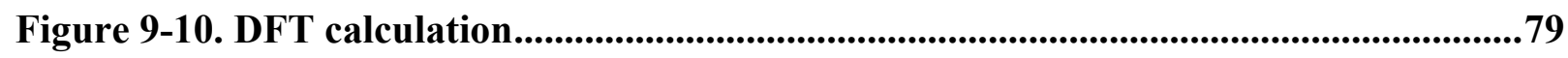

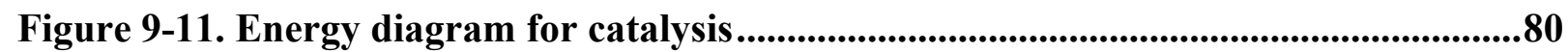




\section{List of Tables}

Table 3-1. Optimization of gold(I)-catalyzed Nakamura reaction ...........................................19

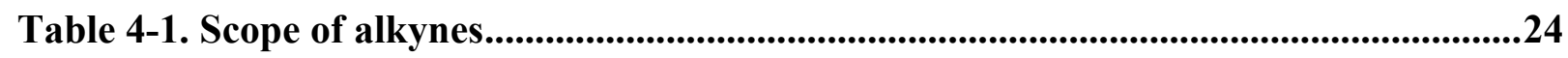

Table 4-2. Scope of 1,3-dicarbonyl compounds ...............................................................25

Table 4-3. Condition optimization for Nakamura reaction at low Au loading ...................26

Table 4-4. Low gold catalyst loading .................................................................................27

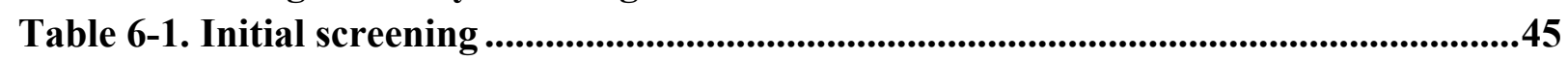

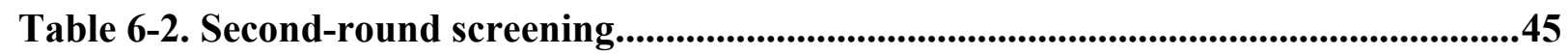

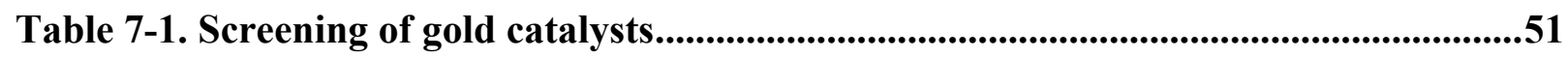

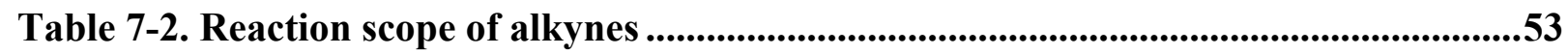

Table 7-3. Reaction scope with aliphatic alkynes .............................................................55

Table 8-1. Condition optimization ...................................................................................59

Table 8-2. Optimization of reaction between $31 \mathrm{a}$ and 33 .............................................60

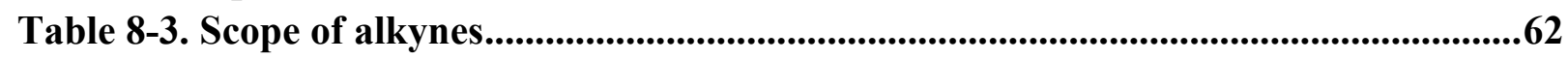

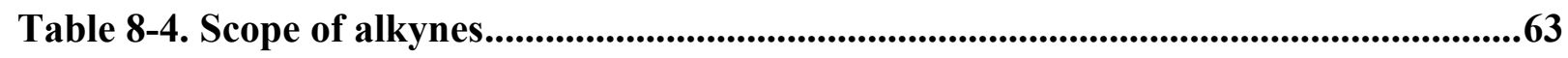

Table 8-5. Scope of sulfinic acids .........................................................................................65 
Chapter 1. Homogenous Gold(I) Catalysis 


\subsection{Introduction}

Homogenous catalysis is one of the major branches in catalysis, and by so far has been a relatively mature area. As a complementary approach to heterogeneous catalysis, it uses welldefined complexes as catalysts and more importantly the catalysts itself and their discrete interaction between substrates can be in deep investigated through an array of spectroscopic techniques or physical experiments. One would argue that homogenous catalysts are not very applicable in industrial process, because of their high loading and cost. However, homogenous catalysis may provide model reaction that ultimately will benefit industry. To appreciate the value of homogenous catalysis, one may look at the recent Nobel prizes in chemistry list. In the past decade, the Nobel prizes have been awarded to synthetic chemists three times, 2001, 2005, and 2010, respectively.

In 2010, Heck, Suzuki and Negishi won the prize for developing fundamental bond formation reaction using homogenous palladium-based catalysts. They are extremely powerful towards fine chemical synthesis and of course in natural product total synthesis. Over the years chemists have put tremendous amount of efforts in developing efficient catalysts and due to the unstabilility of palladium(0) the chemistry often requires inert gas atmosphere and high temperature which leads to catalyst decomposition. An ideal catalyst system should be air- and moisture-stable but reactive towards reactions.

Looking at the periodical table, chemists have investigated all transition metals as possible catalysts for efficient synthesis. Palladium, arguably, is the one that has been mostly exploited. However, new catalyst is associated with new reactivity and therefore new reaction. For example, it is long understood that palladium catalyst often undergoes two-electron process 
to do catalysis, such as oxidative addition, reductive elimination. But other metals, such as iron, nickel, cobalt, can also incorporate single-electron process and even other pathways such as carbine/nitrene chemistry.

\subsection{History of Gold Chemistry}

Gold has long been regarded as catalytically inert metal since their so good stability as gold $(0)$ metal. It resists oxidation by air or in water, and erosion by reasonable acids. However, there does exist a variety of $\mathrm{Au}(\mathrm{I})$ and $\mathrm{Au}(\mathrm{III})$ complexes and even rare $\mathrm{Au}(\mathrm{II})$ complexes. Among those, $\mathrm{AuCl}$ and $\mathrm{HAuCl}_{4}$ are well-known. And due to the high redox potential of $\mathrm{Au}(\mathrm{I})$ and $\mathrm{Au}(\mathrm{III})$, the oxidation state switch is rare in gold(I) catalysis. It is generally acknowledged that gold reluctantly undergoes oxidative addition and reductive elimination, although some recent reports claimed that the rate of reductive elimination is unexpectedly faster. An initial report using gold(I) complex in catalysis can be traced back to 1980s. A catalytic [3+2] cycloaddition was accomplished in an enantioselective manner with a chiral ferrocenylphosphine bound cationic gold(I) species. ${ }^{2}$ The field remained inactive for the next decade. Later not until 1998 that homogenous gold(I) catalysis gained attention from synthetic community. Teles used cationic gold(I) generated in situ by mixing $\mathrm{Ph}_{3} \mathrm{PAuMe}$ with sulfuric acid to achieve a very high TON and TOF for simple unactivated alkyne hydration (Scheme 11). Although the hydration of alkyne with both gold(I) and gold(III) has been documented, but the major drawback is the rapid decomposition of gold to gold metal. In Teles hydration, he used ligand-supported gold to retard the decomposition rate. The community soon recognized 
the potential of gold(I) as a novel catalyst with unique reactivity for transformation development.

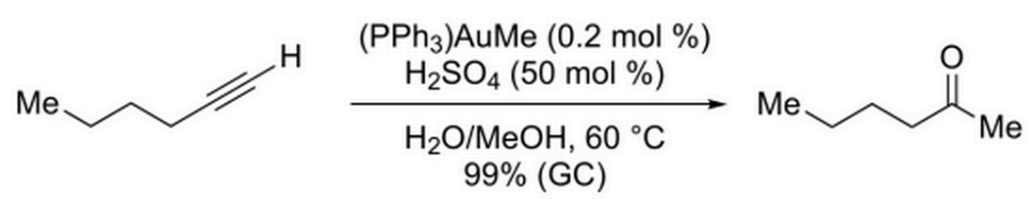

Scheme 1-1. Teles hydration ${ }^{3}$

Due to the powerful catalysis of gold with unactivated alkynes, it was realized the special 'alkynophilic' nature of cationic gold(I) complexes. Apparently this orthogonal reactivity of gold to palladium soon attracted lots of research group, which led to the exploding development of homogenous gold catalysis, which refers to 'golden rush' nowadays.
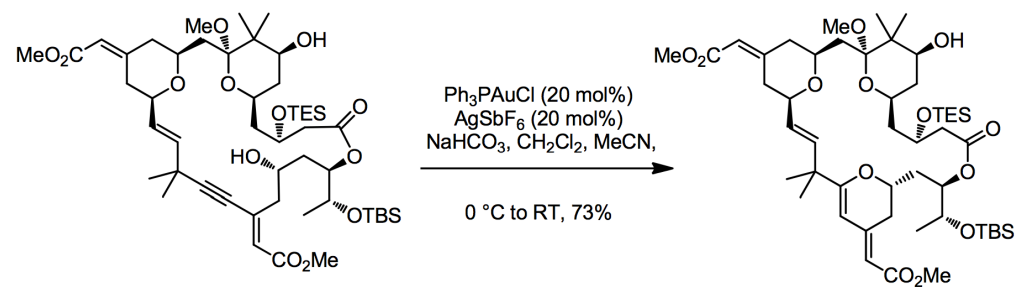

Scheme 1-2. Gold catalysis in total synthesis ${ }^{4}$

The special affinity between gold and alkyne has been previously investigated by theoretical chemists as they claim that the relativistic effect, which leads to $6 \mathrm{~s}$ orbital contraction and 5d orbital expansion, explains (Scheme 1-3). As a late transition-metal, gold atom has an electron configuration of $[\mathrm{Xe}] 6 \mathrm{~s}^{2} 5 \mathrm{~d}^{9}$. This increase in atomic nuclear charge leads to acceleration of electron velocity and therefore higher mass. As a result, these electrons (s electrons) occupy less space and are more closely bound to charge. The relativistic effect maximizes at gold since it just passes the full $5 \mathrm{~d}$ and $4 \mathrm{f}$ shell and it can be demonstrated with 
the comparison of ionization potential of gold and silver: $\operatorname{IP}(\mathrm{Au})$ is $9.2 \mathrm{eV}$ while $\operatorname{IP}(\mathrm{Ag})$ is only 7.6 eV. As a consequence, the unique interaction of gold atoms in metal form can be also extended to gold(I) complexes. This is the reason why that in lots of cases that weak interaction between gold(I) atoms is observed in both solid state and in solution. Aurophilicity is termed to describe this special weak force. Generally it is accepted that gold-gold distance between 2.8A$3.5 \mathrm{~A}$ falls in the aurophilic force which gains a stabilization energy of $\sim 10 \mathrm{kcal} / \mathrm{mol}$, compatible with hydrogen bonding.
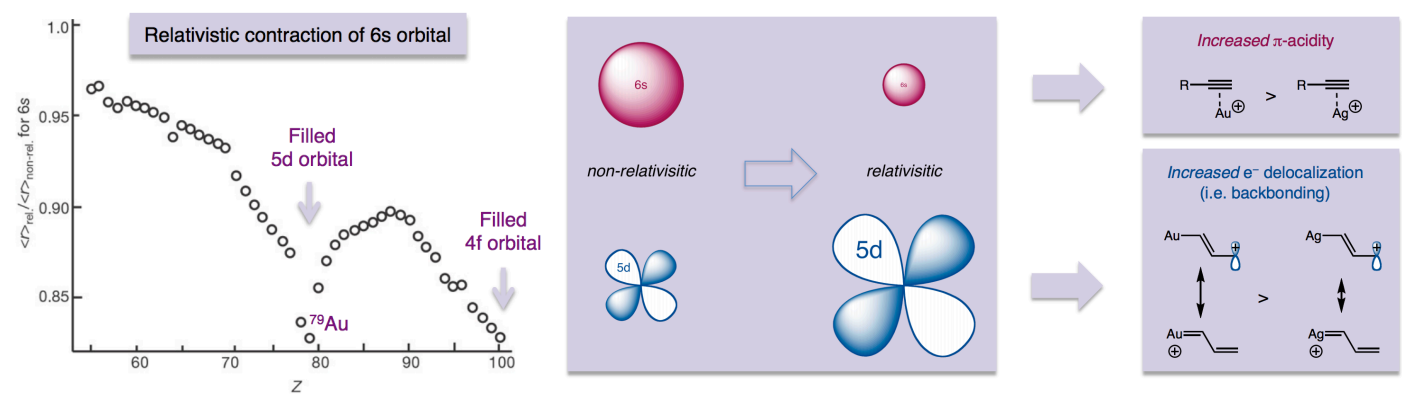

Scheme 1-3. Relativistic effect ${ }^{5}$

The unique relativistic effect of gold leading to $6 \mathrm{~s}$ contraction results in increase in Lewis acidity, and the soft nature of gold cation prefers soft nucleophile, for example, alkyne, but also allene and alkene. Generally the generation of catalytically active cationic gold(I) species involves two methods, first through the mixing of acid with alkyl/aryl gold species, second and most commonly used, by mixing corresponding gold chloride and silver salt. It was previously assumed that the active species is generated immediately, however may not quantitative. This raises several questions: 1) what is the real concentration of the active species 
and 2) what identity is the active species. It was proposed and accepted the active species being the $\left[\mathrm{L}-\mathrm{Au}^{+}\right]$, which is coordination-unsaturated and kinetically favorable.

\subsection{Elementary Steps in Homogenous Gold Catalysis ${ }^{6}$}

The elementary steps in catalysis generally involves three steps: 1) the formation of $\pi$ complex, 2) nucleophilic addition, 3) protodeauration.
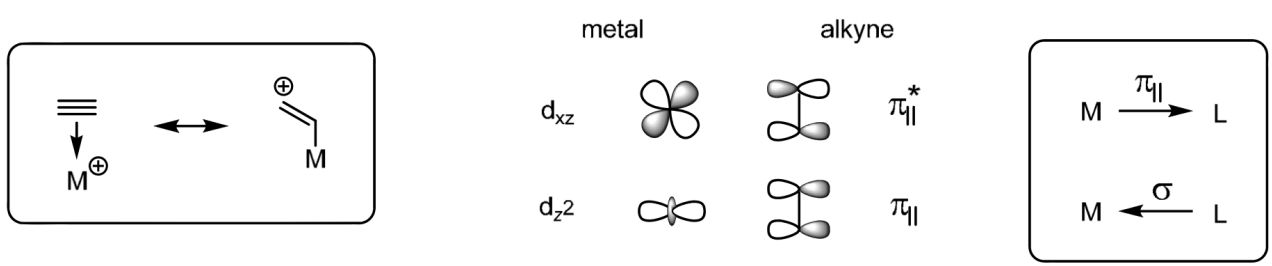

Scheme 1-4. Dewar-Chatt-Duncanson model for gold-alkyne $\pi$-complex

First step of the catalytic cycle generates the $\left[\mathrm{L}-\mathrm{Au}-\mathrm{S}^{+}\right]$complex, whose binding mode can be rationalized through Dewar-Chatt-Duncanson model (Scheme 1-4). It results in decrease in bond order of alkyne and renders it electrophilic toward nucleophilic attack. Although rare, gold-alkyne $\pi$-complex has been isolated and characterized through $\mathrm{x}$-ray crystallography. Toste reported a bis(phosphine-alkyne)digold species. ${ }^{7}$ Second step is the anti-addition of nucleophile to gold-activated alkyne to generate the olefin with new forming $\mathrm{C}_{\mathrm{sp} 2}-\mathrm{Nu}$ bond as well as vinyl-gold bond. This type of intermediates has also been successfully characterized. For example, Hammond isolated a vinyl-gold species that is catalytically relevant in his allene cyclization. ${ }^{8}$ Moreover, Sadighi also reported the fluoro-vinyl-gold species formed from the 
addition of fluoride to alkyne. ${ }^{9}$ The last step, which is often the turnover-limiting step in the cycle, is to substitute gold with proton.

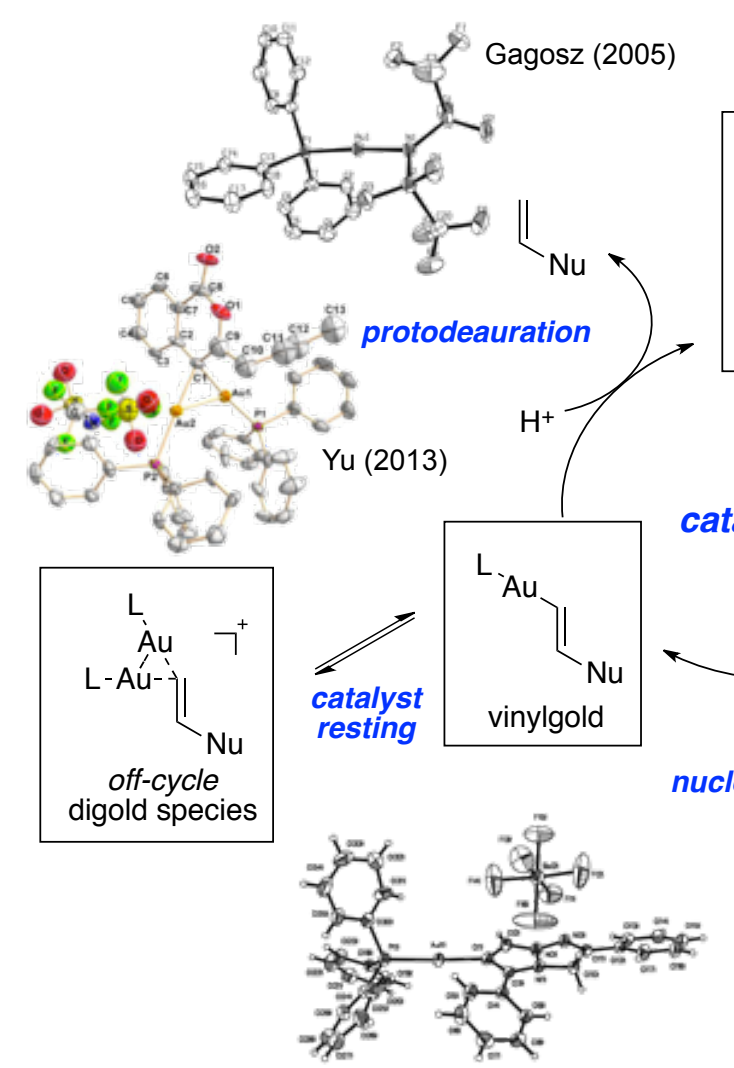

Shi (2010)

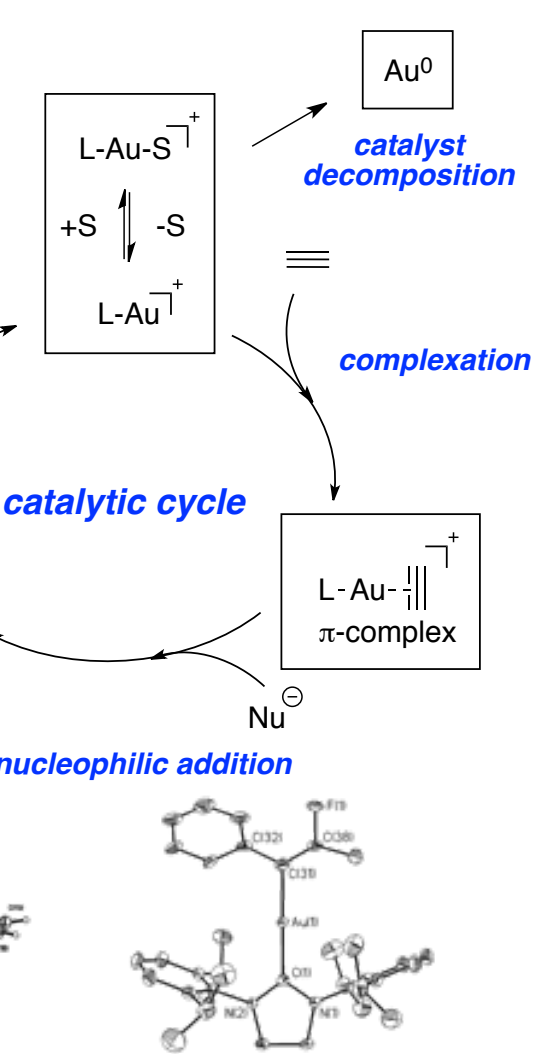

Sadighi (2007)
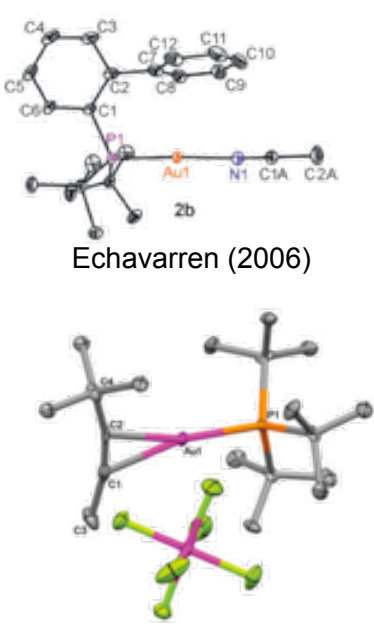

Russell (2010)

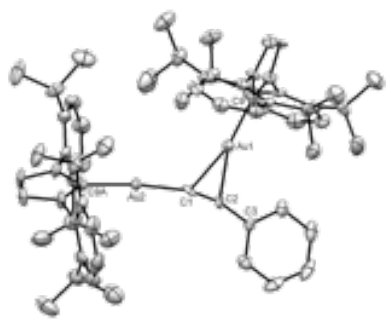

Widenhoefer (2011)

Scheme 1-5. Elementary steps in homogenous gold catalysis

Besides these three elementary steps, there are other off-cycle steps that are very crucial and contribute synergistically with the on-cycle steps. First one is the decomposition of gold catalyst. Similar in some palladium chemistry, the gold community suffers from catalyst decomposition. Thermal decomposition as well as reagent-induced decomposition contributes greatly. The decomposition form varies from small cluster, nanoparticle, gold colloidal as well as gold mirror. Although the community has observed this decomposition for a long time, there has been scarce report on the detailed pathway for the decomposition. In a recent paper, Hammond used NMR kinetics experiments to study the effect of substrates and additive on the 
gold cation stability. ${ }^{10}$ Based on their XPS and MassSpec experiments, they demonstrated the decomposition prominently is caused by disproportionation. And more strikingly, recently Corma observed the extremely high reactivity of Au3-Au6 gold small cluster (higher TON number of 3-order magnitude) and they are responsible for the catalysis instead of cationic gold. ${ }^{11}$ Later they showed that a series of signature reactions in the area are actually catalyzed by the gold cluster. ${ }^{12}$ Their evidences include induction period and corresponding formation of cluster as detected by MALDI spectra. Second is the recent observation of 'silver effect'. It has been a long concern that silver salt that is used to abstract chloride off gold may alter the nature of the active species. Evidence from Gagne and our laboratories ${ }^{13}$ further emphasized this concern. This topic will be briefly discussed in Chapter 2 .

The other important off-cycle step in the catalytic cycle is the formation of digold species. Contributions from dominantly Gagne and Widenhoefer groups revealed that the reversible formation of digold species from vinyl gold species and cationic gold has a great impact on the reaction rate. ${ }^{14}$ And in some cases, digold species is the catalyst resting-state.

Away from the normal $\pi$-activating ability, the expanded $5 \mathrm{~d}$ orbital also allows gold to possess 'pull-push' dual reactivity, which leads to gold carbenoid type reactions. Essentially, this type of transformation relies on the design of substrate that has both nuclephilic site and leaving group. A well-developed class is oxides, such as sulfoxide and N-oxide. Zhang utilized this strategy to generate $\alpha$-oxo gold carbenoid equivalent with pyridine N-oxide derivatives, which could be otherwise synthesized from diazo compound (Scheme 1-5). ${ }^{15}$ 


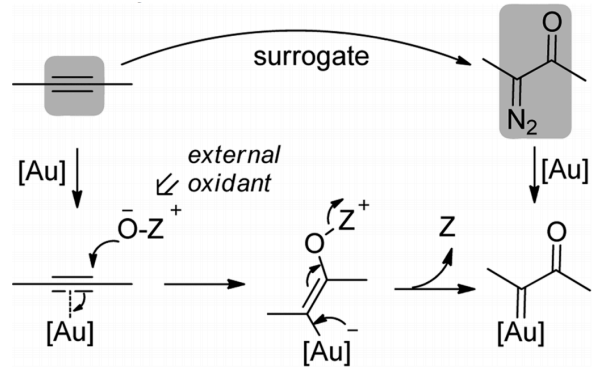

Scheme 1-6. Non-typical gold carbenoid reactivity

In summary, this chapter discusses the fundamental concept in the homogenous gold(I) catalysis and provides the mechanistic ground for the study. 
Chapter 2. Previous Contribution from Shi Laboratory 
Our research group first started to join the gold(I) catalysis community in 2009 when we well established the derivatization of 1,2,3-triazoles. ${ }^{16,17,18}$ Although generally considered as electron-poor heterocycle, which will be a bad $\sigma$-donating ligand, our group found that it forms readily stable complex with rhodium, which initiated our interest in investigating metal-triazole complexes.

\subsection{Hydroamination}

The first version of triazole-gold complex (TA-Au) is synthesized from triazolate and gold chloride. ${ }^{19}$ This anionic triazole-gold complex is extremely stable toward high temperature and possesses no catalytic activity whatsoever. However, catalytic activity can be restored by simply adding acid. It protonates the anionic triazole to form neutral triazole-gold complex. Surprisingly, this complex is catalytically active towards hydroamination and is far stable than previously reported gold complexes. Impressively, catalyst loading could be $0.1 \%$ for terminal alkynes and $1 \%$ for internal alkynes.

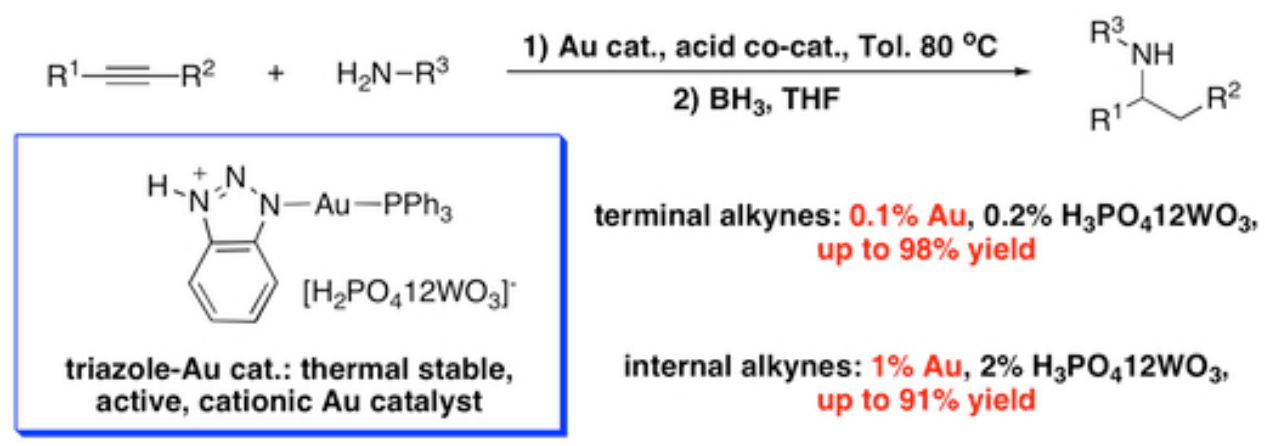

Scheme 2-1. TA-Au catalyzed hydroamination 


\subsection{Propargyl Ester Rearrangement and Thereof}

Another advantage of our triazole-gold complex is its unique chemoselectivity. It preferentially activates alkyne over allene, as demonstrated in two cases. The first case is the synthesis of E- $\alpha$-haloenoneone synthesis, the kinetic product, which can be only achieved with TA-Au. ${ }^{20}$ The normal cationic gold catalyst only yields Z-isomer, which presumably is from the thermodynamically stable allene via rapid cationic gold-induced isomerization. The second case shows more clearly and perceivably. While common cationic gold catalyzes propargyl ester rearrangement to give indene product via presumably allene intermediate, TA-Au furnishes only the allene, which resists further conversion. ${ }^{21}$ As described in Chapter 8 , our kinetic experiments suggested that the chemoselectivity originates from the preferential exchange of triazole ligand with alkyne over allene, which is the turnover-limiting step in the catalytic cycle. Besides, chemoselectivity was observed also with vinyl propargyl ether rearrangement, and this concept was extended to achieve an ambient Schmittel cyclization. ${ }^{22}$
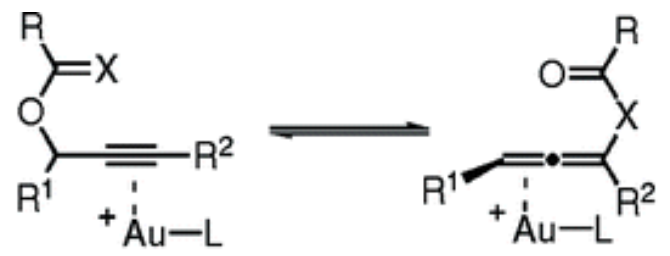

Challenges with $\mathrm{L}-\mathrm{Au}^{+}$

- Lack of chemoselectivity

- poor stereochemistry control
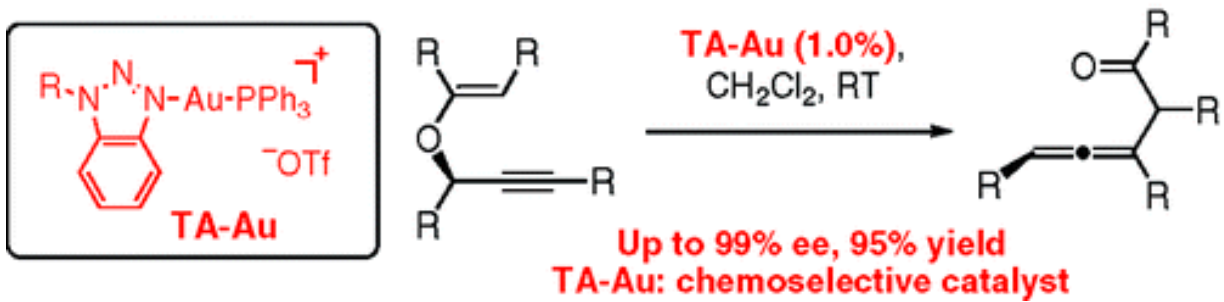

Scheme 2-2. Chemoselectivity of TA-Au

\subsection{Silver Effect}


Another advantage of TA-Au catalyst lies in its silver-free nature as is was observed in the literature that silver salt in solution has a great influence on the overall reactivity.

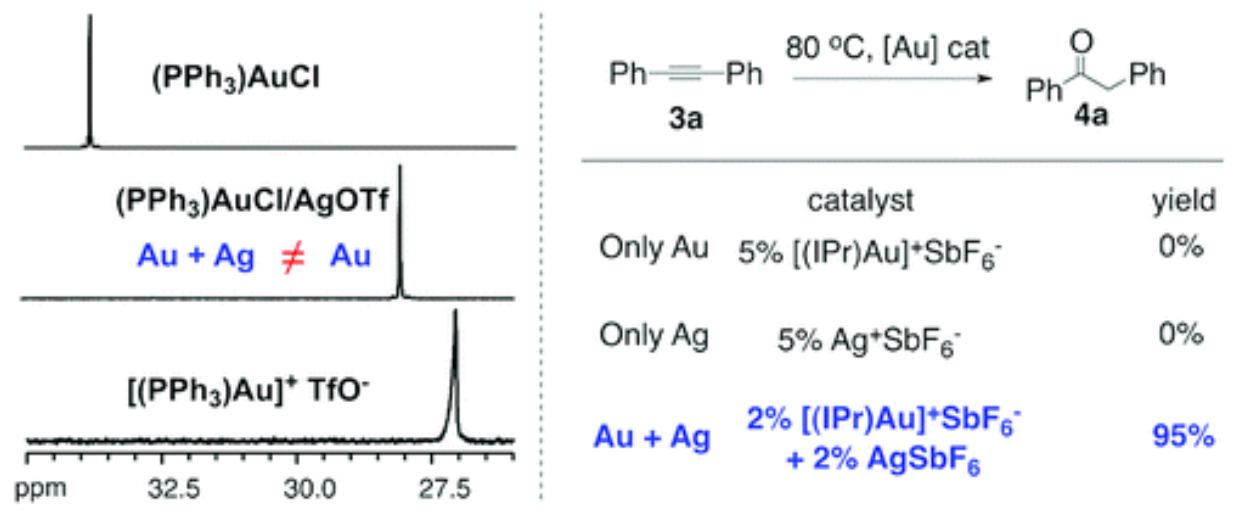

Scheme 2-3. Silver effect

Our group discovered that the celite filtration has a huge impact on the overall catalyst reactivity. ${ }^{23}$ As shown above, the gold-catalyzed hydration could not proceed after celite filtration to get rid of $\mathrm{AgCl}$. However, by additing external silver salt into the filtrate stored the catalytic activity, however lower. Another piece of evidence came from the ${ }^{31} \mathrm{P}$ NMR chemical shift. The chemical shift of $\mathrm{Au} / \mathrm{Ag}$ mixture is different than the silver-free solution after celite filtration. In light of this, other group subsequently reported the isolation of $\mathrm{Au}-\mathrm{Cl}-\mathrm{Ag}^{24}$ or $\mathrm{Au}-$ $\mathrm{Cl}-\mathrm{Au}^{25}$ type complexes, which may be catalytically relevant. 


\section{Chapter 3. Development of Gold-Triazole (TA-Au)/Lewis Acid System}

Part of this work has been published: Xi, Y.; Wang, D.; Ye, X.; Akhmedov, N. G.; Petersen, J. L.; Shi, X. "Synergistic Au/Ga Catalysis in Ambient Nakamura Reaction" Org. Lett. 2014, 16, 306-309. 


\subsection{Initial Rationale}

The key concern of our triazole-gold catalyst, as observed in our own laboratory and pointed by other research groups, is the low reactivity. One has to sacrifice something to achieve thermal stability. When I joined in the Shi laboratory, our research centered at the development of transformations that are only uniquely offered by TA-Au. To largely improve the performance of TA-Au catalyst, a highly efficient catalytic system has to be developed.

The initial rationale for the system development is to answer one simple question: why has intermolecular reaction rarely reported in gold catalysis while most gold-catalyzed reactions are intramolecular? To answer this question, we sought to use a fundamental and well-studied transformation to investigate the potential problems in this area.

Gold-catalyzed Conia-ene Reaction (Toste, 2004)

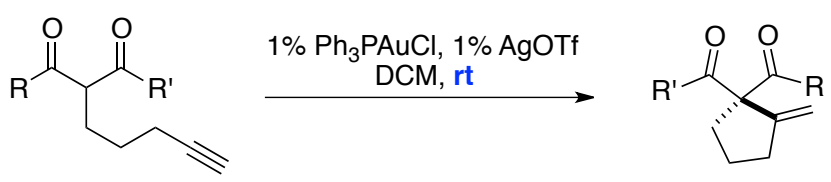

Scheme 3-1. Toste's gold-catalyzed Conia-ene reaction

In 2004, Toste published a mild gold-catalyzed Conia-ene reaction in which the $\beta$-ketoester intramolecularly adds to alkyne which is activated by gold complex (Scheme 3-1). ${ }^{26}$ This is one of the earliest examples demonstrating both the unique reactivity of cationic gold --- $\pi$ activation, and mild nature of this system --- the reaction can be completed within an hour with $1 \%$ loading at room temperature. When this project started, the community has witnessed a rapid growth, however, no one seems to bother developing an intermolecular version of Conia- 
ene reaction. The question then arises: is it because of the inherent low reactivity of cationic gold?

$$
\text { Nakamura Reaction (Nakamura, 2003) }
$$

Scheme 3-2. Nakamura reaction

On the other hand, the intermolecular reaction was indeed published in the literature by Nakamura and co-workers. He used catalytic amount of $\operatorname{In}(\mathrm{OTf})_{3}$ to achieve the addition of 1,3dicarbonyl compound to 1-alkyne (Scheme 3-2). ${ }^{27}$ Although with low catalyst loading, the reaction condition was very harsh requiring high temperature $80-140^{\circ} \mathrm{C}$. The mild nature of cationic gold may provide best condition (Scheme 3-3).

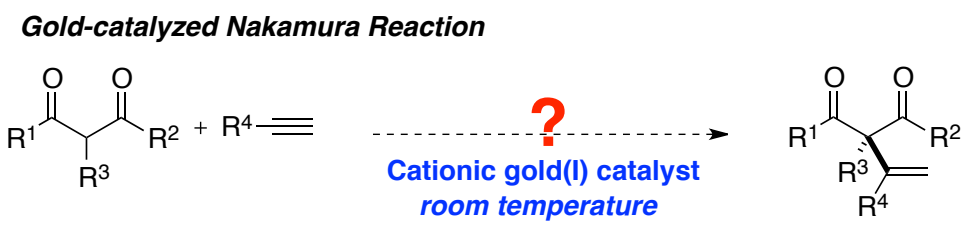

Scheme 3-3. Gold-catalyzed Nakamura reaction

To answer our question, a model reaction (Nakamura reaction with diketone $\mathbf{1}$ and alkyne 2) was chosen to test some most commonly used gold catalyst (Scheme 3-4). The results were expected that none of them offered enough conversion at both room temperature and $80^{\circ} \mathrm{C}$. Our TA-Au catalyst was also tested and gave no conversion at both temperatures whatsoever. The good news was that unlike the cationic gold $\left[\mathrm{L}-\mathrm{Au}^{+}\right]$that formed substantial gold mirror upon 
heating, our TA-Au was stable enough as observed in previous case. The bad news was no conversion.

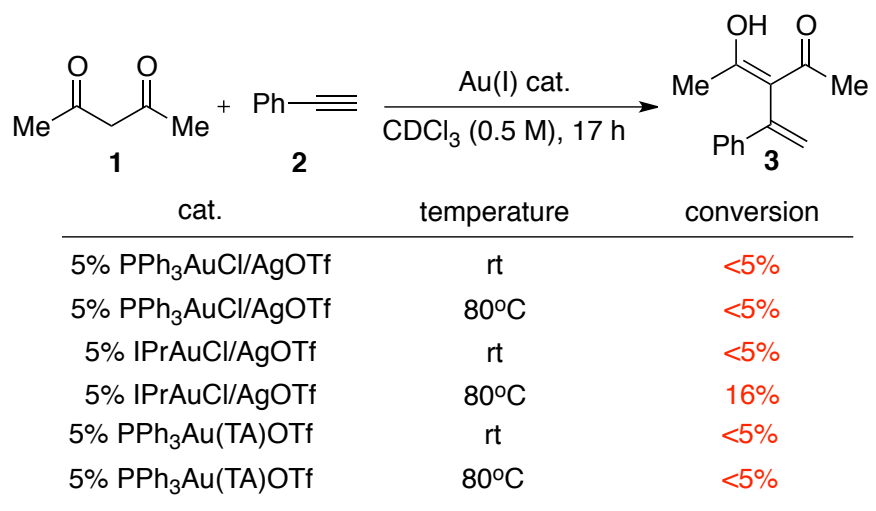

formation of inactive $\mathrm{Au}(0)$ at high temperature

Scheme 3-4. Initial screening of gold-catalyzed Nakamura reaction

At this point, to optimize the gold catalyst definitely would help, and indeed, later we found that this reaction could be well catalyzed by simple $\mathrm{Au} / \mathrm{Ag}$ system. Taking into consideration of orbital energy, different gold catalyst would not lower the LUMO of alkyne so much, however, adding some sort of activator for the nucleophile may largely elevate the HOMO as the diketone may not be a very strong nucleophile in the neutral form, though lots of organocatalytic Michael additions used free diketone. This synergistic catalysis idea has been reported in the literature for Conia-ene and broadly other transformations as well (Scheme 3-5). Therefore, the addition of Lewid acid may generate metal-enolate, which is a better nucleophile (Scheme 3-6). 

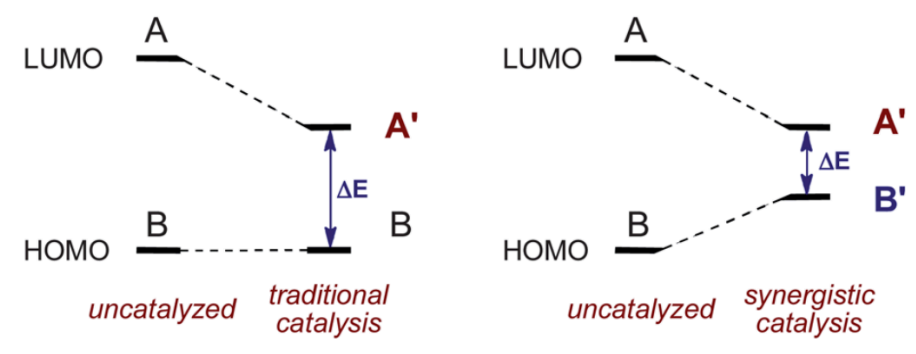

Scheme 3-5. Synergistic catalysis

The only question that was left is the compatibility of gold catalyst with Lewis acid as it was thought that the gold catalyst is relatively fragile. Here, our TA-Au would be a best candidate for its great stability.

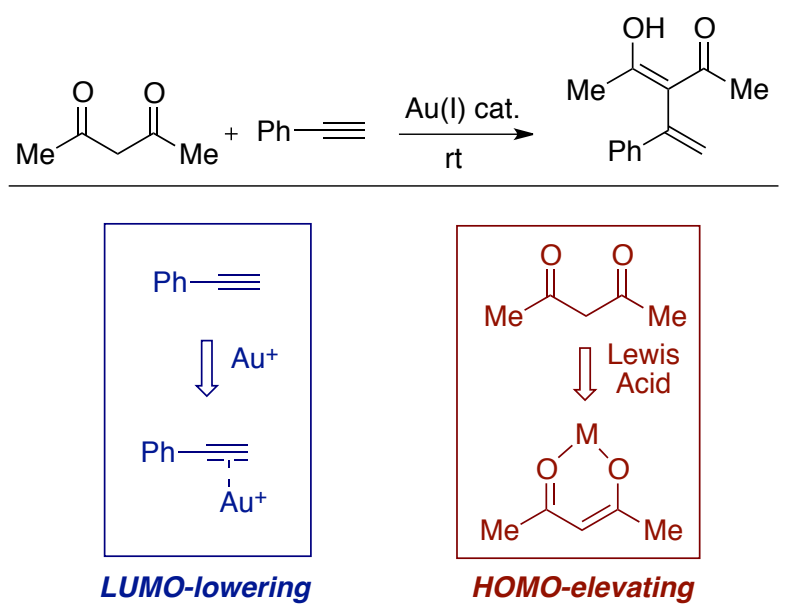

Scheme 3-6. Synergistic catalysis ${ }^{28}$ in gold-catalyzed Nakamura reaction

\subsection{Lewis Acid Screening}

We started our screening with XPhos as primary ligand, since it gave the desired product in 28\% NMR yield (XPhosAuCl/AgOTf), see Table 3-1. However no further conversion was obtained after $17 \mathrm{~h}$. The addition of $5 \% \mathrm{Ga}(\mathrm{OTf})_{3}$ into $5 \%$ XPhosAu(TA)OTf gave a very clean reaction with the desired product observed in $90 \%$ yield ( $91 \%$ conversion). Increasing the $\mathrm{Au} / \mathrm{Ga}$ ratio to 1:2 led to the full conversion and $\mathbf{3}$ was obtained in excellent 
yield (98\%). This was likely due to the improved nucleophilicity of diketone through $\mathrm{Ga}(\mathrm{III})$ chelation (formation of gallium enolate). Combination of $\mathrm{Au} / \mathrm{Ag}$ system with $\mathrm{Ga}(\mathrm{OTf})_{3}$ (instead of TA-Au complex) gave lower yield and slightly messier reaction (unidentified side products), presumably due to the greater stability of triazole-gold complexes over the simple $[\mathrm{L}-\mathrm{Au}]^{+}$. Notably, $\mathrm{Ga}(\mathrm{OTf})_{3}$ alone could not promote this reaction at all either at $\mathrm{rt}$ or at $45{ }^{\circ} \mathrm{C}$, which confirmed the important role of $\mathrm{Au}$ in this transformation. ${ }^{29}$ Other acids, such as $\mathrm{TfOH}$, triflate salts of $\mathrm{Zn}(\mathrm{II}), \mathrm{Ni}(\mathrm{II})$ and $\mathrm{Ag}(\mathrm{I})$, were also tested as the additives, and much worse performances were observed. Copper(II) triflate surprisingly gave almost identical performace as gallium.

Table 3-1. Optimization of gold(I)-catalyzed Nakamura reaction ${ }^{a}$

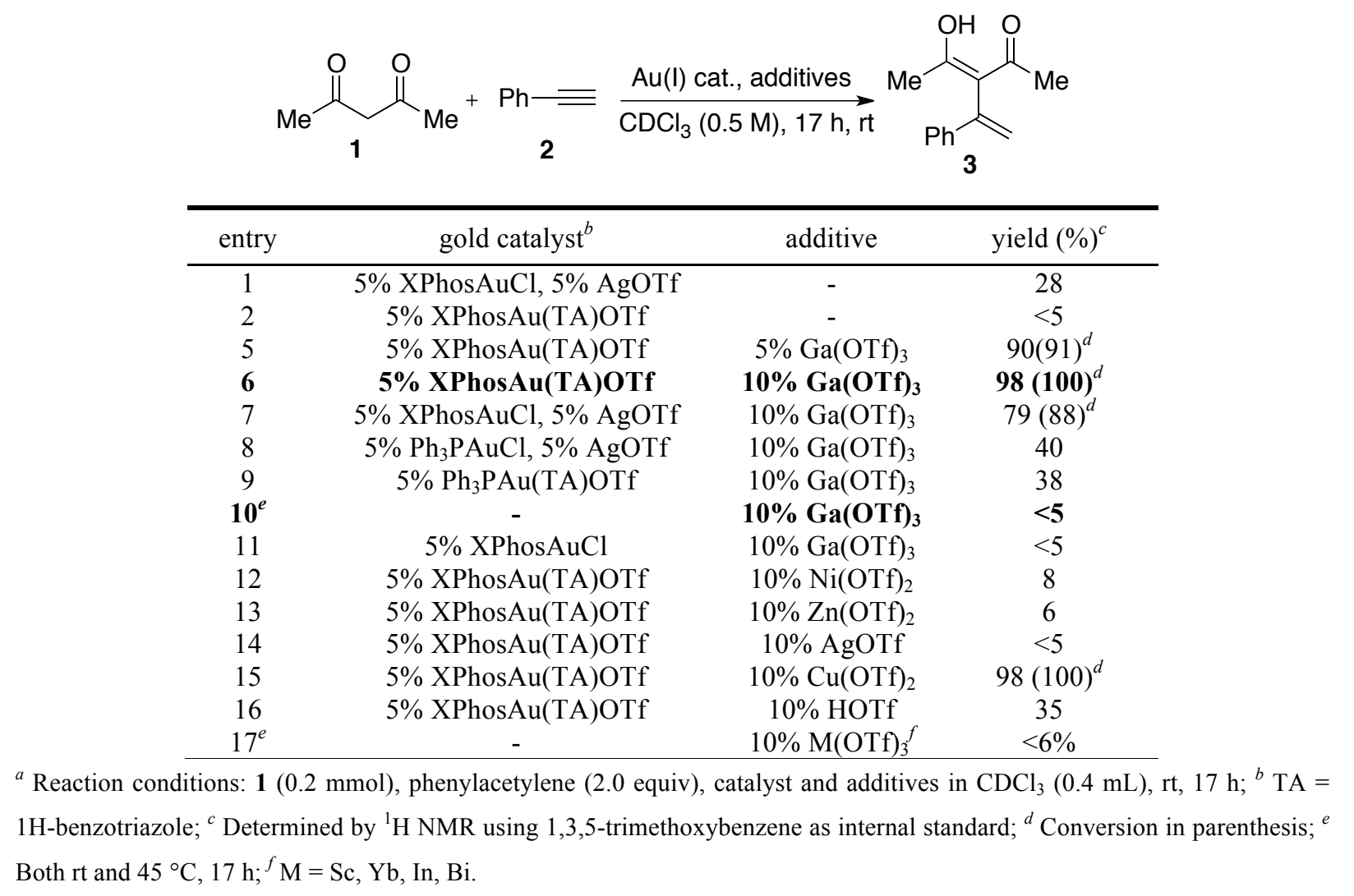


To support the identity of the catalyst, crystals of XPhosAu(TA)OTf suitable for x-ray crystallography were obtained. And the structure is shown below. The distance between the $\mathrm{Au}$ and $\mathrm{C}_{\mathrm{ipso}}$ is $3.099 \AA$, demonstrating very weak interaction of cationic gold with the arene. The triazole ring is little off the plane, suggesting the steric repulsion of triazole with isopropyl group on the benzene ring.

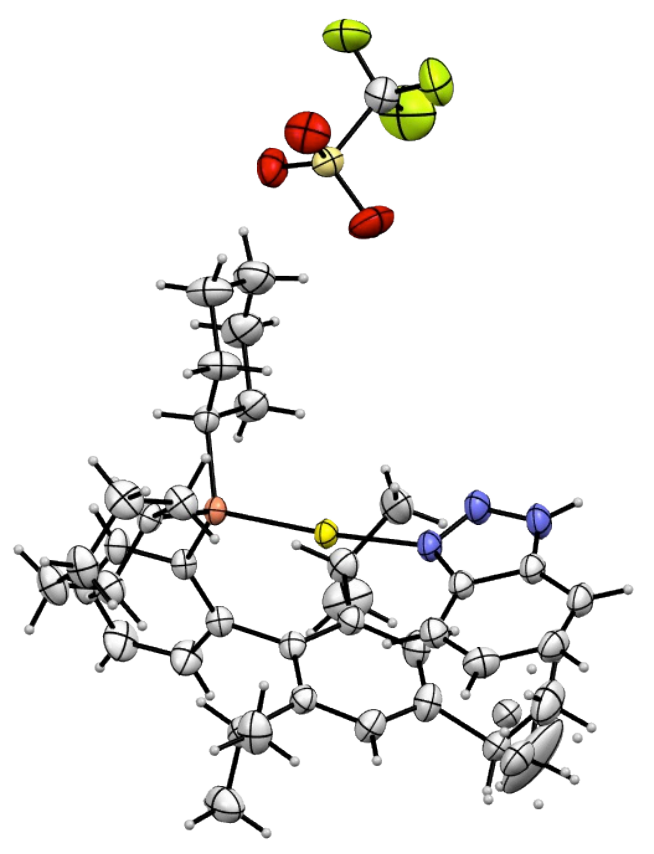

Figure 3-1. OTREP structure of XPhosAu(TA)OTf

\subsection{Generality of TA-Au/Lewis Acid System}

The great reactivity offered by the combination of TA-Au and Lewis acid, especially gallium triflate, led to an obvious question: is this system only effective for Nakamura reaction? It seems that the gallium triflate largely accelerates the reaction rate. The Toste cycloisomerization $^{30}$ was first tested for the reason that the substrate did not have diketone, nor any potential coordination site with gallium triflate. And interesting, while the TA-Au gave a 
very sluggish reaction rate, $7 \%$ conversion after $8 \mathrm{~h}$, the combination gave $85 \%$ in $8 \mathrm{~h}$. This is at least a rate acceleration of 20-fold (Scheme 3-7).

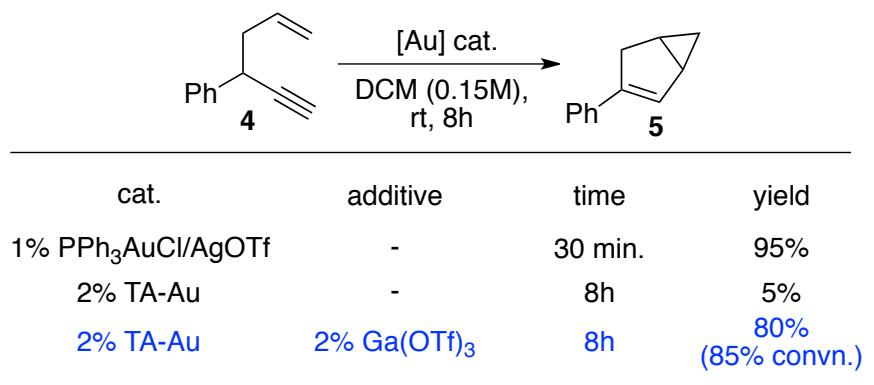

Scheme 3-7. Gallium effect on Toste's cycloisomerization

Further evidence from the propargyl ester rearrangement, ${ }^{31}$ as discussed in the Chapter 2, our TA-Au chemoselectively activates alkyne over allene to give only allenyl ester, however the addition of gallium triflate dramatically reverses this chemoselectivity and gives only the indene product (Scheme 3-8). Based on this information, the nature of TA-Au/Ga(OTf) $)_{3}$ is more like cationic gold.

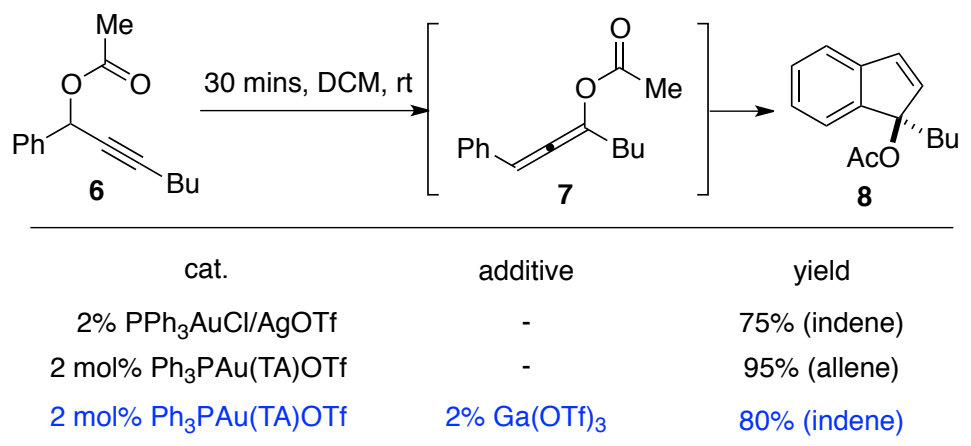

Scheme 3-8. Gallium effect on propargyl ester rearrangement 


\section{Chapter 4. Gold/Gallium-Catalyzed Nakamura Reaction: C-C Bond Formation}

Part of this work has been published: Xi, Y.; Wang, D.; Ye, X.; Akhmedov, N. G.; Petersen, J. L.; Shi, X. "Synergistic Au/Ga Catalysis in Ambient Nakamura Reaction" Org. Lett. 2014, 16, 306-309. 
In the previous Chapter, our study intended to develop an efficient system with the TA-Au with higher reactivity but maintaining its good thermal stability. Lewis acids have been identified as valuable additives. Preliminary mechanistic investigation showed the role of Lewis acid involves reversibly pulling the triazole off the gold center through a dynamic process. As a demonstration of this newly developed system, the efficiency has to be examined in various systems. It is also our anticipation that this system will achieve transformations that previously are challenging.

\subsection{Substrate Scope}

With the optimal condition in hand, we first embarked on the evaluation with various 1,3dicarbonyl compounds and alkynes in order to develop a general methodology. As shown in Table 4-1, a variety of aromatic alkynes were initially tested. Generally, over $90 \%$ yields were achieved. The electronic effect of substituent groups on para-position of phenylacetylene was evaluated. Aromatic alkynes with substituents on meta and ortho positions also gave very promising yields. Alkyne derivatives of electron-rich heterocycle could proceed smoothly through this transformation, as well as aliphatic alkynes, though with lower yield. Unfortunately, internal alkynes, such as 1-phenylhexyne and diphenylacetylene, gave no reactions even at elevated temperature $\left(45^{\circ} \mathrm{C}\right)$. 
Table 4-1. Scope of alkynes
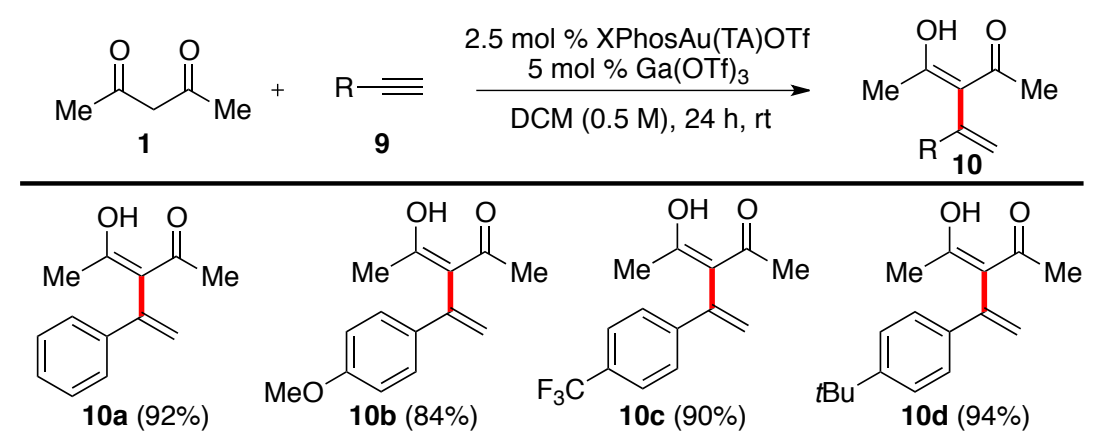<smiles></smiles><smiles>C=C(C(C(C)=O)=C(C)O)C(C(C)=O)=C(C)O</smiles><smiles>CC(=O)C(C(C)=O)=C(C)c1ccccc1[N+](=O)[O-]</smiles><smiles>C=C(C(C)=O)/C(C)=C(\C)O</smiles><smiles>C=C(C(C)=O)C(CCCCCC)C1CCCCC1</smiles><smiles>C=C(C(=C)C1CCCCC1)C(C(C)=O)=C(C)O</smiles><smiles>COC(=O)C(C=CC(C)=O)=C(C)O</smiles>

To demonstrate the broad versatility of this transformation, the scope of 1,3-dicarbonyl nucleophiles was also evaluated as shown in Table 4-2. Although, in some cases, a slightly harsher condition (condition B) was required for the optimal results, this $\mathrm{Au} / \mathrm{Ga}$ bimetallic system worked well with both cyclic and acyclic 1,3-dicorbonyl compounds. The cyclic $\beta$ ketoesters containing ring systems could successfully undergo this transformation. Remarkably, the addition to the ethynyl ferrocene gave good yield, which highlighted the mild reaction conditions of this method. The acyclic $\alpha$-alkyl- $\beta$-ketoester could also undergo this transformation, as well as 3-methyl-2,4-pentadione, dibenzoyl methane and dimethyl malonat. The products of the latter two were the thermodynamically stable $\alpha, \beta$-conjugated carbonyl compounds through olefin isomerization. Interestingly, the enamine derivative of 2,4pentadione could also serve as an effective nucleophile in this transformatio, which provided 
possibility for other carbon nucleophiles with broader synthetic applications. Notably, in most cases, an all-carbon quaternary center was efficiently generated.

Table 4-2. Scope of 1,3-dicarbonyl compounds
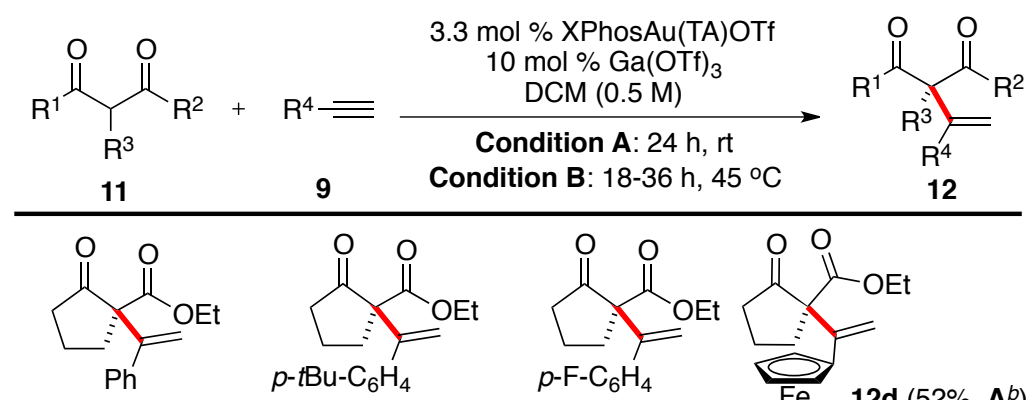

12a $(96 \%$, A)

12b $(95 \%, \mathbf{A})$

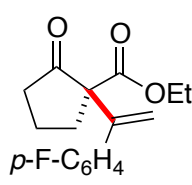

12c $(92 \%, \mathbf{A})$
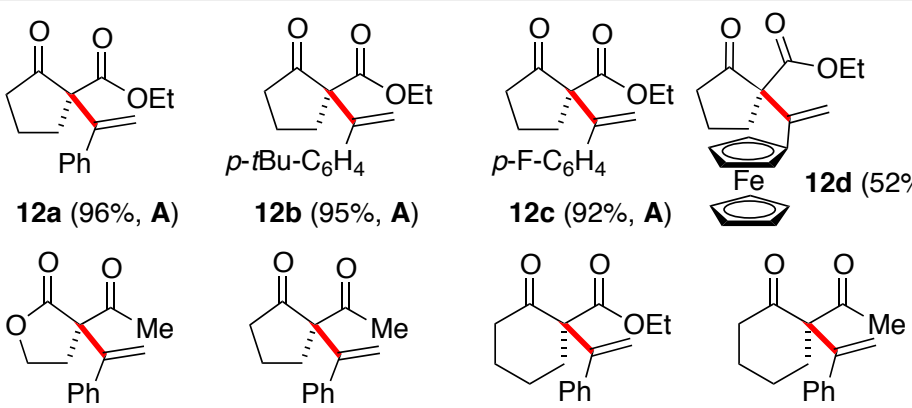

$12 \mathrm{e}(92 \%, \mathbf{A})$

$12 f(93 \%, A)$

12g $(87 \%$, B)

12h $(66 \%, B)$
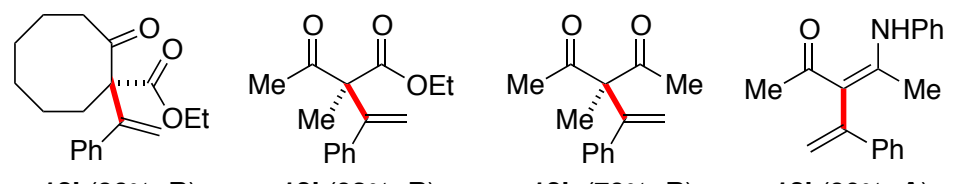

$12 \mathbf{i}(86 \%$, B)

12j $(93 \%, B)$

12k $(79 \%$, B)

12I $(90 \%, \mathbf{A})$

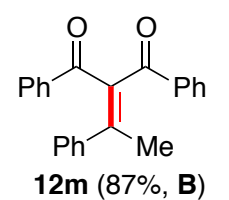<smiles>COC(=O)C(C(=O)OC)=C([18O])[18O]</smiles>

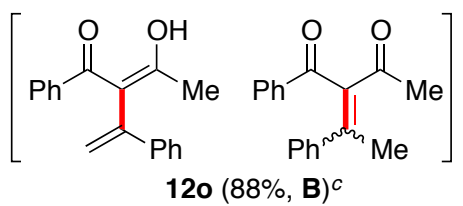

\subsection{Development of Low Loading Catalysis}

The fact that the Nakamura reaction is successfully achieved at room temperature highlights the high efficiency of this new bimetallic catalyst. To test the limit of gold catalyst in this bimetallic system, reactions were performed with decreased gold loading while keeping the $\mathrm{Ga}(\mathrm{OTf})_{3}$ in the similar amount as shown in Table 4-3. 
Table 4-3. Condition optimization for Nakamura reaction at low Au loading ${ }^{a}$

\begin{tabular}{|c|c|c|c|c|c|c|c|}
\hline entry & $\begin{array}{c}\text { gold } \\
\text { loading }\end{array}$ & $\begin{array}{l}\text { gallium } \\
\text { loading }\end{array}$ & $\begin{array}{l}\text { temper } \\
\text { ature }\end{array}$ & conc. & time & $\begin{array}{l}\text { yield } \\
(\%)^{b}\end{array}$ & $\begin{array}{c}\text { convn } \\
(\%)^{b}\end{array}$ \\
\hline $1^{c}$ & $2.5 \mathrm{~mol} \%$ & $5 \mathrm{~mol} \%$ & $\mathrm{rt}$ & $0.5 \mathrm{M}$ & $17 \mathrm{~h}$ & 92 & 94 \\
\hline 2 & $1 \mathrm{~mol} \%$ & $5 \mathrm{~mol} \%$ & $45^{\circ} \mathrm{C}$ & $0.5 \mathrm{M}$ & $46 \mathrm{~h}$ & 91 & 96 \\
\hline 3 & $0.1 \mathrm{~mol} \%$ & $5 \mathrm{~mol} \%$ & $45^{\circ} \mathrm{C}$ & $1.0 \mathrm{M}$ & $46 h$ & 87 & 94 \\
\hline 4 & $0.05 \mathrm{~mol} \%$ & $5 \mathrm{~mol} \%$ & $45^{\circ} \mathrm{C}$ & $1.0 \mathrm{M}$ & $46 \mathrm{~h}$ & 83 & 88 \\
\hline 5 & $0.02 \mathrm{~mol} \%$ & $5 \mathrm{~mol} \%$ & $45^{\circ} \mathrm{C}$ & $1.0 \mathrm{M}$ & $46 \mathrm{~h}$ & 15 & 25 \\
\hline 6 & $0.01 \mathrm{~mol} \%$ & $5 \mathrm{~mol} \%$ & $45^{\circ} \mathrm{C}$ & $1.0 \mathrm{M}$ & $46 \mathrm{~h}$ & $<5$ & $<5$ \\
\hline 7 & $0.01 \mathrm{~mol} \%$ & $10 \mathrm{~mol} \%$ & $45^{\circ} \mathrm{C}$ & $1.0 \mathrm{M}$ & $46 \mathrm{~h}$ & 20 & 28 \\
\hline 8 & $0.05 \mathrm{~mol} \%$ & $2 \mathrm{~mol} \%$ & $45^{\circ} \mathrm{C}$ & $1.0 \mathrm{M}$ & $46 \mathrm{~h}$ & 69 & 77 \\
\hline 9 & $0.05 \mathrm{~mol} \%$ & $1 \mathrm{~mol} \%$ & $45^{\circ} \mathrm{C}$ & $1.0 \mathrm{M}$ & $46 \mathrm{~h}$ & 41 & 47 \\
\hline 10 & - & $5 \mathrm{~mol} \%$ & $45^{\circ} \mathrm{C}$ & $1.0 \mathrm{M}$ & $46 \mathrm{~h}$ & $<5$ & $<5$ \\
\hline
\end{tabular}

To our great delight, after some optimizations, we discovered that $0.05 \mathrm{~mol} \%$ (500 ppm) was sufficient to promote this transformation if $\mathrm{Ga}(\mathrm{OTf})_{3}$ was kept at the $5 \%$ level $\left(\right.$ at $\left.45{ }^{\circ} \mathrm{C}\right)$. The scope at low Au loading is summarized in Table 4-4. Notably, a loading as low as 100 ppm could promote the reaction $(\mathbf{1 0 b})$, albeit with the low yield $(\mathrm{TON}=3600)$. 
Table 4-4. Low gold catalyst loading

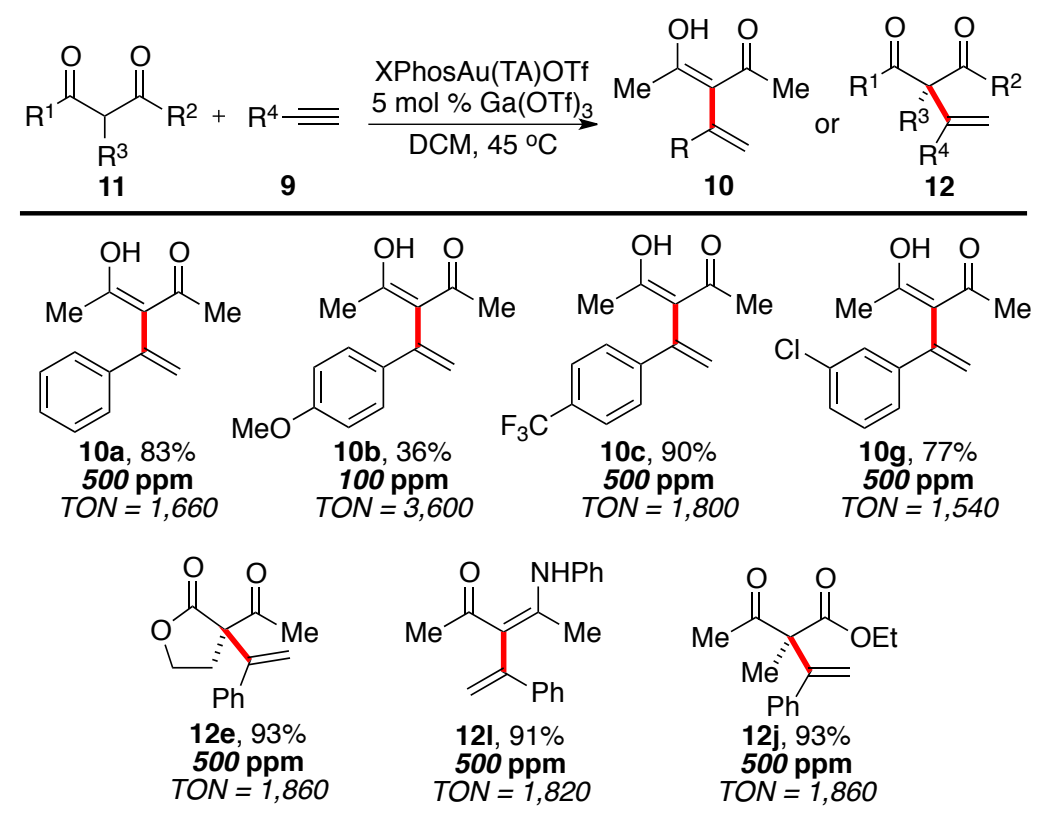

For most cases in gold(I) homogenous catalysis, the catalyst loadings are usually 1-5 mol \%. The high catalytic efficiency of small gold-cluster reported by Corma provided an alternative approach in reaching active gold catalysts with low loading. ${ }^{32}$ Meanwhile, very recently, Hashmi reported a highly active mononuclear gold(I) catalyst which could promote the alkyne activation at $0.01 \mathrm{ppm}$ loading. Thus, at this time, it is uncertain whether the gold cluster or the 'genuine' gold(I) cation serves as the active catalytic species in this Nakamura reaction.

\subsection{Preliminary Mechanistic Investigation}

As discussed in the Chapter 3 that our initial rationale to develop this TA-Au/Lewis relied on the idea of synergistic catalysis, where Lewis acid activates the diketone and gold activates the alkyne. To elucidate the detailed mechanism, a set of preliminary experiments was conducted (Scheme 4-1). 


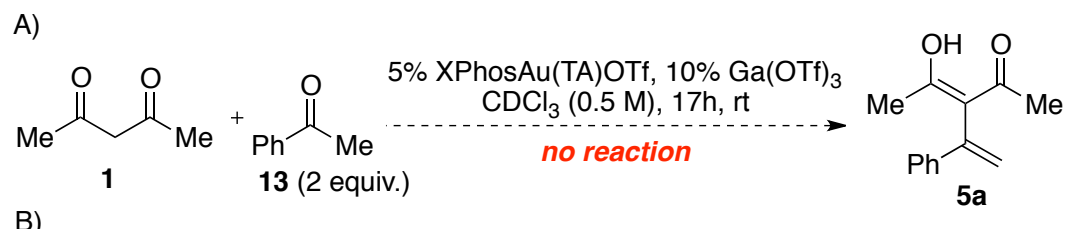

B)

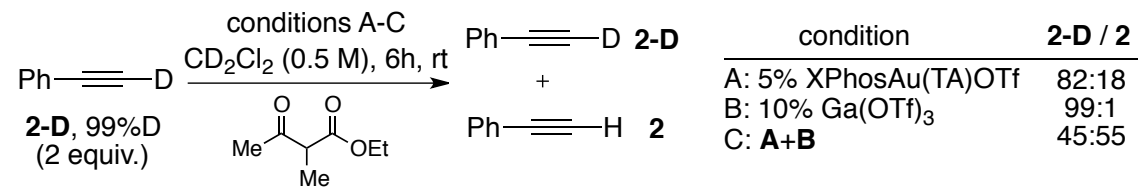

C)

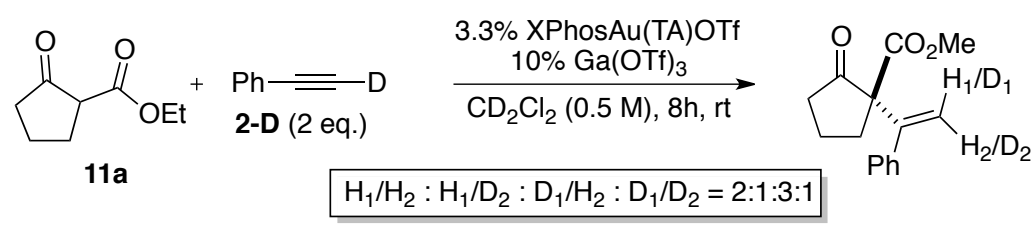

D)

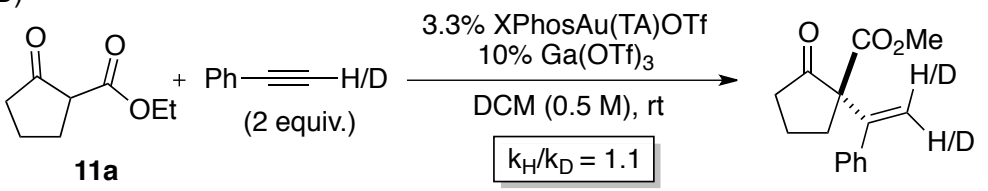

E)

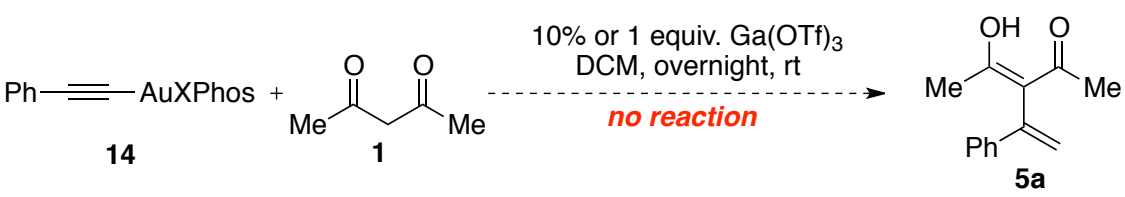

Scheme 4-1. Mechanistic Investigation

First, the reaction with 2,4-pentadione and acetophenone was subject to identical condition giving no product. This ruled out the possibility of an aldol/hydration pathway. Second, an isotope labeling experiment was performed. The result showed that the $\mathrm{Au} / \mathrm{Ga}$ system exhibited significant H/D exchange level while XPhosAu(TA)OTf did promote some level of H/D exchange. Only $\mathrm{Ga}(\mathrm{OTf})_{3}$ resulted in no exchange at all, suggesting the inability of activation of acetylenic proton by $\mathrm{Ga}(\mathrm{OTf})_{3}$ alone. A H/D scrambling was also observed in the catalytic reaction. A crude kinetics comparison between $\mathrm{H}$ - and D-labeled phenylacetylene gave a kinetic isotope effect of $\mathrm{k}_{\mathrm{H}} / \mathrm{k}_{\mathrm{D}}=1.1$. To completely rule out the possibility that the gallium actually activates alkyne, the corresponding gold acetylide was synthesized and subject to 
reaction in the presence of only gallium triflate. No reaction suggests that the alkyne is not activated by gallium alone unambiguously.

To gain further information, the reaction was later studied with in situ IR. First, the monitoring of the catalytic reaction was conducted. A clear catalytic induction period was observed at the beginning of the reaction, which suggested the formation of new species as the active catalyst for this transformation.
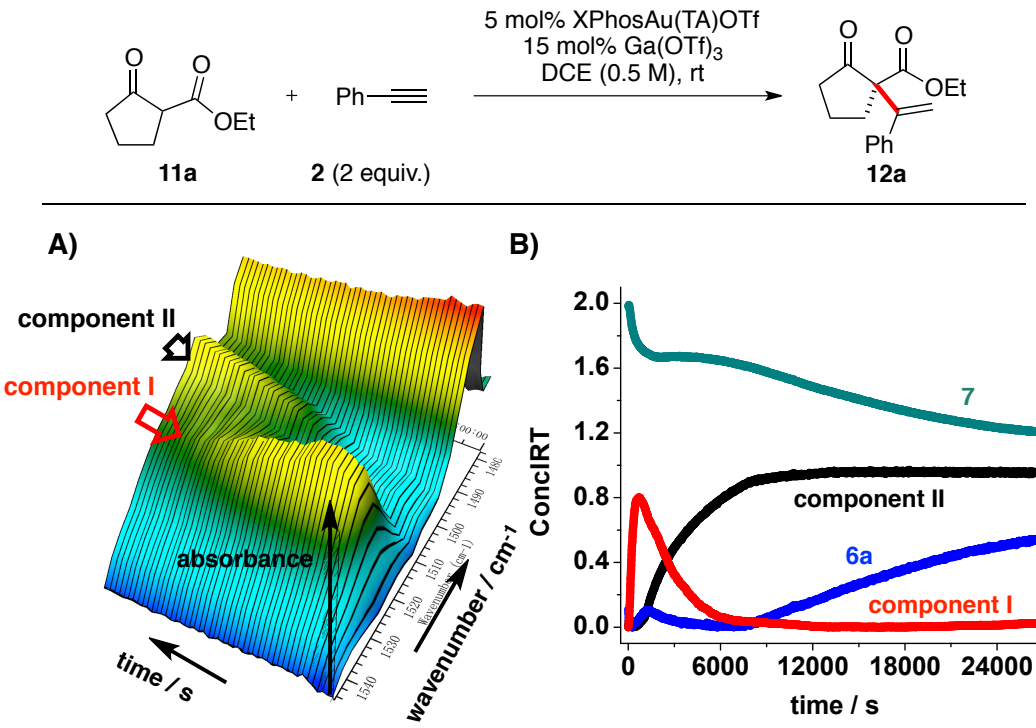

B)

Figure 4-1. In situ IR monitoring of catalytic Nakamura reaction
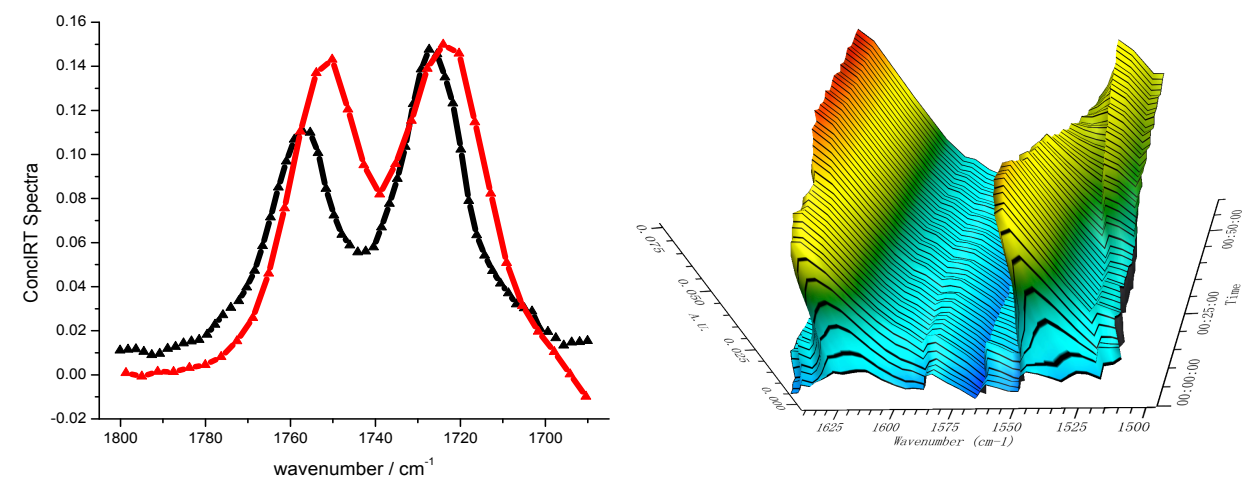

Figure 4-2. ConcIRT spectra of 12a (black curve) and 11a (red curve). Real-time spectra of the catalytic Nakamura reaction $\left(1640-1495 \mathrm{~cm}^{-1}\right.$ region) 
After scrutiny of the spectrum, two components (I and II) were identified, whereby I was generated rapidly within the first 15 min reaching its maximum and then decreased. II started to form after $\mathbf{I}$ reached its maximum. To identify the component $\mathbf{I}$, a stoichiometric reaction between compound 11a and $\mathrm{Ga}(\mathrm{OTf})_{3}$ was performed and monitored. Two peaks at 1523 and $1604 \mathrm{~cm}^{-1}$ started to build up after the addition of $\mathrm{Ga}(\mathrm{OTf})_{3}$.
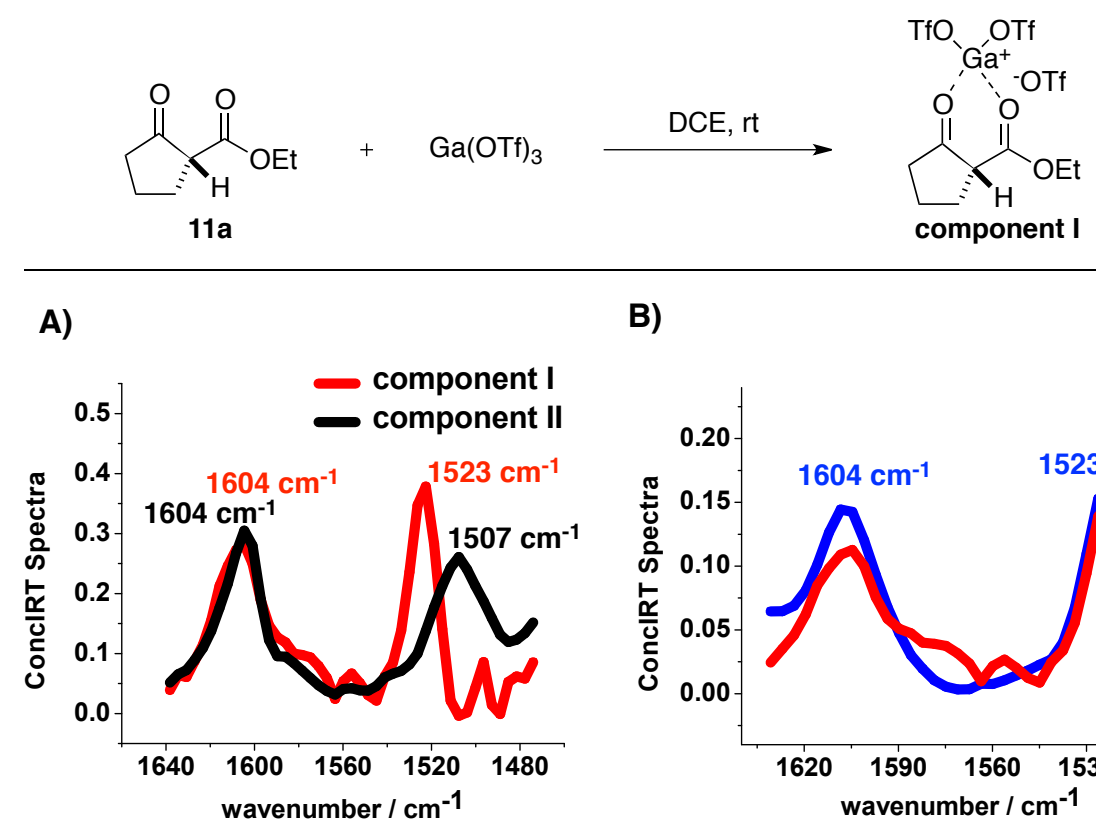

B)

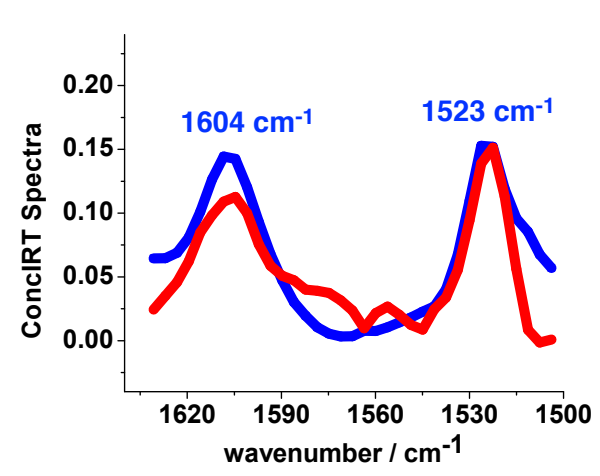

Figure 4-3. Identification of component I

Comparison of this spectrum with the ConcIRT spectrum of I gave excellent match, suggesting that $\mathbf{I}$ is the complex between 11a and $\mathrm{Ga}(\mathrm{OTf})_{3}$, which was also confirmed by ${ }^{1} \mathrm{H}$ NMR spectroscopy as the line-broadening could be observed (Figure 4-4). Notably, Li has shown that $\mathrm{Ga}(\mathrm{OTf})_{3}$ can form gallium enolate with $\beta$-ketoester. Therefore, it is reasonable to assume that component II should be the corresponding gallium enolate resulting from the deprotonation of I along with the formation of HOTf. 


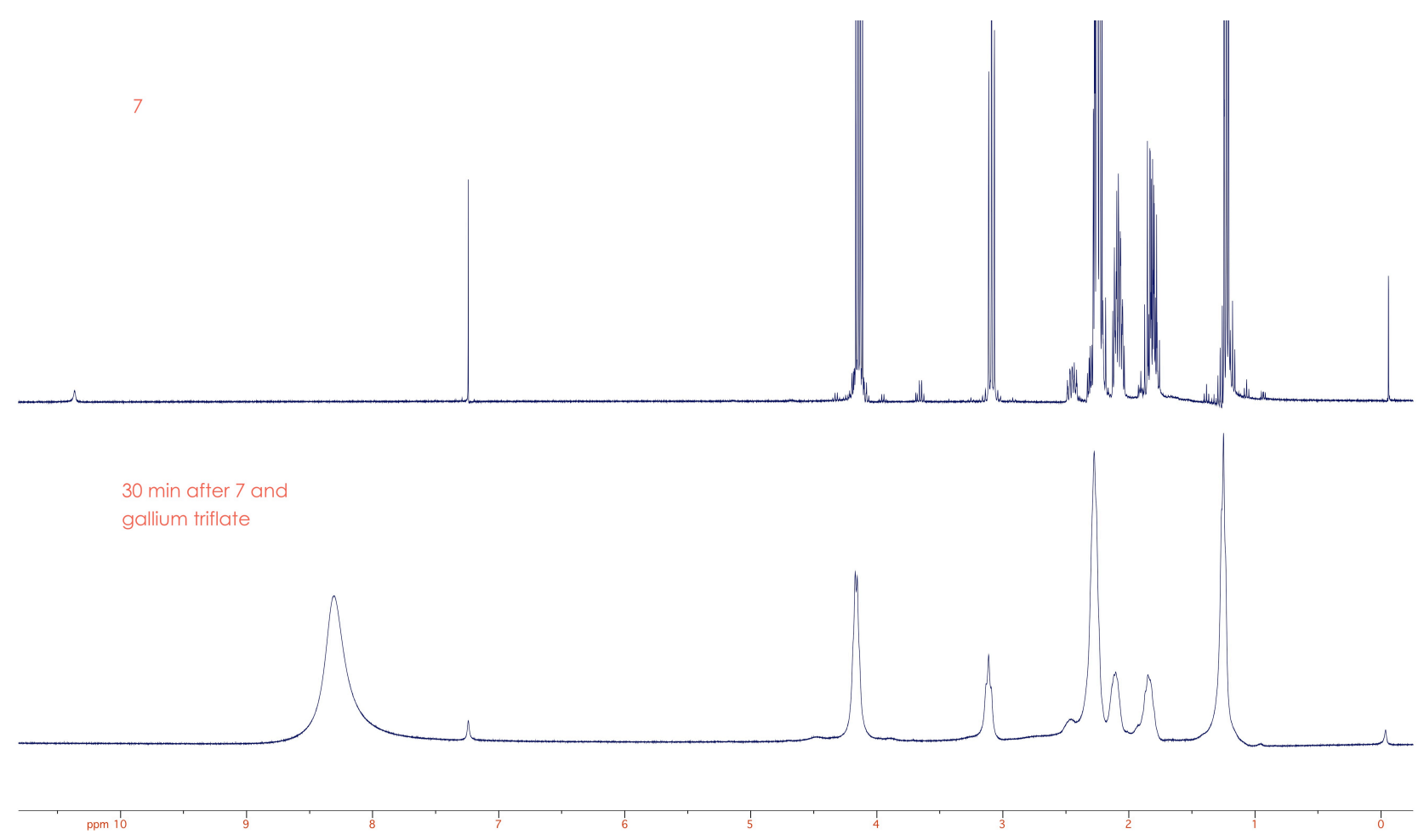

Figure 4-4. Stoichiometric reaction between 11a and $\mathrm{Ga}(\mathrm{OTf})_{3}$.

To monitor the interactions between $\mathrm{Ga}(\mathrm{III})$ and $\mathrm{Au}(\mathrm{I})$, a titration of $\mathrm{Ga}(\mathrm{OTf})_{3}$ to XPhosAu(TA)OTf was performed (Figure 4-5). Upon the additions of $\mathrm{Ga}(\mathrm{OTf})_{3}(1 / 3$ equiv. to $\mathrm{Au}$ each time, 3 times), the concentration of XPhosAu(TA)OTf decreased rapidly in correspondence to the generation of another new species. The ConcIRT spectrum of this new species is in close similarity to the ConcIRT spectrum of the species generated when the $1-\mathrm{H}$ benzotriazole (TA) solution was added stoichiometric $\mathrm{Ga}(\mathrm{OTf})_{3}$. 


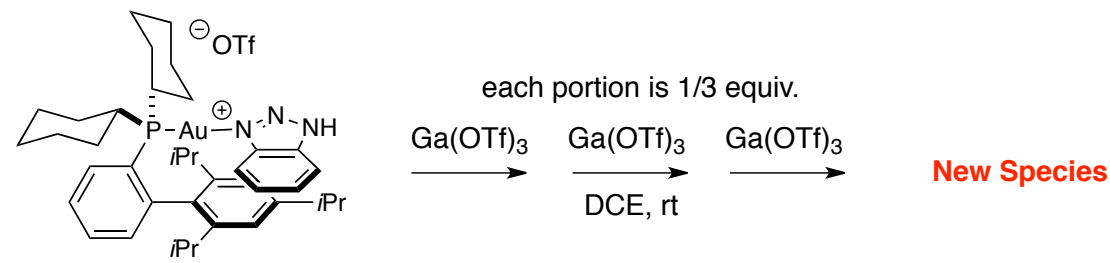

XPhosAu(TA)OTf
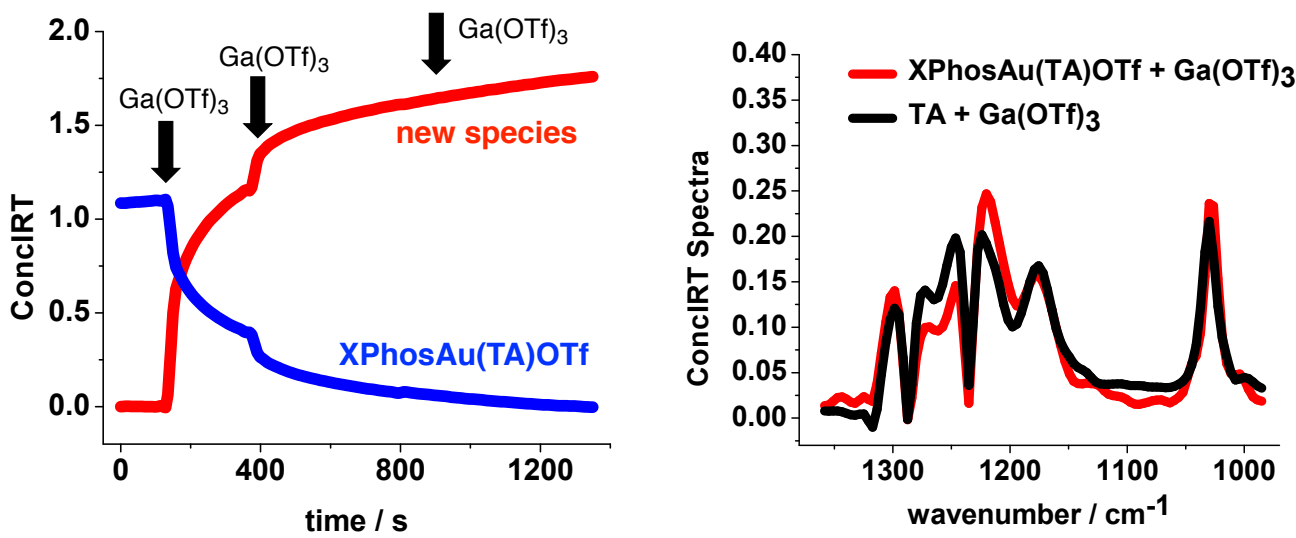

Figure 4-5. Titration of $\mathrm{Ga}(\mathrm{OTf})_{3}$ with $\mathrm{XPhosAu(TA)OTf}$
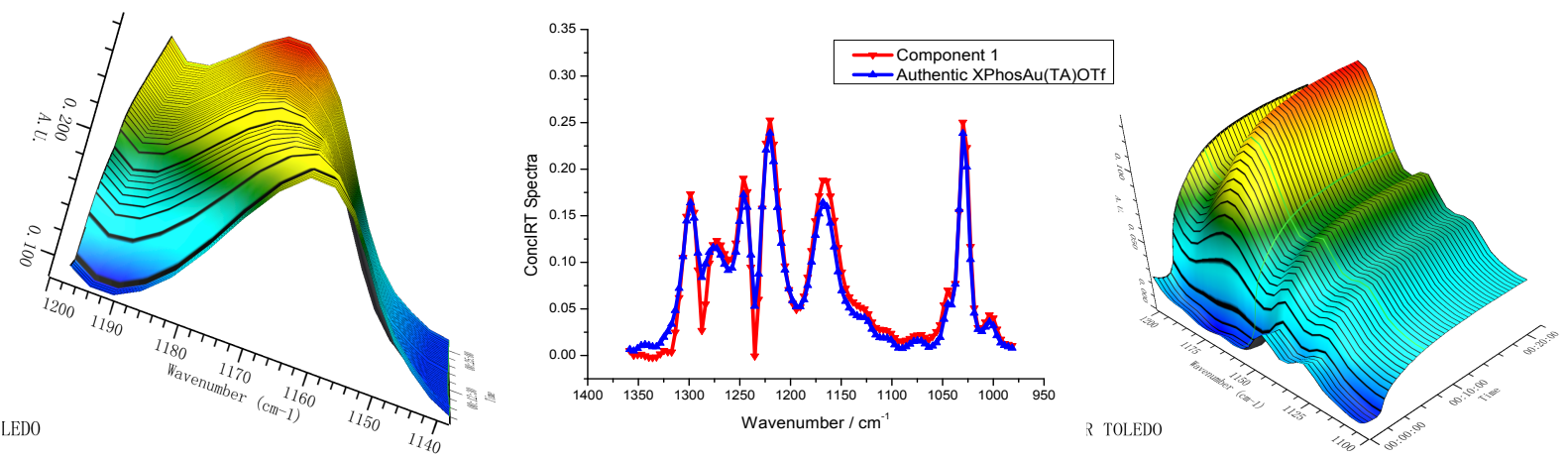

Figure 4-6. a) Real-time IR spectra of stoichiometric reaction between $\mathrm{Ga}(\mathrm{OTf})_{3}$ and XPhosAu(TA)OTf. b) Spectra of XPhosAu(TA)OTf given by ConcIRT analysis and authentic XPhosAu(TA)OTf. c) Real-time IR spectra of stoichiometric reaction between $\mathrm{Ga}(\mathrm{OTf})_{3}$ and 1H-benzotriazole

These results are very interesting since they suggested that the $\mathrm{Ga}(\mathrm{OTf})_{3}$, besides activating the dicarbonyl substrate, also serves as the activator for TA-Au: slow release of the 
activated $[\mathrm{Au}]$ catalysts through competing coordination with TA ligands. Based on these results, a tentative mechanism is proposed in Scheme 4-2.

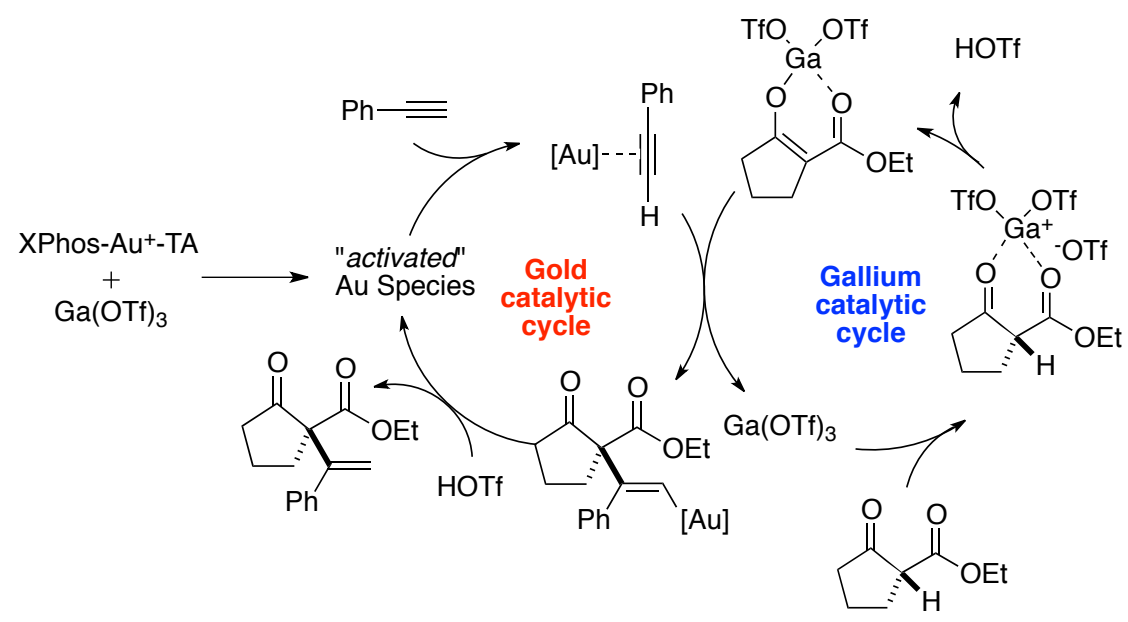

Scheme 4-2. Proposed mechanism

\subsection{Attempts at Enantioselective Version}

Finally, some efforts were devoted into developing an enantioselective version. Preliminary screening of different system gave all less than $6 \%$ ee. 


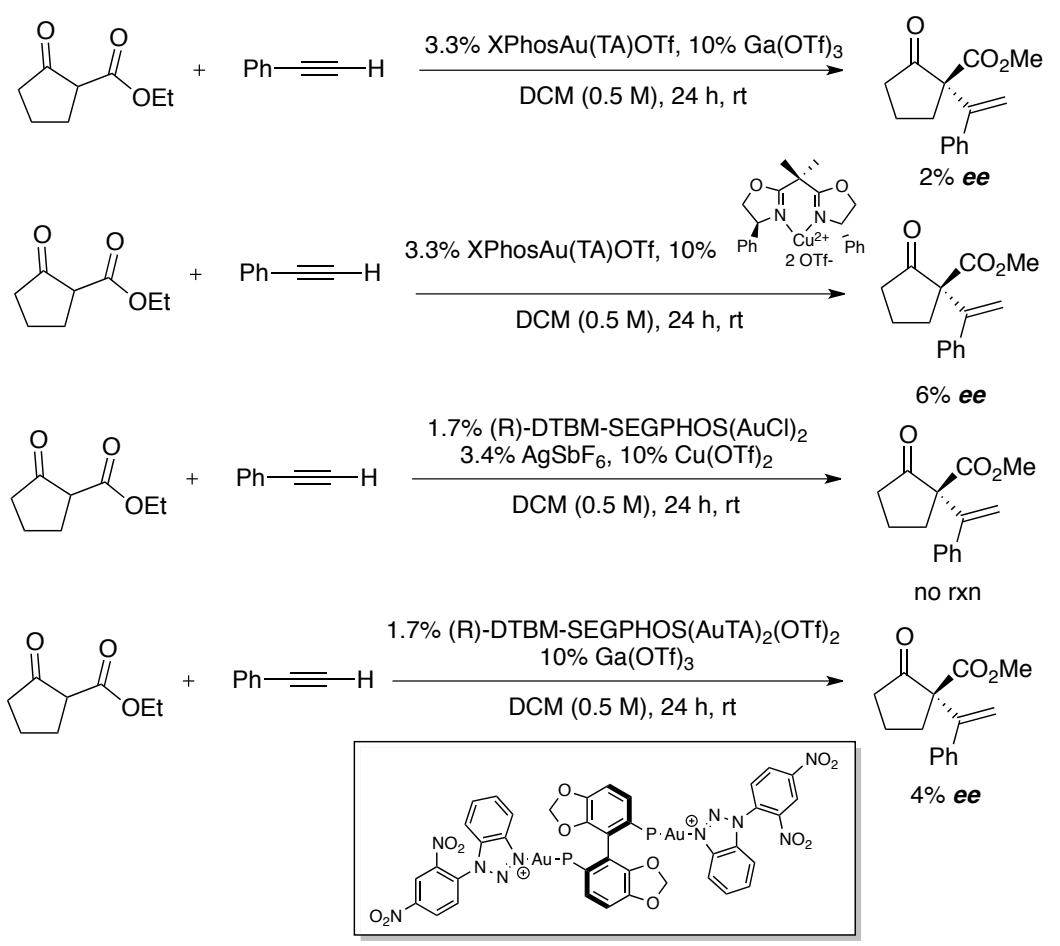

Scheme 4-3. Attempted enantioselective Nakamura reaction 
Chapter 5. Mechanistic Study of Gold-Triazole (TAAu)/Lewis Acid System 
In the previous Chapter, a highly efficient system with the combination of TA-Au and Lewis acid was developed and evaluated in Nakamura reaction. The low loading experiment demonstrates the profound catalytic activity of this system. Previous experience showed that this system behaves more like cationic gold instead of TA-Au.

\subsection{NMR Study}

To understand the nature of this developed system, a series of NMR experiments were conducted firstly. As shown below that a solution prepared from mixing the molar ratio 1:1 of XPhosAu(TA)OTf and Ga(OTf) $)_{3}$ was analyzed by ${ }^{31} \mathrm{P}$ NMR and ${ }^{19}$ F NMR (Scheme 5-1)
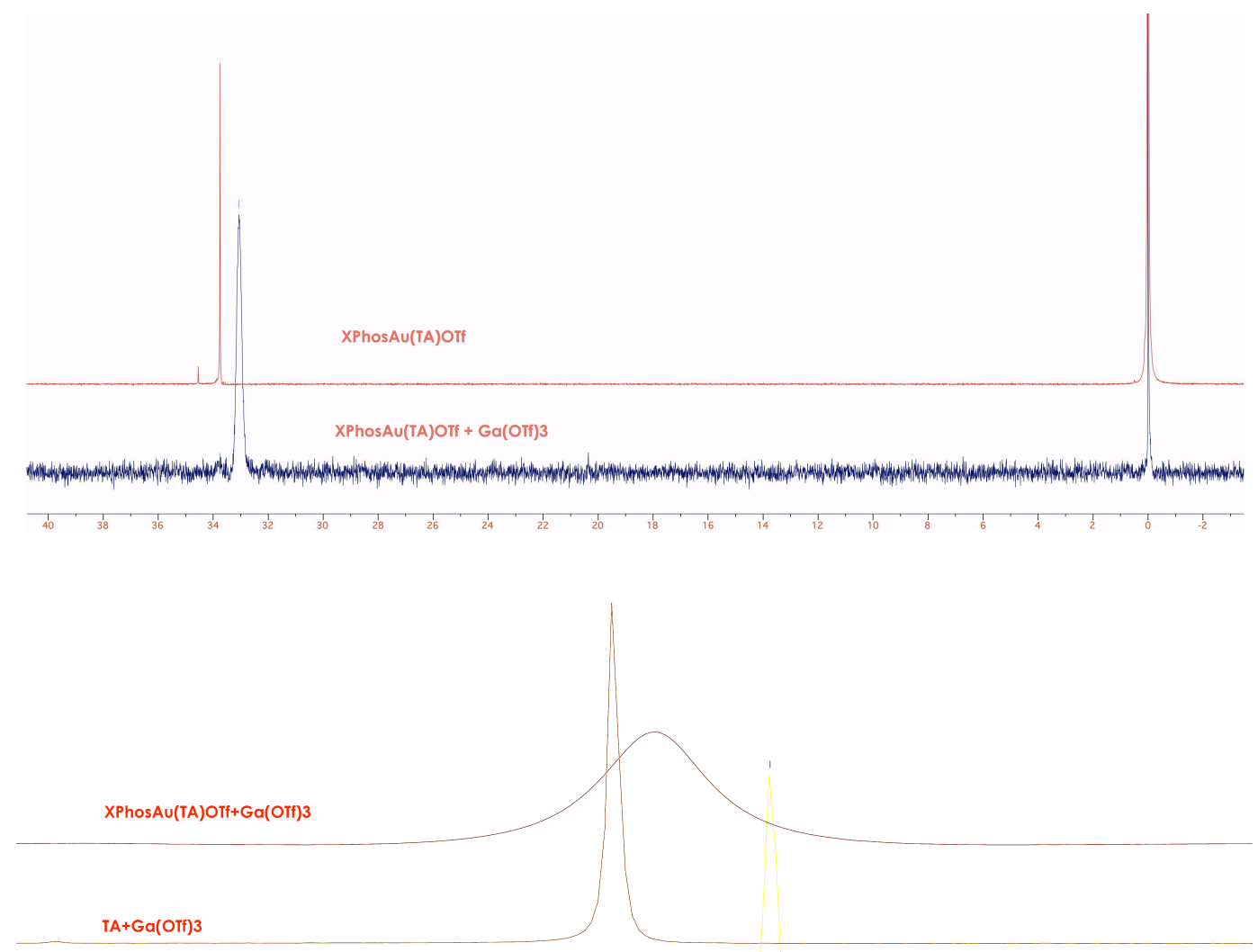

XPhosAu(TA)OTf

Figure 5-1. ${ }^{31} \mathrm{P}$ NMR and ${ }^{19} \mathrm{~F}$ NMR experiment 
Apparent chemical shift change was observed, and the mixture showed also broader signal compared to pure sample, which clearly demonstrated the dynamic nature of the mixture. And the chemical shift also suggested the formation of free cationic gold species. This result is in good consistence with previous gold/gallium titration experiment in Chapter 4.

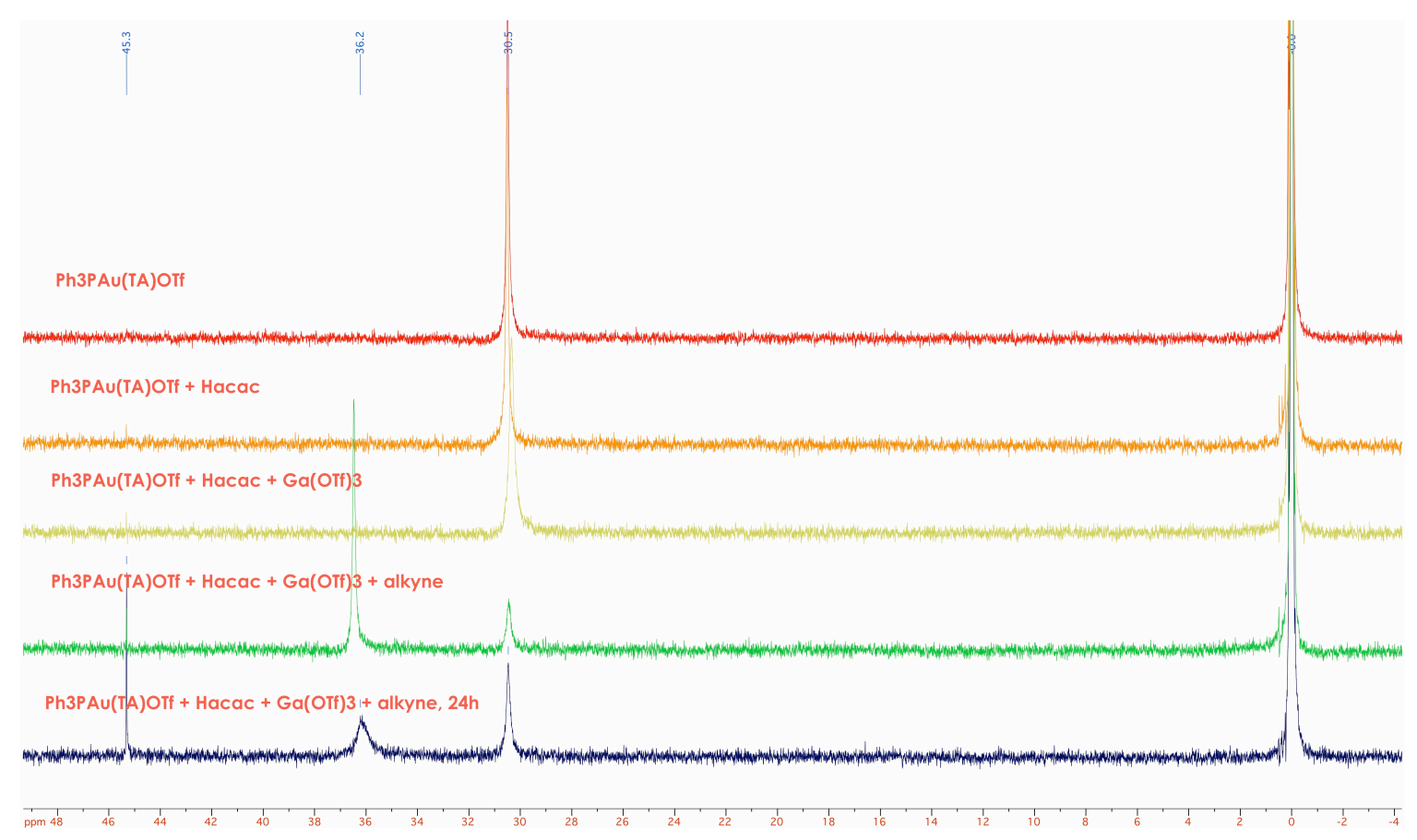

Figure 5-2. Stoichiometric Nakamura reaction with ${ }^{31} \mathrm{P}$ NMR

Stoichiometric Nakamura reaction was also performed in steps. As shown in Figure 5-2 when mixing the $\mathrm{Ph}_{3} \mathrm{PAu}(\mathrm{TA}) \mathrm{OTf}$ with 2,4-pentadione resulted in no change in chemical shift, a little upfield shift was observed with the addition of $\mathrm{Ga}(\mathrm{OTf})_{3}$. This is consistent with formation of activated species. A new peak at chemical shift $\delta 36$ became the major peak when phenyl acetylene was added. According to the literature, this peak is corresponding to $\sigma, \pi-$ diaurated alkyne, as reported by Widenhoefer. NMR after $24 \mathrm{~h}$ still could see the original peaks 
at $\delta 36$ and TA-Au and also it was associated with decomposition product assigned as $\left(\mathrm{Ph}_{3} \mathrm{P}\right)_{2} \mathrm{Au}^{+}$

The reaction progress also was monitored with MassSpec. The continuous observation of $(\mathrm{XPhos} A u)_{2}(\mathrm{CCPh})$ supported the formation of $\sigma, \pi$-diaurated alkyne overall the progression of the reaction.

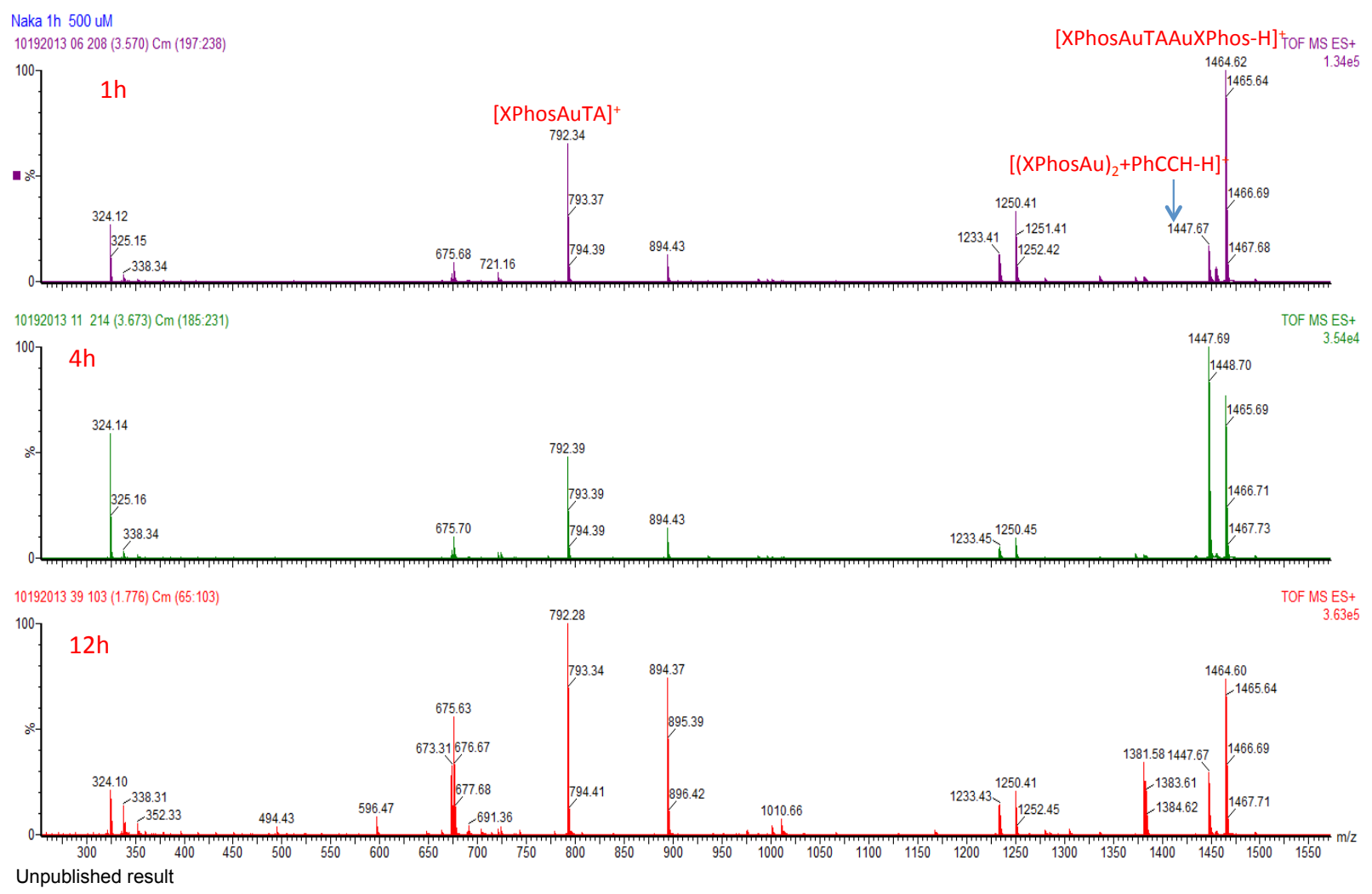

Figure 5-3. Monitoring catalytic Nakamura reaction with MassSpec

\subsection{UV-Vis Study}

In the Chapter $3, \mathrm{Cu}(\mathrm{OTf})_{2}$ was also identified as an active additive for reactivity improvement. In light of the poor solubility of both $\mathrm{Cu}(\mathrm{OTf})_{2}$ and $\mathrm{Ga}(\mathrm{OTf})_{3}$ in $\mathrm{DCM} / \mathrm{DCE}$, quantitative experiment would be very difficult to conduct. On the other hand, it was 
discovered that $\mathrm{Cu}(\mathrm{OTf})_{2}$ dissolves extremely well in acetronitrile and forms a greenish-blue solution. A UV-Vis study may be helpful to reveal the nature of TA-Au and Lewis acid.

A series solution with $\mathrm{Cu}(\mathrm{OTf})_{2}$ and benzotriazole in different ratio was prepared and the photo below shows the color trend. Simialarly, a series solution with $\mathrm{Cu}(\mathrm{OTf})_{2}$ and TA-Au in different ratio was also prepared.

$\mathrm{Cu}(\mathrm{OTf})_{2}+$ benzotriazole in $\mathrm{ACN}(0.005 \mathrm{M})$
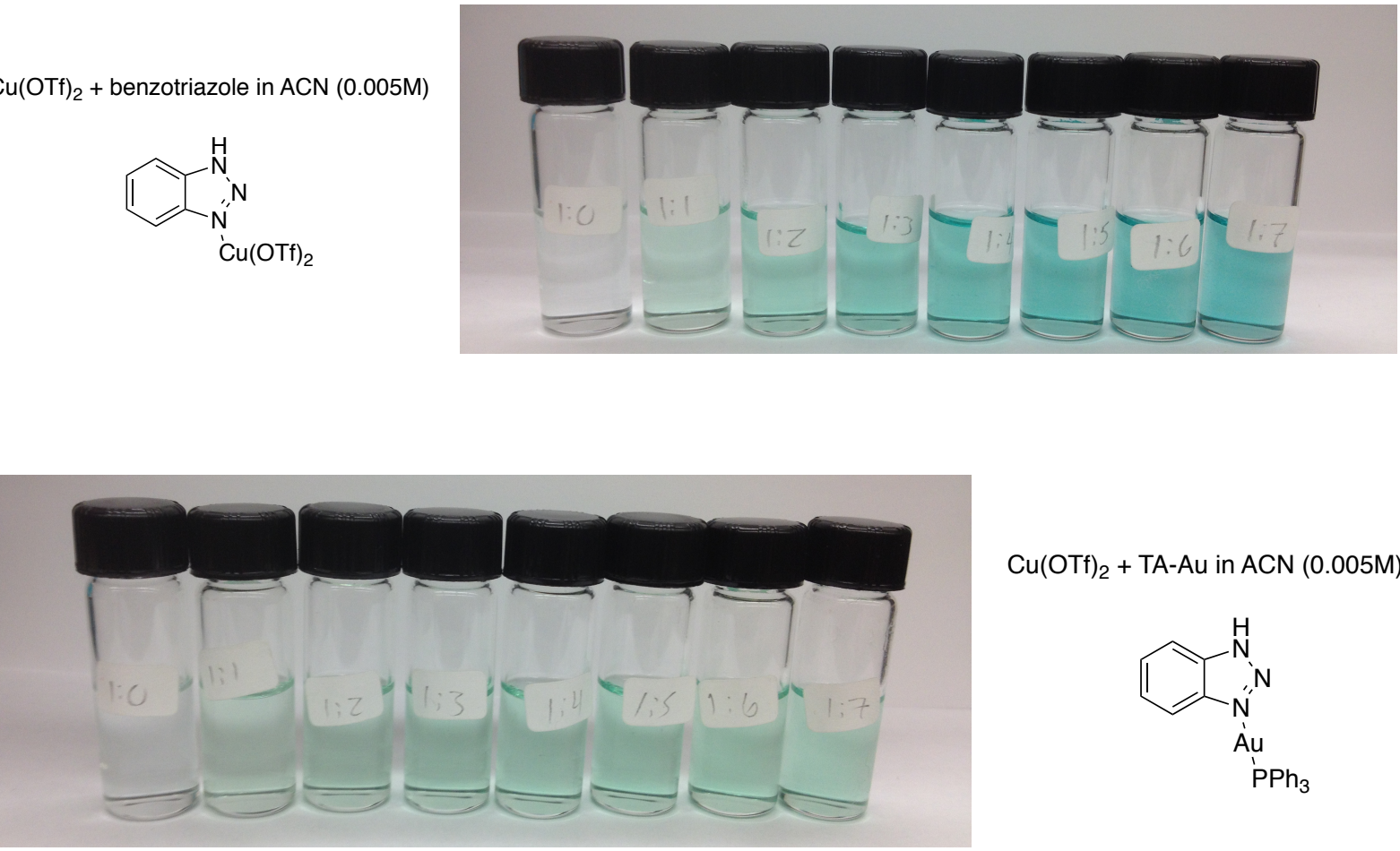

$\mathrm{Cu}(\mathrm{OTf})_{2}+\mathrm{TA}-\mathrm{Au}$ in ACN $(0.005 \mathrm{M})$<smiles></smiles>

Figure 5-4. Color trend of $\mathrm{Cu}(\mathrm{OTf})_{2} / \mathrm{BTA}$ and $\mathrm{Cu}(\mathrm{OTf})_{2} / \mathrm{TA}-\mathrm{Au}$ solutions in different ratio

The UV-Vis spectra for both series show meaningful trend. As the ratio gets bigger, the $\lambda_{\max }$ of copper complex in visible region blue shifts toward a certain wavelength. Meanwhile, the peak at $\lambda_{\max } \sim 380 \mathrm{~nm}$ also shows certain saturation. 

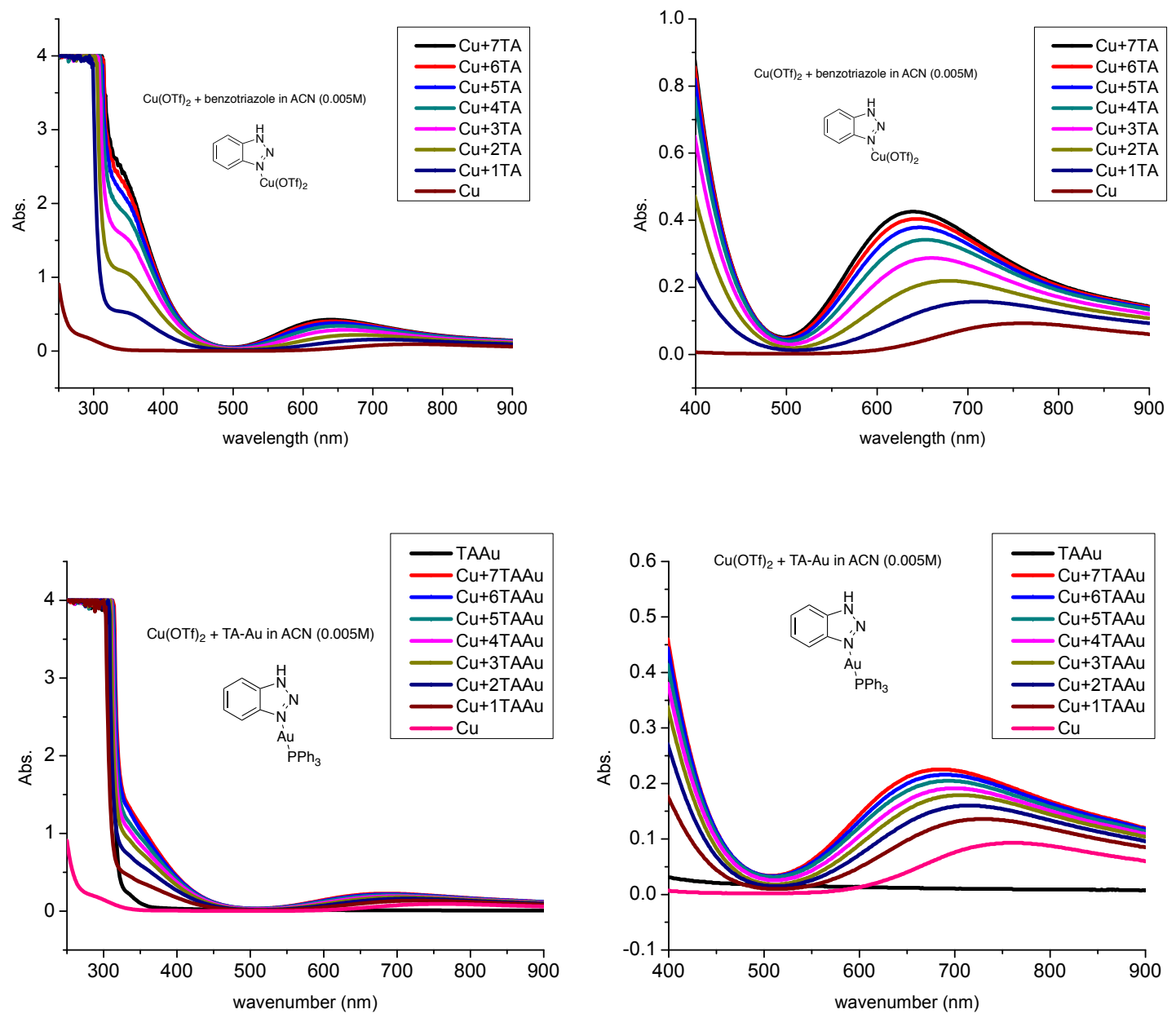

Figure 5-5. UV-Vis spectra of $\mathrm{Cu}(\mathrm{OTf})_{2} / \mathrm{BTA}$ and $\mathrm{Cu}(\mathrm{OTf})_{2} / \mathrm{TA}-\mathrm{Au}$ solutions in different ratio

Although efforts to obtain a crystal structure with this system were not fruitful, the combined NMR, UV-Vis and in situ IR experiments altogether argue strongly the interaction of TA-Au and Lewis acid used.
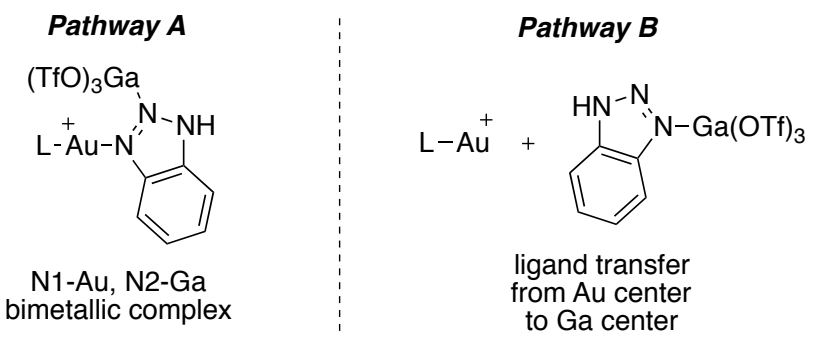

Scheme 5-1. Two possible pathways 
Two pathways for the interaction are proposed herein (Scheme 5-1). Pathway A involves the formation of bimetallic $\mathrm{Au}$, Ga-complex. Pathway $\mathrm{B}$ just is an equilibrium between $\mathrm{TA}-\mathrm{Au} / \mathrm{Ga}(\mathrm{OTf})_{3}$ and $\mathrm{L}-\mathrm{Au}^{+} / \mathrm{Ga}(\mathrm{TA})_{\mathrm{n}}(\mathrm{OTf})_{3}$. It is impossible to rule out one from the other. But pathway A serves as the transition state for the equilibrium in pathway B. Further study will shed light on this process. 
Chapter 6. Gold/Copper-Catalyzed Divinyl Ether Synthesis: C-O Bond Formation 


\subsection{Initial Discovery}

In the Chapter 4, an ambient Nakamura reaction was efficiently developed, demonstrating the good catalytic activity of TA-Au/LA system.

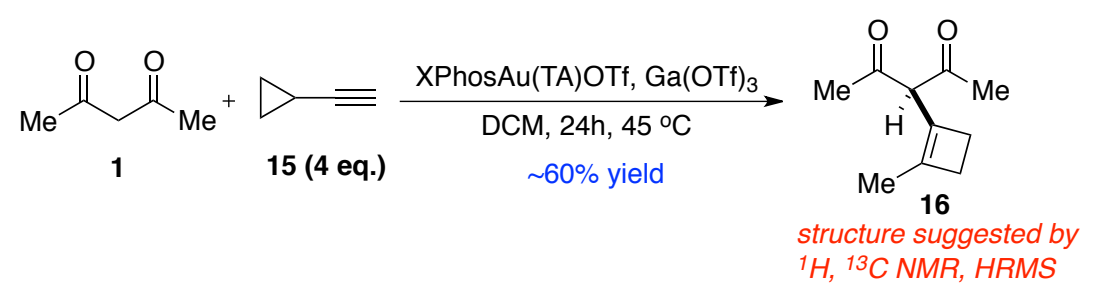

Scheme 6-1. Initial observation

An interesting observation along the substrate scope development came from the use of cyclopropyl acetylene. It was discovered that when cyclopropyl acetylene was reacted with 2,4pentadione in the presence of gallium triflate and TA-Au, a ring expansion product was isolated as main product and along with trace amount of direct addition product. Attempts to isolate pure Nakamura product failed since the reaction never reached completion. However crude NMR showed the existence of such a compound. And luckily the proton and carbon NMR spectra of ring expansion product were obtained.

The rationale that led us to propose a cyclobutene structure relies on the singlet at chemical shift $\delta 5.8$, which represent the $\alpha$-proton of diketone. The product exists in its diketone form instead of enol form. Generally the enol proton is invisible due to the fast exchange with the solvent. Further evidence came from the carbon NMR in which a peak at chemicals shift $\delta$ 207, which represent simple carbonyl carbon. In the spectra of other Nakamura adduct, the carbonyl chemical shift lies around $\delta 190$, which is a result of large conjugation of enol form. 


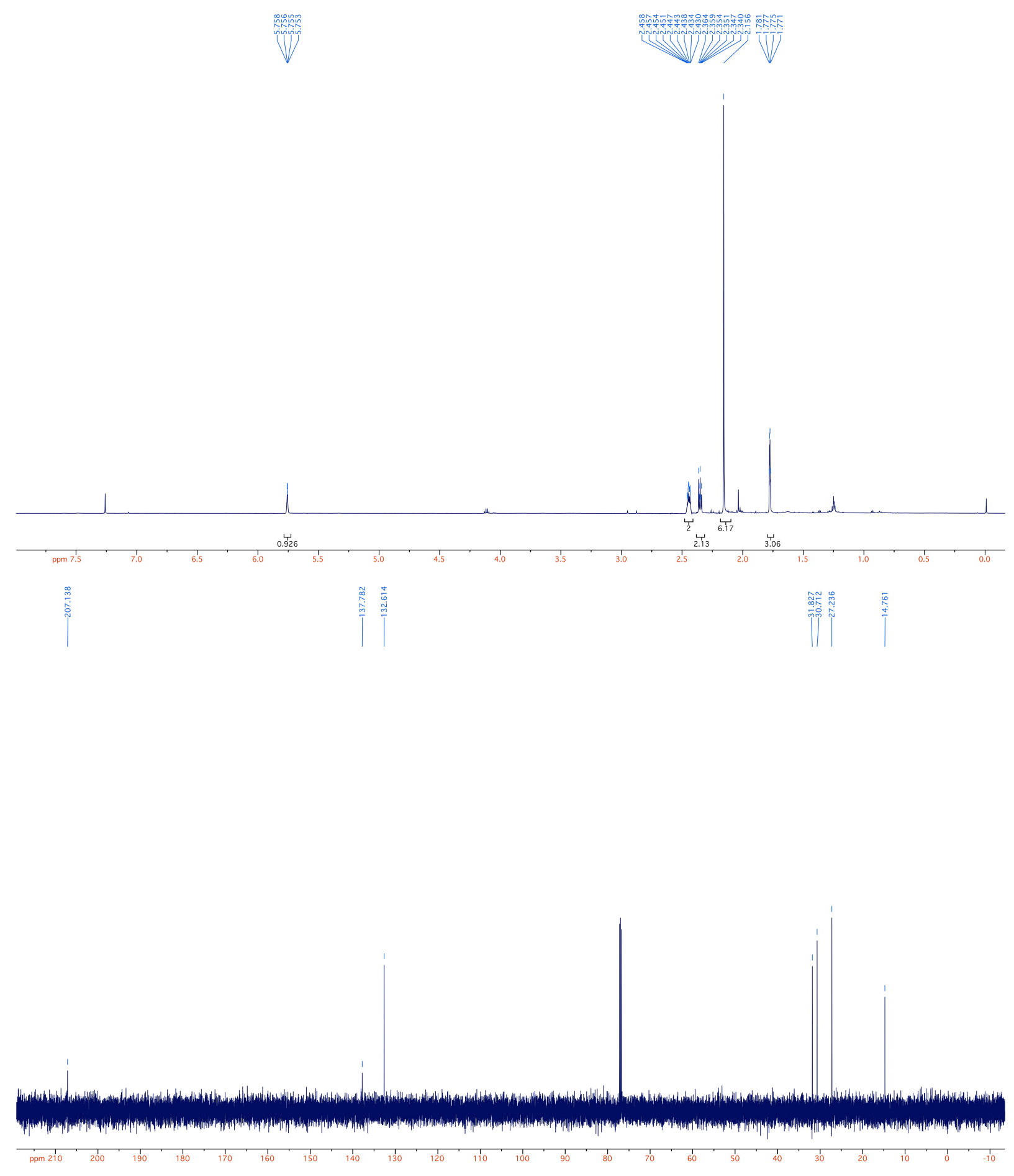

Figure 6-1. ${ }^{1} \mathrm{H}$ and ${ }^{13} \mathrm{C}$ NMR spectra of compound $\mathbf{1 6}$

\subsection{Catalyst Screening}

To push the limit of the selectivity, two rounds of screening were performed. As shown in, the $\mathrm{Au} / \mathrm{Ag}$ system gave no or low conversion to both products and only the 
$\mathrm{XPhos} \mathrm{AuCl} / \mathrm{AgSbF}_{6}$ gave reasonable conversion exclusively giving direct adduct. On the other hand, XPhosAu(TA)OTf with gallium triflate gave an overall $90 \%$ conversion and a ratio of 2:1 favoring our desired product.

Table 6-1. Initial screening<smiles>C=C(C(=O)O)/C(C(C)=O)=C(\C)O</smiles>

\begin{tabular}{|c|c|c|c|}
\hline entry & gold catalyst (2.5 mol\%) & additives & yield $(16+17)$ \\
\hline 1 & $\mathrm{Ph}_{3} \mathrm{PAuCl}, \mathrm{AgOTf}$ & - & $0 \%+5 \%$ \\
\hline 2 & $\mathrm{Ph}_{3} \mathrm{PAuCl}, \mathrm{AgBF}_{4}$ & - & $0 \%+<5 \%$ \\
\hline 3 & $\mathrm{Ph}_{3} \mathrm{PAuCl}, \mathrm{AgSbF}_{6}$ & - & $0 \%+10 \%$ \\
\hline 4 & $\mathrm{Ph}_{3} \mathrm{PAuNTf}_{2}$ & - & $0 \%+<5 \%$ \\
\hline 5 & IPrAuCl, AgOTf & - & $0 \%+8 \%$ \\
\hline 6 & XPhosAuCl, AgOTf & - & $0 \%+11 \%$ \\
\hline 7 & XPhosAuCl, $\mathrm{AgSbF}_{6}$ & - & $0 \%+46 \%$ ( $48 \%$ conv. $)$ \\
\hline 8 & XPhosAu(TA)OTf & $5 \% \mathrm{Ga}(\mathrm{OTf})_{3}$ & $55 \%+26 \%(90 \%$ conv. $)$ \\
\hline 9 & - & $5 \% \mathrm{Ga}(\mathrm{OTf})_{3}$ & $0 \%$ \\
\hline 10 & - & $10 \%$ HOTf & $0 \%$ \\
\hline
\end{tabular}

Table 6-2. Second-round screening

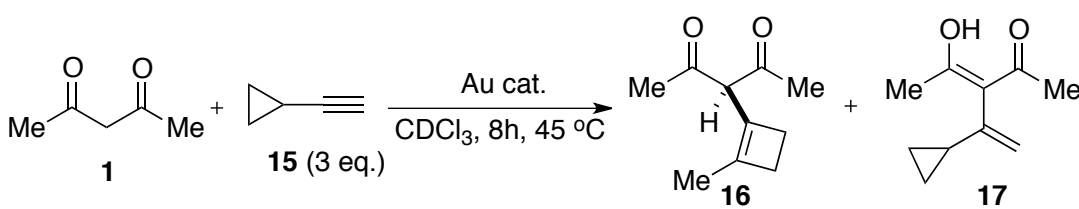

\begin{tabular}{cccc}
\hline entry & gold catalyst (5 mol\%) & additives & yield $(\mathbf{1 6 + 1 7})$ \\
\hline 1 & XPhosAu(TA)OTf & 5 mol\% Ga(OTf) & $0 \%+51 \%(77 \%$ conv. $)$ \\
2 & XPhosAu(TA)OTf & 15 mol\% Ga(OTf) & $66 \%+10 \%(100 \%$ conv. $)$ \\
3 & XPhosAu(TA)OTf & 10 mol\% Cu(OTf) & 2 is major product \\
4 & BrettPhosAu(TA)OTf & $10 \% \mathrm{Ga}(\mathrm{OTf})_{3}$ & $31 \%+39 \%(100 \%$ conv. $)$ \\
5 & $(\text { ArO })_{3}$ PAu(TA)OTf & $10 \% \mathrm{Ga}(\mathrm{OTf})_{3}$ & $77 \%+12 \%(100 \%$ conv. $)$ \\
6 & tBuXPhosAu(TA)OTf & $10 \% \mathrm{Ga}(\mathrm{OTf})_{3}$ & $26 \%+38 \%(100 \%$ conv. $)$ \\
7 & XPhosAu(TA-NO $\left.{ }_{2}\right)$ OTf & $10 \% \mathrm{Ga}(\mathrm{OTf})_{3}$ & $31 \%+37 \%(100 \%$ conv. $)$
\end{tabular}


Second screening of primary ligand showed that the electron-poor phosphite ligand favored more towards our desired product and gave a ratio of 7:1.

\subsection{Substrate Selectivity}

So far the evidences pointed to the reagent-controlled selectivity, a brief screening of substrate scope revealed that the selectivity also largely depended on the substrate type. Below is a summary of substrate selectivity.

The trend of chemoselectivity can be clearly seen. 1,3-diketone without substituted group at $\alpha$-position (methylene), gave ring expansion product. 1,3-diketone with one substituted group at $\alpha$-position gave direct addition product. Surprisingly, $\beta$-ketone ester with one substituted group at $\alpha$-position gave a different product, which is assigned as the ring opening product, based on ${ }^{1} \mathrm{H}$ and ${ }^{13} \mathrm{C}$ NMR. However, further evidence from MassSpec is required.
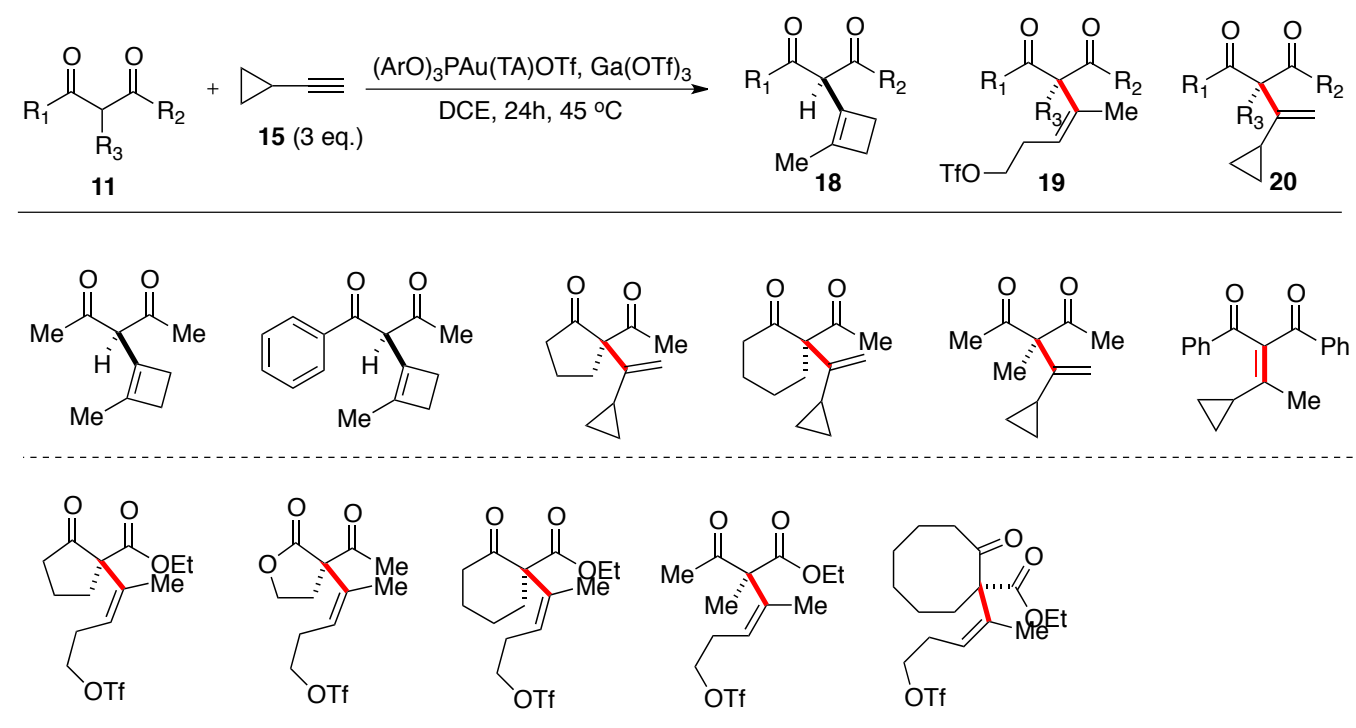

Scheme 6-2. Substrate chemoselectivity 
The explanation of the chemoseletivity is proposed. The ring expansion only will proceed if no substituted group is on $\alpha$-position (methylene). This requires an enolate formation after the direct Nakamura adduct, followed by protonation at $\delta$-position. The ring expansion then occurs through conjugate addition of gallium-activated enone and carbocation rearrangement. Further study on the mechanism will be performed.

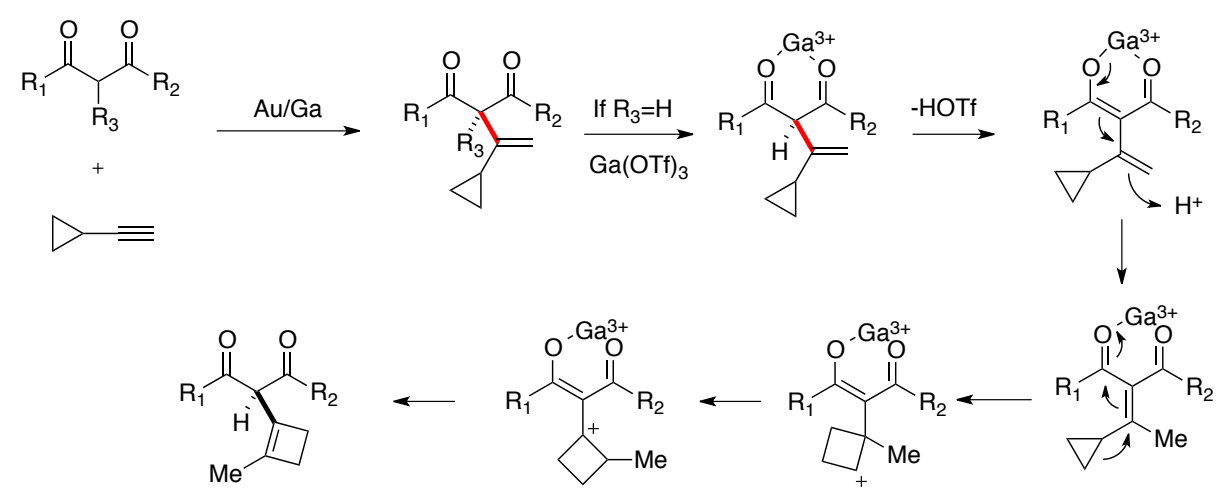

Scheme 6-3. Proposed mechanism for ring expansion 


\section{Chapter 7. Gold/Copper-Catalyzed Divinyl Ether Synthesis: C-O Bond Formation}

Part of this work has been published: Xi, Y.; Dong, B.; Shi, X. "Ambient gold-catalyzed Ovinylation of cyclic 1,3-diketone: A vinyl ether synthesis" Beilstein J. Org. Chem. 2013, 9, $2537-2543$. 


\subsection{Introduction}

In the Chapter 4, the newly developed TA-Au/LA system could catalyze the addition of 1,3-dicarbonyl compounds to unactivated 1-alkynes in an efficient manner.
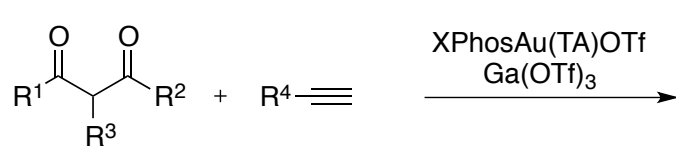

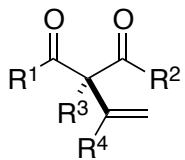

C-nucleophilic attack

Scheme 7-1. Gold-catalyzed Nakamura reaction

As a dual-reactivity nucleophile, O-nucleophilic attack of 1,3-dicarbonyl compound was also well-known. To develop an O-addition will certainly broaden the synthetic scope and lead to the formation of divinyl ether, a rare moiety in the literature.

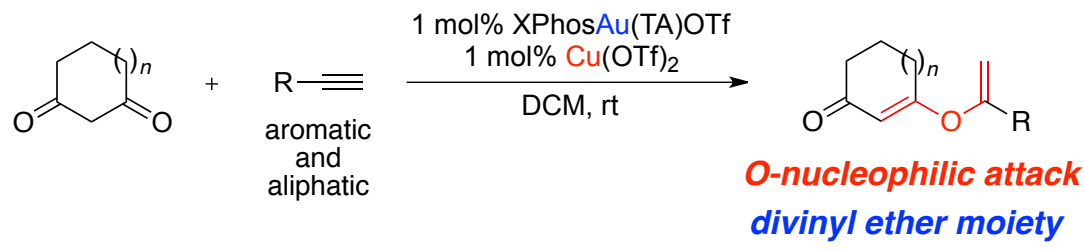

Scheme 7-2. Gold-catalyzed vinyl ether synthesis

\subsection{Rationale}

As indicated in Scheme 7-3, the main challenge for the intermolecular O-nucleophile addition to alkyne is the competitive hydration. ${ }^{33}$ It was hypothesized in the literature, an activated water by gold, [L-Au- $\left.\left(\mathrm{H}_{2} \mathrm{O}\right)\right]^{+}$is responsible for the addition. The good binding of TA-Au complexes might suppress such water coordination. 


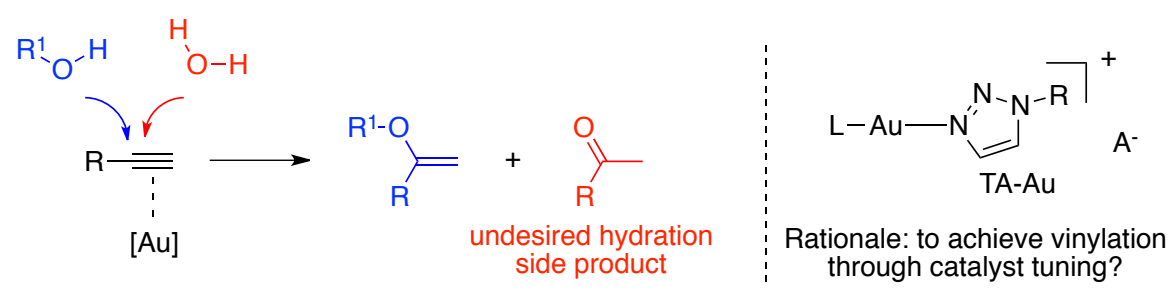

Scheme 7-3. Intermolecular O-addition to alkyne

\subsection{Condition Screening}

1,3-cyclohexanedione and phenylacetylene were used as the model substrates for the evaluation of various gold catalysts. As shown in Table 7-1, the use of $\mathrm{Ph}_{3} \mathrm{PAuCl} / \mathrm{AgOTf}(5 \%)$ gave an acceptable yield (59\%) of the desired vinyl addition product $\mathbf{2 2}$. Thermally-stable $\mathrm{Ph}_{3} \mathrm{PAu}(\mathrm{TA}) \mathrm{OTf}$ (TA-Au, 5\%) slightly improved the performance, yielding $63 \%$ of the desired product and less hydration byproduct 13. When changing the primary ligand from triphenylphospine to a NHC, the yield slightly decreased. However, the corresponding TA-Au complexes indicated significantly improved selectivity towards the diketone addition over the hydration (entry 4). Finally, the application of the XPhos ligand and the corresponding TA-Au complex largely promoted this reaction, giving 22 in $85 \%$ yields with $12 \%$ hydration byproduct.

The fact that TA-Au complexes generally gave improved selectivity of diketone addition over hydration (compared with the corresponding [L-Au $]^{+}$complexes) supported our hypothesis and made the TA-Au catalysts for this important transformation. Slightly increasing the ratio of alkyne to 1.2 equivalent (relative to the nucleophile) helped the formation of the 
desired vinyl ester to a near quantitative yield (98\% NMR yield, 95\% isolated yield), even with only $1 \%$ catalyst loading.

Table 7-1. Screening of gold catalysts ${ }^{a, b}$

$\mathrm{OH}^{+} \mathrm{Ph}=\frac{\text { Au cat. }}{\mathrm{CDCl}_{3}(0.5 \mathrm{M}), \mathrm{rt}, 17 \mathrm{~h}}$

21<smiles>C=C(OC1=CC(=O)CCC1)c1ccccc1</smiles>

22<smiles>CC(=O)P</smiles>

13

\begin{tabular}{cccccccc}
\hline Entry & {$[\mathrm{Au}]$ cat. } & 2 (eq.) & Loading & Time $(\mathrm{h})$ & Conversion of $\mathbf{2}(\%)$ & Yield of 22 (\%) & Yield of 13 (\%) \\
\hline 1 & $\mathrm{PPh}_{3} \mathrm{AuCl} / \mathrm{AgOTf}$ & 1.0 & $5 \%$ & 17 & 81 & 59 & 17 \\
2 & $\mathrm{PPh}_{3} \mathrm{Au}(\mathrm{TA}$ )OTf & 1.0 & $5 \%$ & 17 & 82 & 63 & 11 \\
3 & IPrAuCl/AgOTf & 1.0 & $5 \%$ & 17 & 100 & 55 & 34 \\
4 & IPrAu(TA)OTf & 1.0 & $5 \%$ & 17 & 64 & 50 & 5 \\
5 & XPhosAuCl/AgOTf & 1.0 & $5 \%$ & 10 & 100 & 76 & 22 \\
6 & XPhosAu(TA)OTf & 1.0 & $5 \%$ & 10 & 100 & 85 & 12 \\
7 & XPhosAu(TA)OTf & 1.2 & $5 \%$ & 10 & 100 & 99 & n.d. \\
8 & XPhosAu(TA)OTf & 1.2 & $3 \%$ & 17 & 100 & 99 & n.d. \\
9 & XPhosAu(TA)OTf & 1.2 & $1 \%$ & 20 & 100 & $98(95)$ & n.d. \\
\hline
\end{tabular}

${ }^{a}$ General condition: $\mathbf{1}(0.2 \mathrm{mmol})$, $\mathbf{2 a}$ (1 or 1.2 equiv.), and catalyst in $\mathrm{CDCl}_{3}(0.4 \mathrm{~mL})$, rt. ${ }^{b}$ Yield and conversion is determined by using 1,3,5-trimethoxybenzene as the internal standard. Isolated yield is in parenthesis.

Given the encouraging results associated with XPhosAu-TA catalysts, we explored the reaction scope. However, surprisingly, significantly slower reaction was observed when conducting the reaction in dichloromethane DCM or 1,2-dichloroethane (DCE), though selectivity for the diketone addition over hydration was maintained as shown in Table 7-1. Solvent screening shown in Scheme 7-4 proved that the trace amount of acid from chloroform decomposition was crucial for the optimal performance, which likely helped the formation of the enol isomer (over keto isomer). Other Lewis acids have also been screened and the $\mathrm{Cu}(\mathrm{OTf})_{2}$ was identified as the optimal choice due to the practical reasons (easy to weigh and less hygroscopic) and excellent reactivity. The $\mathrm{Cu}(\mathrm{OTf})_{2}$ and HOTf by itself could not catalyze the reaction, suggesting that it is indeed a gold-catalyzed process. Finally, it is worth noting 
that the use of $1 \mathrm{~mol} \%$ Echavarren catalyst $t \mathrm{BuXPhosAu}(\mathrm{MeCN}) \mathrm{SbF}_{6}$ gave slightly lower yield (71\%), and the combination of $1 \mathrm{~mol} \% t \mathrm{BuXPhosAu} \mathrm{MeCN}) \mathrm{SbF}_{6}$ and $1 \mathrm{~mol} \% \mathrm{Cu}(\mathrm{OTf})_{2}$ gave $86 \%$ yield (under otherwise identical conditions). This result highlights the synthetic utility of TA-Au catalyst in the transformation.

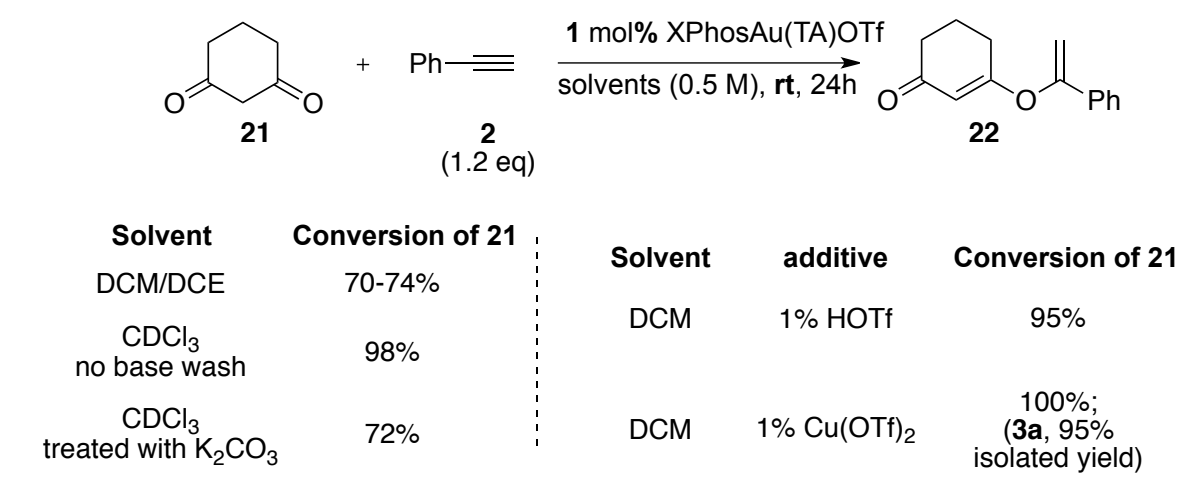

Scheme 7-4. Acid as the critical additive for optimal performance

\subsection{Substrate Scope}

With this optimal condition in hand, we embarked on the evaluation of the substrate scope for this transformation. A variety of aromatic alkynes were initially tested as summarized in Table 7-2. 
Table 7-2. Reaction scope of alkynes ${ }^{a}$

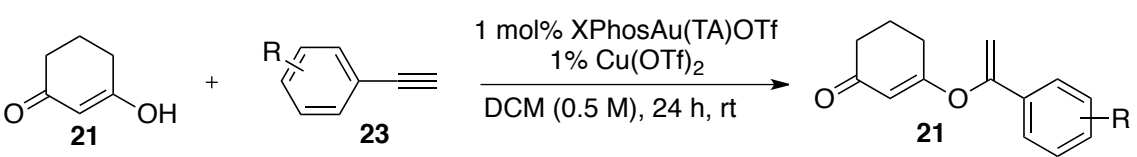

entry

${ }^{a}$ General condition: 1 (0.4 mmol), 2 (1.2 equiv.), 1 mol\% XPhosAu(TA)OTf and 1 mol\% Cu(OTf $)_{2}$ in dry DCM $(0.8 \mathrm{~mL})$, rt. $^{b}$ Isolated yield. ${ }^{c} 1(0.4 \mathrm{mmol}), 2$ (2 equiv.), 3 mol\% XphosAu(TA)OTf and $3 \mathrm{~mol} \% \mathrm{Cu}(\mathrm{OTf})_{2}$.

This method tolerated both electron-rich and electron-poor aromatic alkynes. Substituents on para, meta, ortho all gave good yields. Electron-rich heterocycle-containing alkynes, for example, thiophene and ferrocene, were also suitable substrates for this transformation. However, electron-poor alkynes, such as 2- and 3-pyridyl acetylenes, did not undergo the reaction.

A series of aliphatic alkynes were also underwent this reaction. Alkynes containing 6-, 5- and 3-membered rings worked well. Notably, the cyclopropyl acetylene formed the direct 
O-addition adduct with no ring opening product observed, which was unexpected based on the observation described in Chapter 6. In some cases, thermodynamically more stable internal alkenes were also observed, likely through olefin isomerization.

Table 7-3. Reaction scope with aliphatic alkynes ${ }^{a}$

entry

${ }^{a}$ General condition: 1 (0.4 mmol), 5 (2 equiv.), 1 mol\% XPhosAu(TA)OTf and 1 mol\% Cu(OTf $)_{2}$ in dry DCM $(0.8 \mathrm{~mL})$, rt. $^{b}$ Isolated yield. ${ }^{c}$ A ratio of 1:0.4 is observed for terminal/internal alkene mixtures. Combined yield.

The internal alkyne was much less reactive, giving 30\% product in a ratio of 1:0.75 regioisomers after refluxing at $60^{\circ} \mathrm{C}$ for $48 \mathrm{~h}$ The diphenylacetylene gave trace amount of the desired product under the identical condition. 
(A)

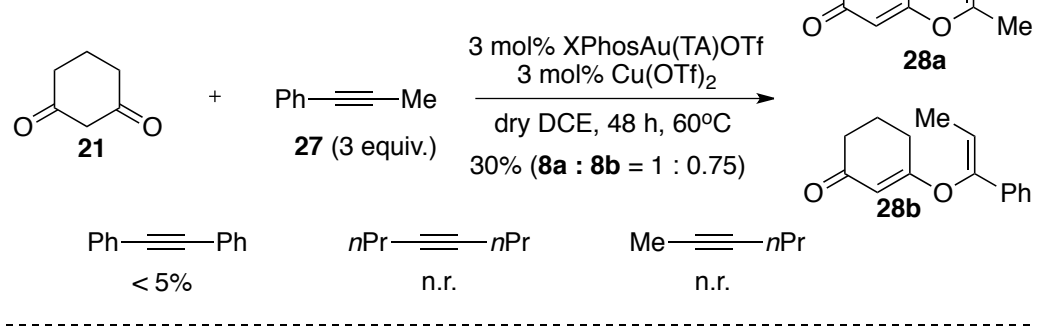

(B)

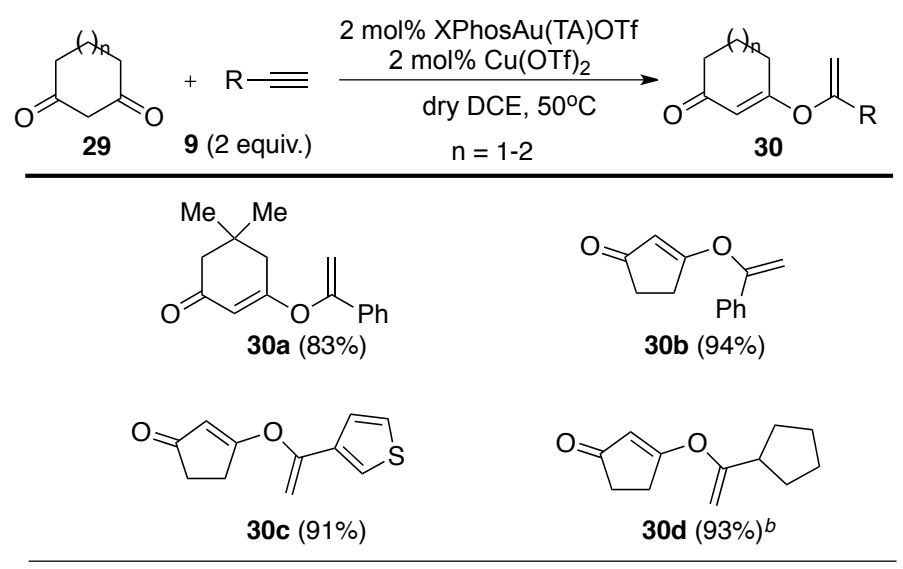

Scheme 7-5. Reactions of internal alkyne and other O-nucleophiles

Other diketones were examined to study the scope of nucleophiles. 1,3-diketones with 5- or 6-membered rings generally worked well with our method, although slightly modified condition may be used to achieve optimal yields. Finally, acyclic 1,3-diketones as well as cyclic 1,2-diketone gave no O-addition products under the current reaction conditions, likely caused by the intramolecular H-bonding.

Overall, the method described here represents an effective way of making these vinyl ether compounds. 


\section{Chapter 8. Gold/Gallium-Catalyzed $\alpha$-Substituted Vinylsulfone: C-S Bond Formation}

Part of this work has been published: Xi, Y.; Dong, B.; McClain, E.J.; Wang, Q.; Gregg, T. L.; Akhmedov, N. G.; Petersen, J. L.; Shi, X. "Gold-Catalyzed Intermolecular C-S Bond Formation: Efficient Synthesis of $\alpha$-Substituted Vinyl Sulfones " Angew. Chem. Int. Ed. 2014, in press, DOI:10.1002/anie.201310142. 


\subsection{Introduction}

C-S bond formation is one of the fundamental transformations in organic synthesis. ${ }^{34}$ Organosulfur substances, such as thiol, sulfide, disulfide units, represent unique classes of compounds that are useful synthetic intermediates. They also exist abundantly in biological system ranging from small natural metabolites to proteins. Therefore, effective and simple method to build these molecules is always desirable.

Previously the success in developing $\mathrm{C}-\mathrm{C}$, and $\mathrm{C}-\mathrm{O}$ bond formation reactions with the TA-Au/Lewis acid system prompted the investigation of more challenging and novel reactions. Gold-catalyzed C-S bond formations are rare in the literature, due to the fact that Snucleophiles could form stable complex with cationic gold(I), which dampens the reactivity and accelerates the rate of decomposition. ${ }^{35}$ This was recently demonstrated by Lee using NMR and X-ray crystallographic techniques (Figure 8-1). ${ }^{36}$ In light of this, a rationally designed catalytic system and carefully chosen nucleophile are highly desirable.

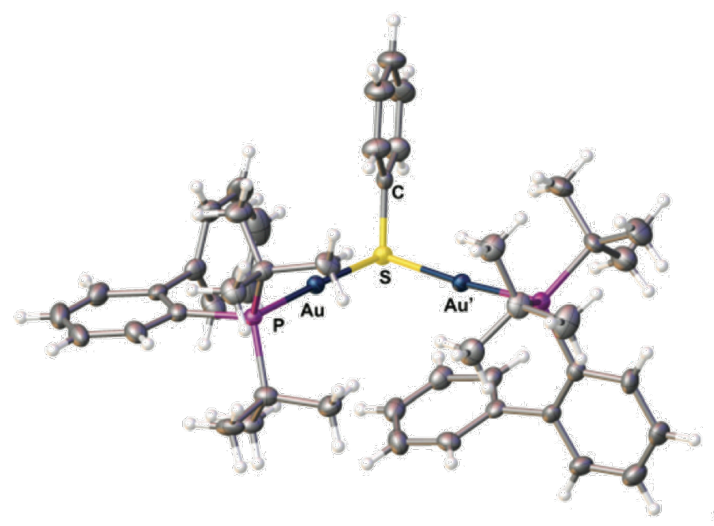

Figure 8-1. Crystal structure of (JohnPhos Au $)_{2} \mathrm{SPh}^{+}$ 
Sulfinic acid, a unique class of acid, is chosen for the task. The rationale is: a) the sulfur atom of sulfinic acid is less basic, which may not form a stable complex with cationic gold(I); b) the $\mathrm{pKa}$ (around 3) of sulfinic acid is similar to that of carboxylic acid and phosphoric acid, which have been proven to be successful substrates for such addition; ${ }^{37}$ c) the soft nature of gold(I)-alkyne complex will likely prefer the S-addition over O-addition (Scheme 8-1).
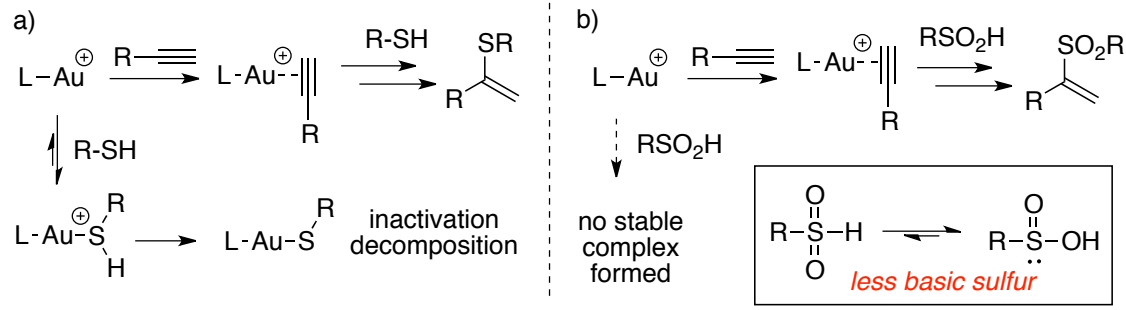

Scheme 8-1. Rationale for gold-catalyzed C-S bond formation

Moreover, the proposed addition of sulfinic acid to alkyne will yield $\alpha$-substituted vinylsulfone. To the best of our knowledge, effective synthesis of $\alpha$-substituted vinyl sulfone is rarely documented in literature (Scheme 8-2). Most of the reported reactions suffered from limited substrate scope and poor $\alpha / \beta$ regioselectivity.

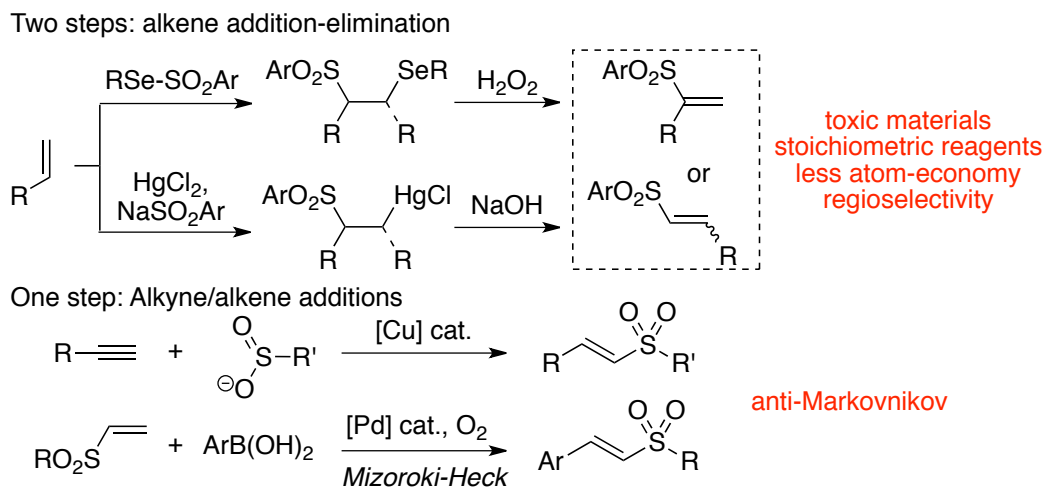

Scheme 8-2. Literature synthesis of vinylsulfone 
Literature synthesis also required long steps and toxic stoichiometric reagents. ${ }^{38}$ More efficient transition metal catalyzed alkyne or alkene addition reactions allowed rapid C-S and $\mathrm{C}-\mathrm{C}$ formation, but gave exclusively $\beta$-trans products due to the preferred anti-Markovnikov addition. ${ }^{39}$ If our approach is successful, it will provide a general strategy for achieving this molecule.

\subsection{Condition Screening}

We commenced our investigation with the evaluation of various carbophilic Lewis acids with $p$-toluenesulfinic acid and phenylacetylene as starting materials (Table 8-1).

Table 8-1. Condition optimization ${ }^{[\mathrm{a}]}$

\begin{tabular}{ccccc} 
dry DCE $(0.25 \mathrm{M})$, rt, $6 \mathrm{~h}, \mathrm{Ar}$ \\
\hline 1
\end{tabular}

[a] Reaction conditions: 31a $(0.2 \mathrm{mmol}), 2$ (1.4 equiv.), gold catalyst (5 mol\%), and additivein dry DCE (0.8 mL), Ar. 
As shown in Table 8-1, $\mathrm{Ph}_{3} \mathrm{PAuCl} / \mathrm{AgX}$ gave the best result (11\% yield) after $6 \mathrm{~h}$ at room temperature with no further reaction observed. Other $\pi$-acids, such as $\mathrm{PtCl}_{2}, \mathrm{AuCl}_{3}$ $\mathrm{Ga}(\mathrm{OTf})_{3}, \operatorname{In}(\mathrm{OTf})_{3}$ did not promote this reaction at all. Further efforts were devoted to optimize the reaction. First different counteranions were screened but no significant changes were obtained. When changing the ligand to more electron-rich and bulkier ligand, from IPr, XPhos to BrettPhos, a yield of $76 \%$ could be eventually obtained. This is presumably due to the fact that steric congestion, imposed by the bulky substituents, stabilizes the gold cation, avoiding decomposition. Finally our newly developed TA-Au/Lewis acid system was used and gave the best result. Au:Ga ratio of 1:2 yielded $91 \%$ desired product.

\subsection{Substrate Scope}

To evaluate the substrate scope of the method, firstly various aromatic alkynes were tested. Generally modest to good yields were obtained. Electron-donating and electronwithdrawing groups on para, ortho and meta positions all gave good performance. Heteroaromatic alkyne could also proceed through this reaction.

Table 8-2. Optimization of reaction between 31a and 33

\begin{tabular}{|c|c|c|c|c|c|c|}
\hline entry & gold cat. & gallium cat. & temp. & solvent & yield & convn. \\
\hline 1 & $5 \%$ BrettPhosAuTA & $20 \% \mathrm{Ga}(\mathrm{OTf})_{3}$ & $45^{\circ} \mathrm{C}$ & toluene & $51 \%$ & $79 \%$ \\
\hline 2 & $5 \%$ BrettPhosAuTA & $20 \% \mathrm{Ga}(\mathrm{OTf})_{3}$ & $45^{\circ} \mathrm{C}$ & $\mathrm{CDCl}_{3}$ & $52 \%$ & $84 \%$ \\
\hline 3 & $5 \%$ BrettPhosAuTA & $20 \% \mathrm{Ga}(\mathrm{OTf})_{3}$ & $45^{\circ} \mathrm{C}$ & $\mathrm{PhCl}$ & $52 \%$ & $84 \%$ \\
\hline 4 & $5 \%$ BrettPhosAuTA & $20 \% \mathrm{Ga}(\mathrm{OTf})_{3}$ & $45^{\circ} \mathrm{C}$ & dioxane & $35 \%$ & $74 \%$ \\
\hline 5 & $5 \%$ BrettPhosAuTA & $20 \% \mathrm{Ga}(\mathrm{OTf})_{3}$ & $80^{\circ} \mathrm{C}$ & toluene & $52 \%$ & $91 \%$ \\
\hline 6 & $5 \%$ BrettPhosAuTA & $20 \% \mathrm{Ga}(\mathrm{OTf})_{3}$ & rt & toluene & $60 \%$ & $82 \%$ \\
\hline
\end{tabular}


Aliphatic alkynes generally led to the corresponding vinyl sulfone in modest yield (35$45 \%$ ) at room temperature. To obtain better yield, a screening was also performed. It was found that using cyclohexyl acetylene the yield decreased upon heating. Close examination of the crude NMR spectra revealed the formation of byproduct ar higher temperature.

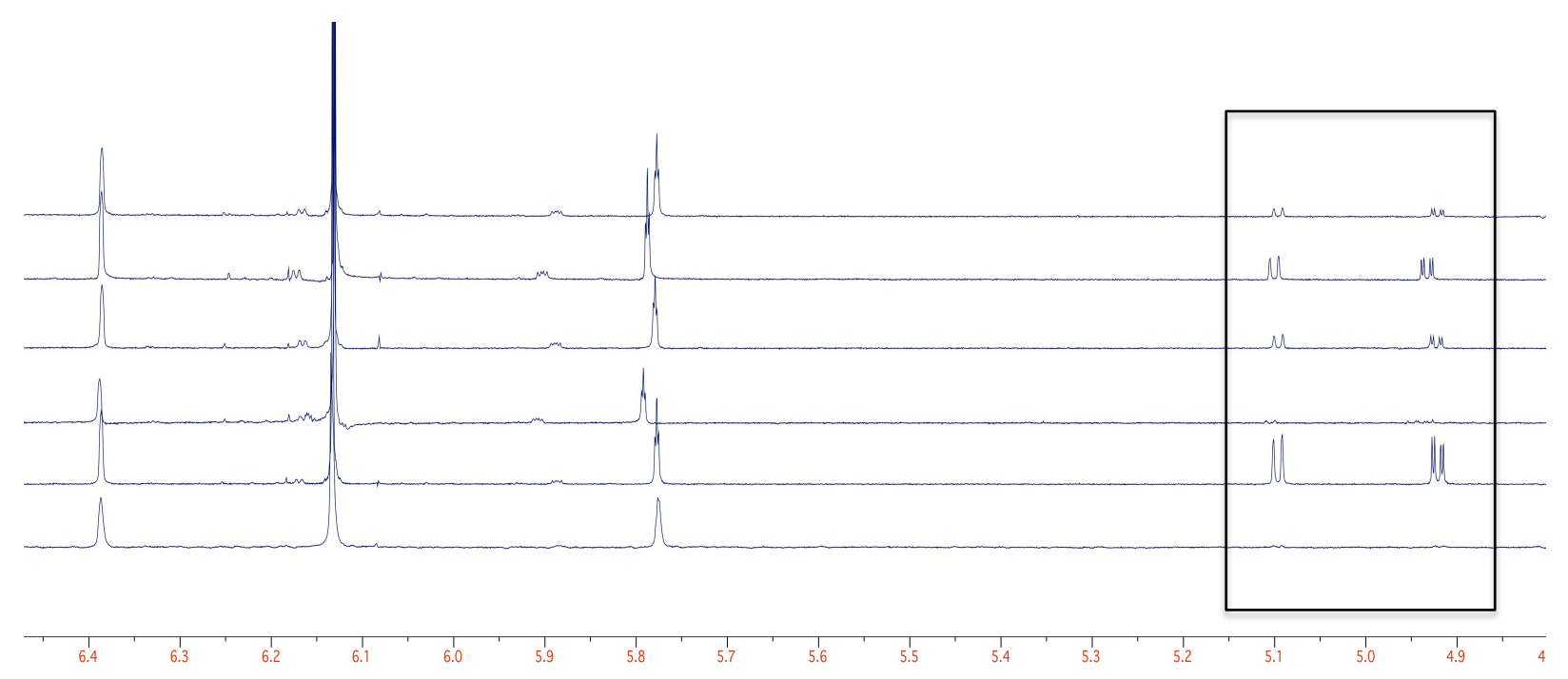

Figure 8-2. Crude ${ }^{1} \mathrm{H}$ NMR spectra of optimization for Table 8-2

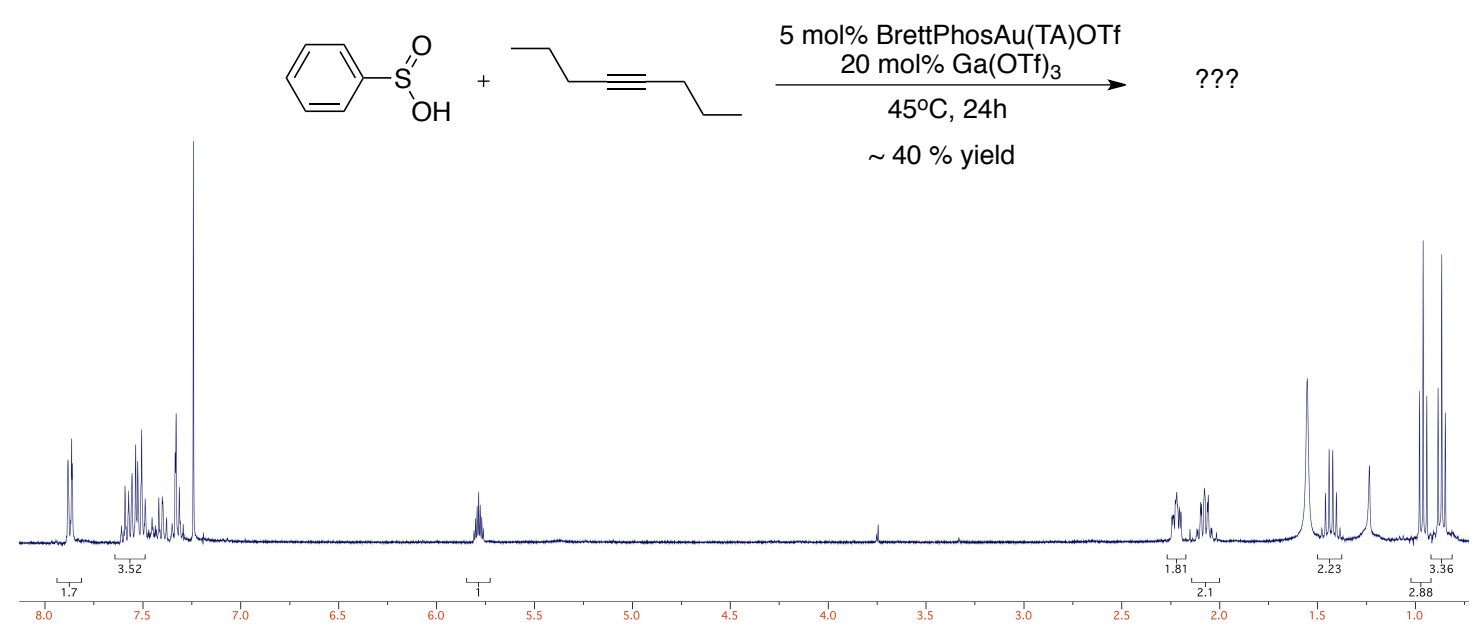

Figure 8-3. ${ }^{1} \mathrm{H}$ NMR spectrum of the product from benzenesulfinic acid and 4-octyne 
Internal alkynes failed to give the desired product in general. The $\alpha, \beta$-diaryl and $\alpha$-aryl$\beta$-alkyl alkynes gave complex reaction mixtures, presumably due to the decomposition of sulfinic acid at higher temperatures. The $\alpha, \beta$-dialkyl alkyne, namely, 4-octyne, gave similar product, whose structure has not been identified at this moment. It seems to be the oxidation product of corresponding vinylsulfone. The summary of substrate scope with various alkynes is shown in Table 8-3.

Table 8-3. Scope of alkynes ${ }^{[\mathrm{a}]}$

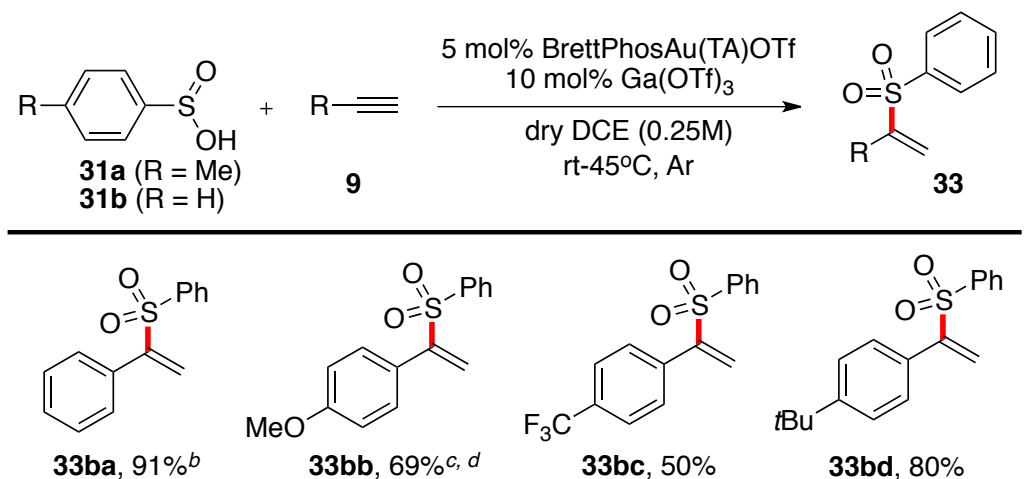<smiles>C=C(c1ccc(F)cc1)S(=O)(=O)c1ccccc1</smiles>

33be, $76 \%$<smiles>C=C(c1ccsc1)S(=O)(=O)c1ccccc1</smiles>

33bi, $59 \% b$<smiles>C=C(C1CC1)S(=O)(=O)c1ccccc1</smiles>

33bm, $70 \%$ e<smiles>C=C(c1cccc(C)c1)S(=O)(=O)c1ccccc1</smiles>

33bf, $84 \%$<smiles>C=C(c1ccoc1)S(=O)(=O)c1ccccc1</smiles>

33bj, $74 \%^{b}$<smiles>C=C(c1cccc(Cl)c1)S(=O)(=O)c1ccccc1</smiles>

33bg, $62 \% b$<smiles>C=C(C1=CCCCC1)S(=O)(=O)c1ccccc1</smiles>

33bk, $78 \%^{c}$<smiles>C=C(c1ccccc1C)S(=O)(=O)c1ccccc1</smiles>

33bh, 85\%<smiles>C=C(C1CCCCC1)S(=O)(=O)OCCC</smiles>

33al, $71 \% c, e$

[a] General reaction conditions: 1b $(0.2 \mathrm{mmol}), 2$ (0.4 mmol), 5 mol\% BrettPhosAu(TA)OTf and $10 \mathrm{~mol} \% \mathrm{Ga}(\mathrm{OTf})_{3}$ in DCE $(0.8 \mathrm{~mL})$, Ar, isolated yield. 
To demonstrate the synthetic utility, complex molecules such as the amino acid derivative, estrone derivative and cholesterol derivative were also successfully prepared.

Table 8-4. Scope of alkynes ${ }^{[\mathrm{a}]}$
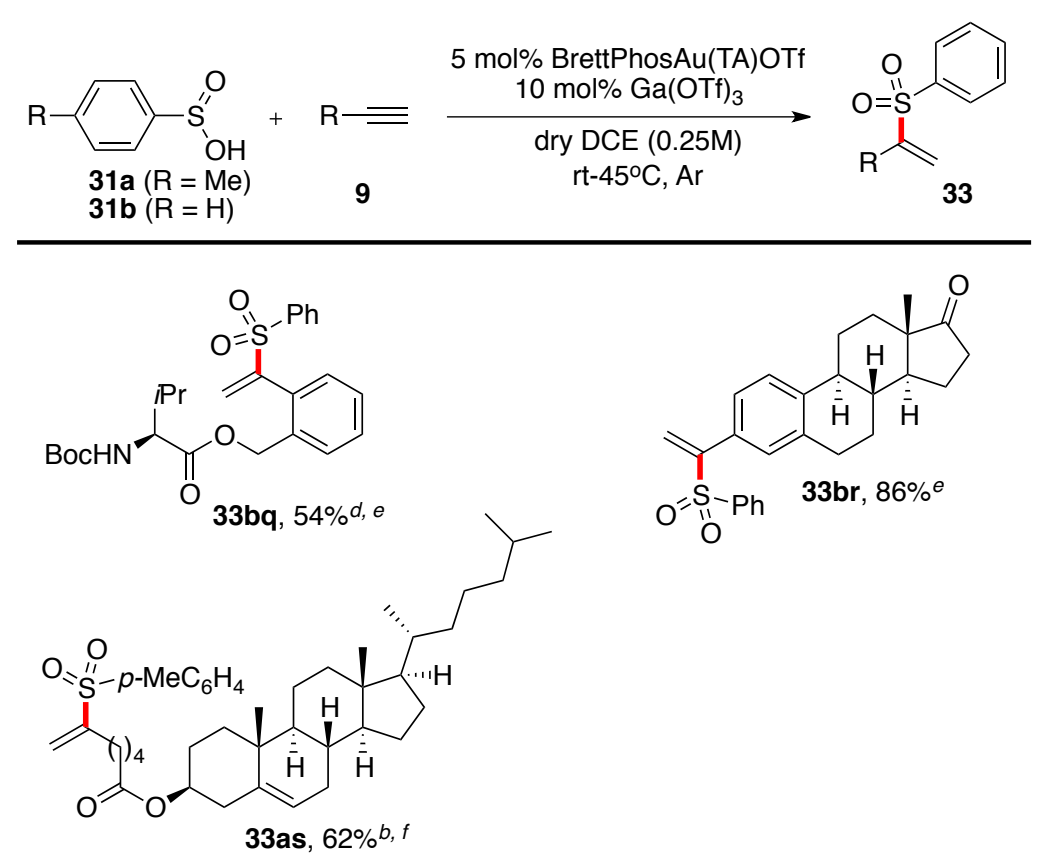

It is also worth noting that regioselectivity of the nucleophilic addition was first confirmed by ${ }^{1} \mathrm{H}$ NMR analysis and later unequivocally established via X-ray crystallographic.

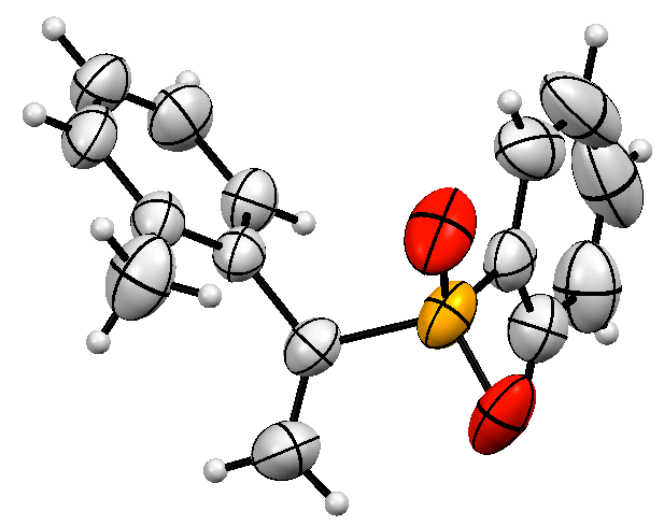

Figure 8-4. OTREP structure of $\mathbf{3 3 b h}$ 
To develop a robust synthetic methodology, the unstable sulfinic acid should be avoided and the bench-stable sodium benzenesulfinate provides the better candidate. The in situ generation of sulfinic acid will be more practical. Different acids were screened in the presence of gold and gallium salts. TFA was found to be the best choice of acid, giving the desired product in 91\% NMR yield.

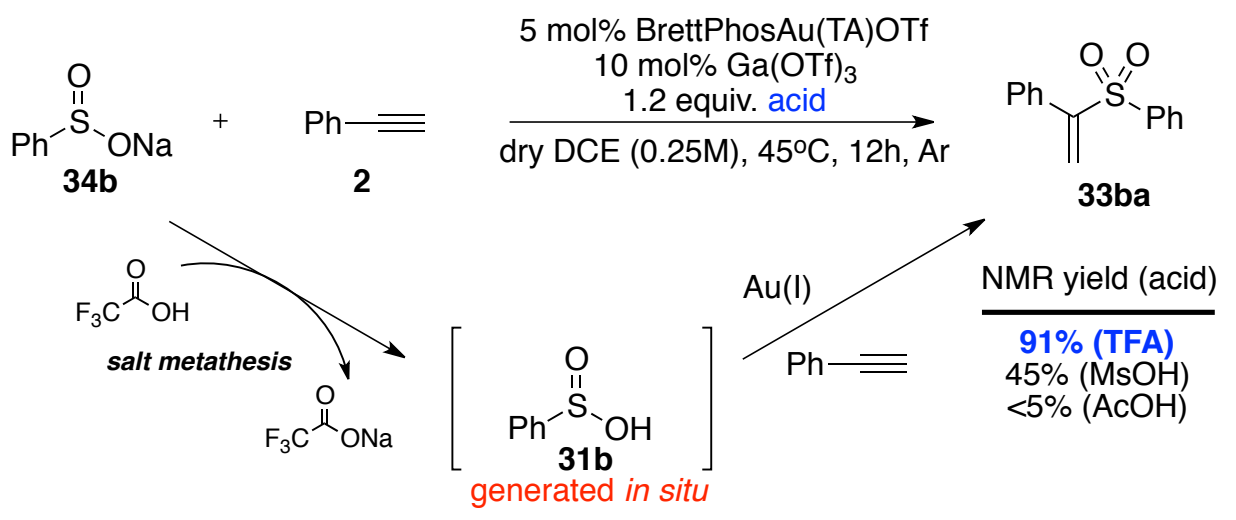

Scheme 8-3. One-pot synthesis of vinyl sulfones starting from bench stable sodium sulfinates

After the success in developing the one-pot procedure, the scope of sulfinic acids was then examined. Generally substituted benzenesulfinates gave promising yields. The halogen on the benzene ring allows the possibility of further derivatization through transition-metal catalyzed cross-coupling reactions. Heterocyclic sulfinic acid was also a successful substrate for this transformation. Aliphatic sulfinic acids gave slight lower yields. 
Table 8-5. Scope of sulfinic acids ${ }^{[a]}$
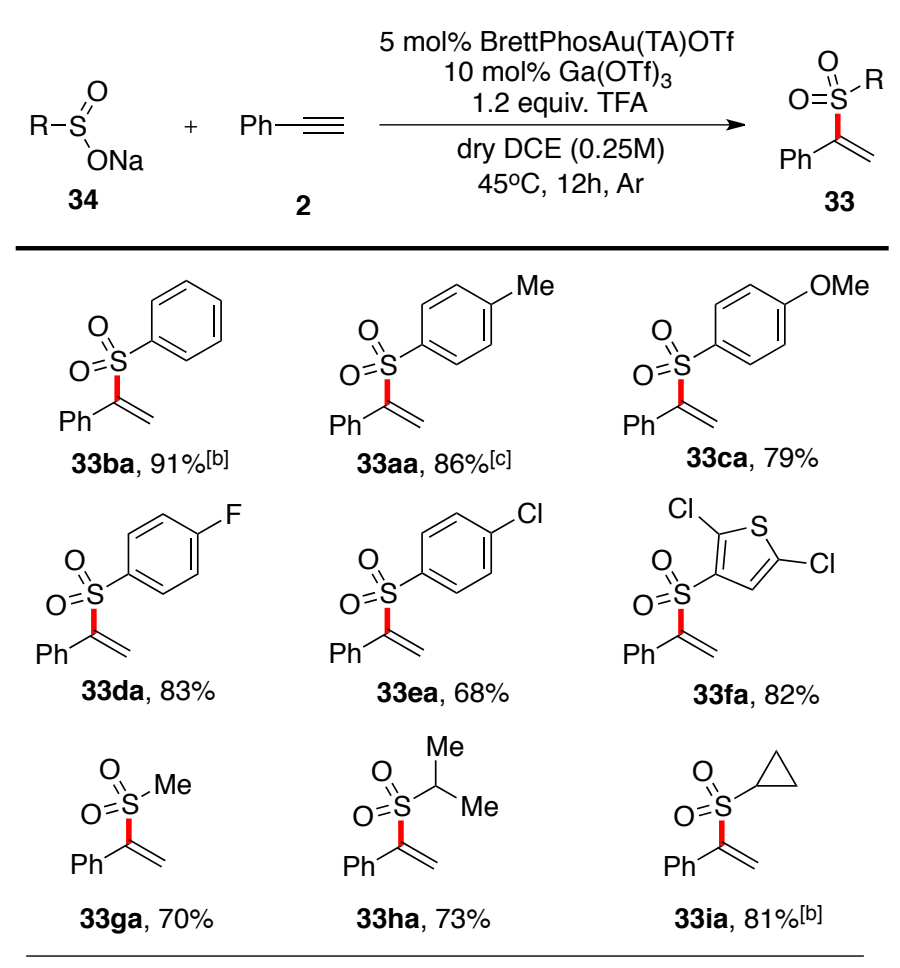

[a] General reaction conditions: 34 (0.2 mmol), TFA (0.24 mmol), 2 (0.3 mmol), 5 mol\% BrettPhosAu(TA)OTf and 10 mol\% $\mathrm{Ga}(\mathrm{OTf})_{3}$ in DCE $(0.8 \mathrm{~mL}), \mathrm{Ar}, 45^{\circ} \mathrm{C}$.

\subsection{Potential Application}

The synthetic utility of $\alpha$-substituted vinyl sulfone still remains underexplored due to the paucity of these compounds. However, duto the close resemblance to other vinyl sulfones, $\alpha$-substituted vinyl sulfone may be reactive towards further reactions, such cycloaddition, Michael addition, desulfonylation, with different regioselectivity. For example, Diels-Alder reaction ${ }^{40}$ of the synthesized 2-sulfonyl diene and N-methyl maleimide afforded the tricyclic ring system with excellent endo selectivity. The product stereochemistry was confirmed by the comprehensive 1D and 2D NMR analysis. 
<smiles>C=C(C1=CCCCC1)S(=O)(=O)c1ccccc1</smiles>

33bk<smiles>CN1C(=O)C=CC1=O</smiles>

35 toluene, $100^{\circ} \mathrm{C}, 1.5$ days

exo : endo $>20: 1$

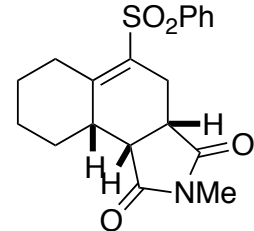

$36(80 \%)$

Scheme 8-4. Diels-Alder reaction between 2-sulfonyl diene (33bk) and N-methyl maleimide

The importance of vinyl sulfones lays in thier widespread applications in biological research as covalent protease inhibitors or substrates for bioconjugation for their good ability as the Michael acceptor to trap nucleophiles by forming stable covalent adducts. ${ }^{41}$ Theorectically, $\alpha$-substituted vinyl sulfone, with much less hindered $\beta$-carbon, will be kinetically favored and therefore a better candidate for Michael addition. However, in most cases, only trans-bsubstituted vinyl sulfones are used. This is mainly due to the limited availability of methods for the vinyl sulfone synthesis.
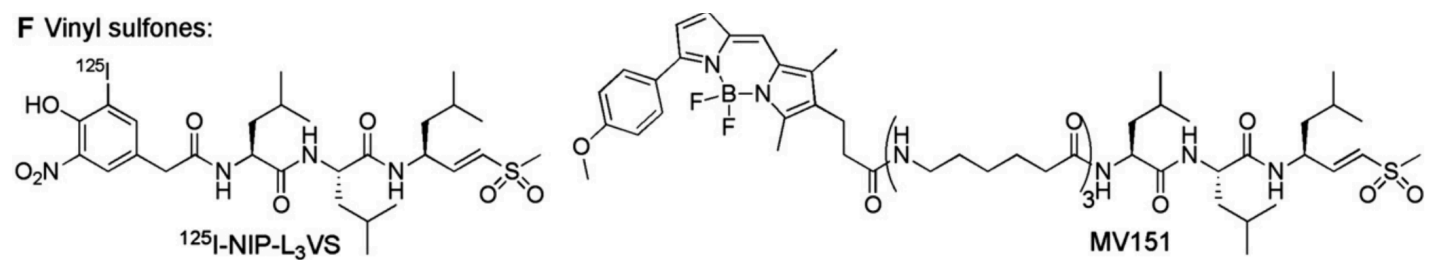

Scheme 8-5. Representative vinylsulfone protease inhibitors

The developed method provides an entry to the $\alpha$-substituted vinyl sulfone. To test the hypothesis, analogous $\alpha$-substituted vinyl sulfone and $\beta$-substituted vinyl sulfone were subject to secondary amine morpholine as the nucleophile. ${ }^{42}$ Only $\alpha$-substituted vinyl sulfone gave 
desired product, in almost quantitative yield. Therefore, $\alpha$-substituted vinyl sulfone may find future applications in biological science.

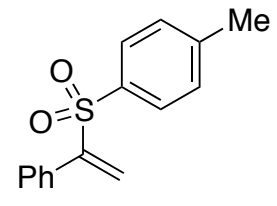

33aa<smiles>Cc1ccc(S(=O)(=O)/C=C/c2ccccc2)cc1</smiles>

38

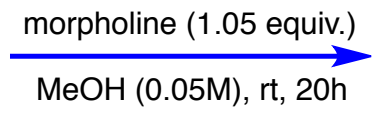

$95 \%$ isolated yield

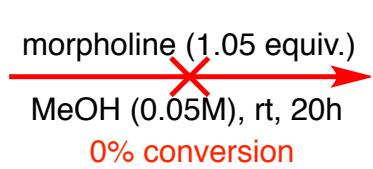

$0 \%$ conversion<smiles>[As]C(CN1CCOCC1)c1ccccc1</smiles><smiles>[As]CC(c1ccccc1)N1CCOCC1</smiles>

39

Scheme 8-6. Comparison of the aza-Michael addition between secondary amine and $\alpha$ - or $\beta$ vinyl sulfone 


\section{Chapter 9. Mechanistic Investigation on TA-Au Catalyzed Propargyl Rearrangement}

Part of this work has been published: Xi, Y.; Wang, Q.; Su, Y.; Li, M.; Shi, X. "Quantitative Kinetic Investigation of Triazole-Gold(I) Complex Catalyzed [3,3]-Rearrangement of Propargyl Ester" Chem. Commun. 2014, 50, 2158-2160. 


\subsection{Introduction}

The past decade has witnessed the fast growing homogenous gold catalysis. Compared with the fast paces of new transformation development, the mechanistic investigations left much behind. As discussed in the Chapter 1 that many gold complexes that are relevant to catalysis have been isolated and characterized by both NMR and X-ray crystallography, the mechanistic complexity is far beyond the capability of these techniques. On the hand, kinetic experiments, acquiring data in situ, better represent the nature of gold catalysis in reality, which may provide more accurate understanding. However, the complex system with gold/silver mixture hampers the mechanistic investigation, for the reason that the identity and real concentration of the active catalyst remain unclear. To gain fundamental understanding of elementary steps in gold catalysis, a simplified catalytic system has to be devised. For years, study on stoichiometric reactions has been very fruitful, providing very insightful data for future study. ${ }^{43}$ However, they may not necessarily reflect the catalytic reactions accurately.

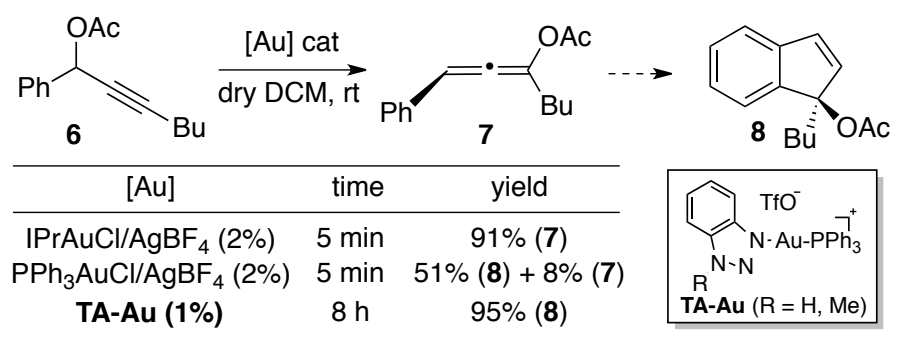

Scheme 9-1. TA-Au as chemoselective catalyst for alkyne activation

Our interest in conducting this study stems from our observation with chemoselective TA-Au catalyst. As discussed previously, TA-Au selectively catalyzed propargyl ester [3,3]rearrangement ${ }^{44}$ to give allene, which won't further convert to indene. ${ }^{45}$ As a simple reaction, 
this system provides a unique model reaction for kinetic study and allows for the collection of quantitative kinetic information associated with TA-Au. In addition, it is also very important to understand why TA-Au offered the chemoselectivity with excellent stereochemistry control, while other $[\mathrm{L}-\mathrm{Au}]^{+}$gave rapid racemization at the propargyl position with poor chemoselectivity (activation of both alkyne and allene).

\subsection{Kinetic Data}

To acquire meaningful kinetic data for a catalytic reaction, the turnover-limiting step needs to be established. For $\mathrm{LAuCl} / \mathrm{AgX}$ system, the concentration of catalyst is unclear and varied. Moreover it suffers a lot from decomposition. Our TA-Au that offers good thermal stability will be an ideal catalyst for this study, since it keeps relatively steady concentration of the catalyst. Therefore, a set of kinetic experiments was performed to evaluate the kinetic dependence of concentration of substrate and TA-Au. The standard reaction was chosen as the model reaction for the detailed investigation.
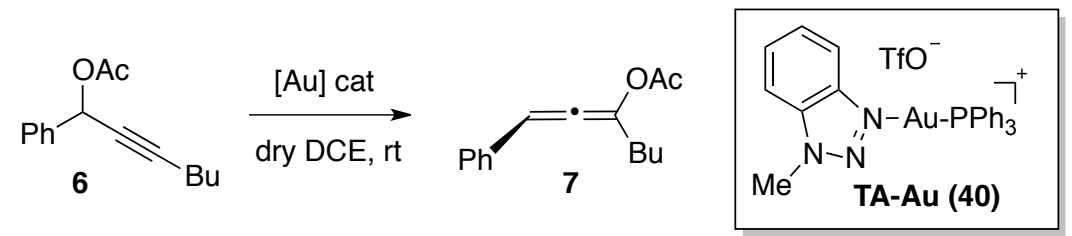

To avoid the potential influence of acid (formation of HOTf), the N-Me-benzotriazole (instead of $\mathrm{N}-\mathrm{H}$ ) bound TA-Au 40 was selected. In situ $\mathrm{IR}^{46}$ was used to acquire accurate kinetics data. The summary of peaks that were used to calculate the concentration is shown below. The peak at $1740 \mathrm{~cm}^{-1}$ represents the starting material and the peak at $1756 \mathrm{~cm}^{-1}$ represents the product. 

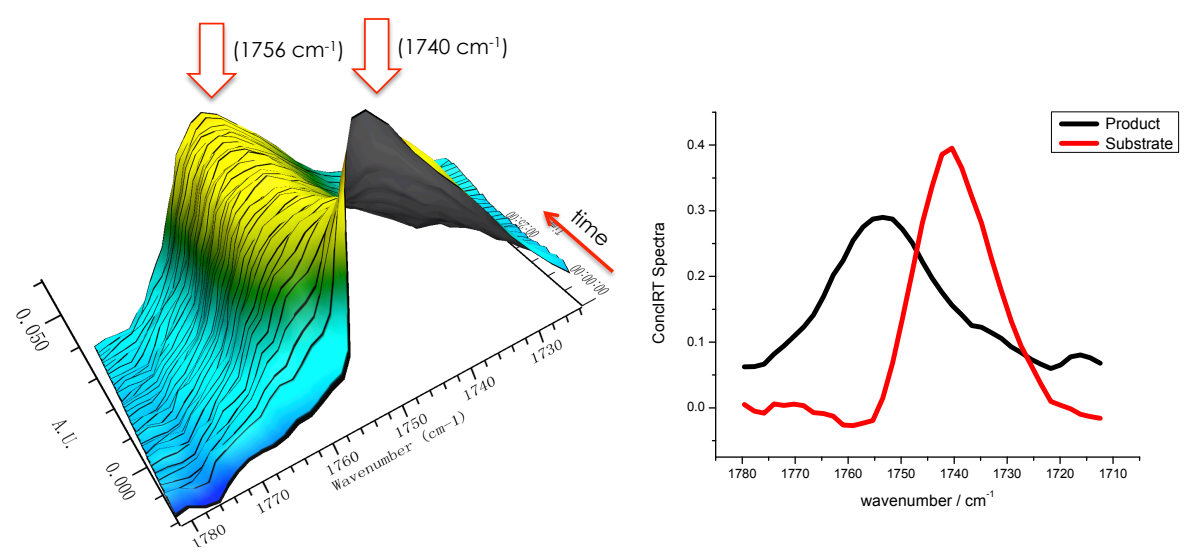

Figure 9-1. 3D-kinetic profile of rearrangment ConcIRT spectra

First, the kinetic order of TA-Au catalyst was determined through plotting the initial rates versus concentration varying from $0.002-0.008 \mathrm{M}$. The real concentration was calculated with iCIR 4.3, ConcIRT and origin 8.0. A linear relationship is established as depicted in Figure 1. The reaction is therefore first-order dependent on [40], suggesting the involvement of $\mathbf{4 0}$ in the turnover-limiting step.
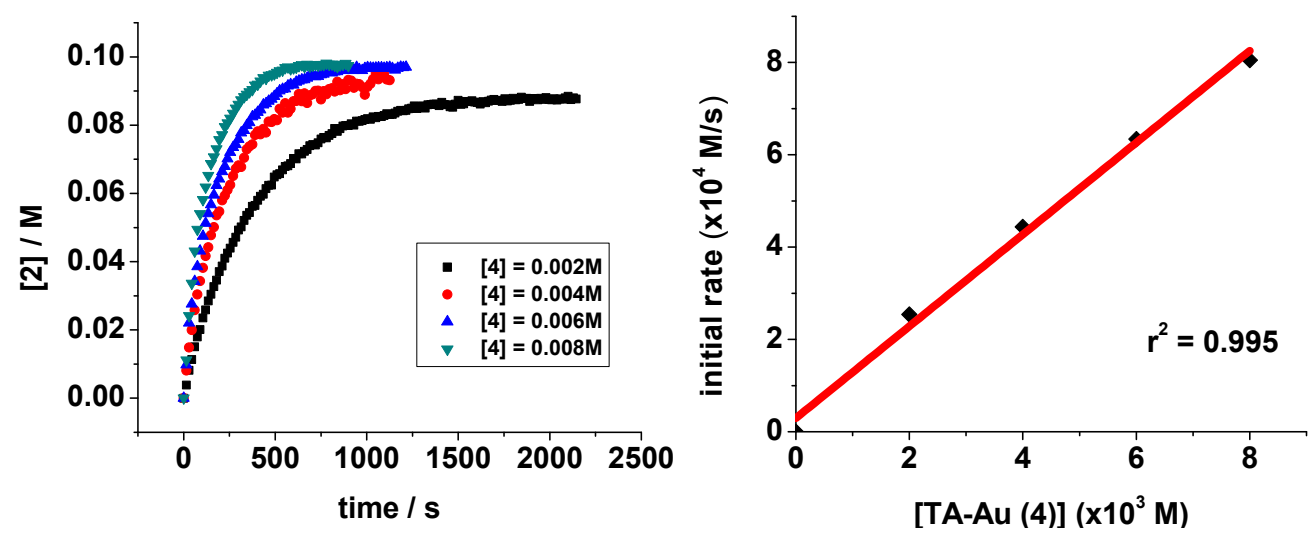

Figure 9-2. Dependence of the initial rates on catalyst concentrations for rearrangement of $\mathbf{4 0}$.

Reaction conditions: 6 (0.10 M in DCE, $1.2 \mathrm{~mL}), \mathbf{4 0}\left(0.002-0.008 \mathrm{M}\right.$ in DCE), $30^{\circ} \mathrm{C}$. 
Similarly, the dependence of the initial rates on the concentration of $\mathbf{6}$ was studied with varied concentrations from 0.10-0.20 M. Again, a first-order dependence was observed, as shown in Figure 9-3. Combined with two experiments, the rate law was derived for this reaction: $\mathrm{r}=\mathrm{k}_{\mathrm{obs}}[\mathbf{6}]^{1}[\mathbf{4 0}]^{1}$.
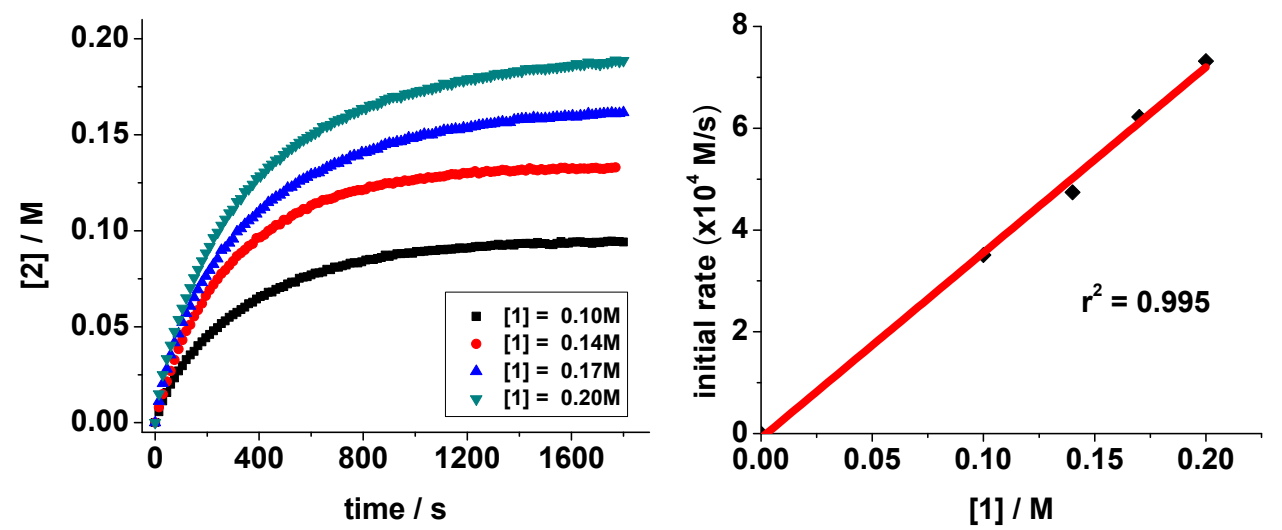

Figure 9-3. Dependence of the initial rates on substrate concentrations for rearrangement of 6. Reaction conditions: $6(0.10-0.20 \mathrm{M}$ in DCE, $1.2 \mathrm{~mL}), \mathbf{4 0}\left(0.003 \mathrm{M}\right.$ in DCE), $30^{\circ} \mathrm{C}$.

The rate law includes both the catalyst $\mathbf{4 0}$ and substrate $\mathbf{6}$, revealing the electronic activation of alkyne as the turnover-liming step. To further support the ligand exchange as the tol, the reaction was monitored by in situ ${ }^{31} \mathrm{P}$ NMR. 40 is the main species observed throughout the reaction (Scheme 9-4). 


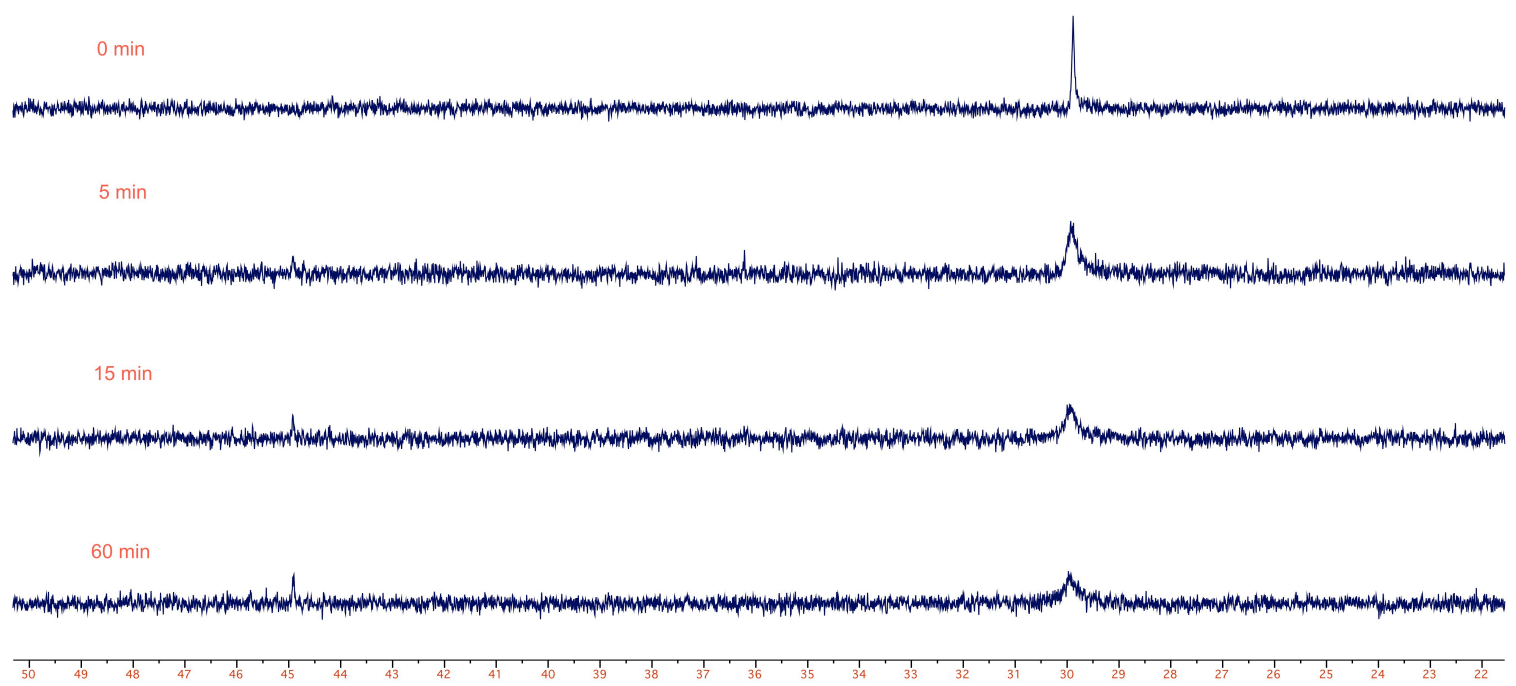

Figure 9-4. ${ }^{31} \mathrm{P}$ NMR monitoring of the reaction progress

Combined above information, a tentative proposed mechanism of TA-Au catalyzed propargyl ester [3,3]-rearrangement is shown in Scheme 9-2. First, the TA-Au undergoes the turnover-limiting ligand exchange with substrate to form cationic gold(I) alkyne $\pi$-complex. This complex then rapidly converts the propargyl ester to the corresponding allene. The ligand exchange step significantly slows the reaction rate compared to the use of free cationic gold(I) (Scheme 9-1), which is consistent with the fact that the same reaction catalyzed by $\operatorname{IPrAu}(\mathrm{L})^{+}$ $\left(\mathrm{L}=\mathrm{Et}_{3} \mathrm{~N}\right.$, py) was also slower. ${ }^{47}$
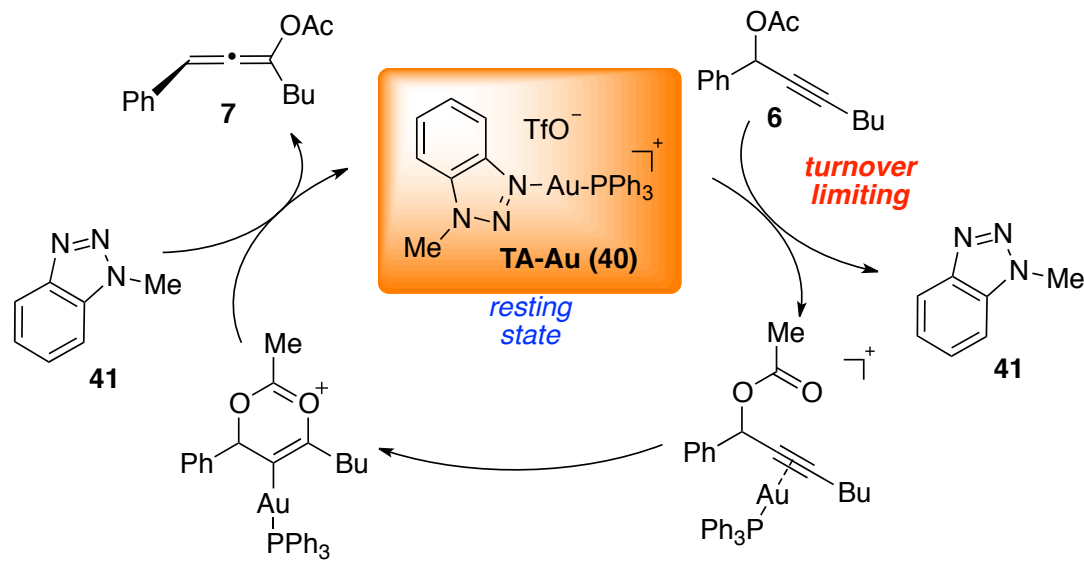

Scheme 9-2. Proposed Mechanism for TA-Au catalyzed propargyl ester [3,3]-rearrangement 


\subsection{Variable Temperature Experiment}

To obtain the quantitatively activation parameter, a temperature dependent experiment was carried out to further probe physical organic nature of this turnover-limiting ligand exchange. The initial rates obtained from in situ IR at different temperatures (295-319 K) was plotted against the temperature as $\ln \left(\mathrm{k}_{\text {obs }} / \mathrm{T}\right)$ vs. 1/T. According to Erying equation, the activation enthalpy of this elementary was calculated to be $7.8 \mathrm{kcal} / \mathrm{mol}$, a facile process at room temperature. Echavarren reported a lower activation enthalpy values (3.7 and 6.2 $\mathrm{kcal} / \mathrm{mol}$ ) for his studies in the enyne cycloisomerization. ${ }^{48}$

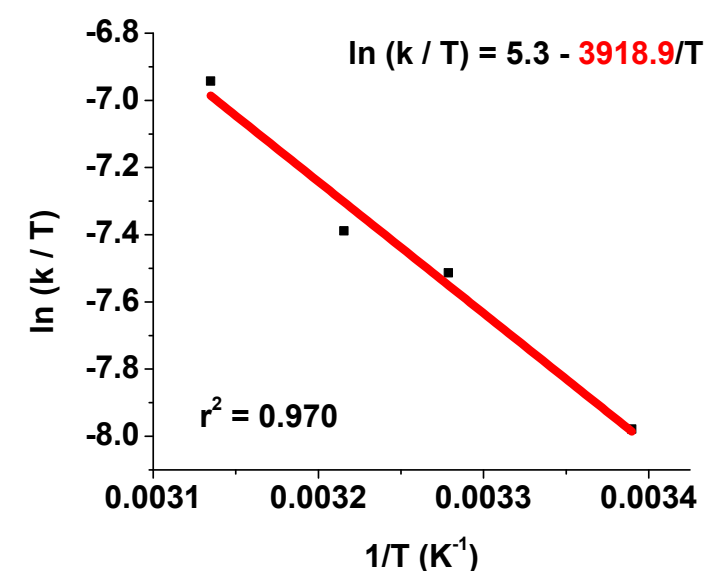

Figure 9-5. Kinetics profile at different temperatures. Reaction conditions: 1 (0.10 M in DCE, $1.2 \mathrm{~mL}), 40$ (0.003 $\mathrm{M}$ in DCE), at $22,32,38$, and $46^{\circ} \mathrm{C}$.

Similarly, the activation entropy was determined as $-36.6 \mathrm{eu}$, if assume that $[40]_{0}$ is identical to active catalyst concentration. This negative and relative large value supports the associative ligand substitution through a transient 3-coordinate gold(I) complex. 


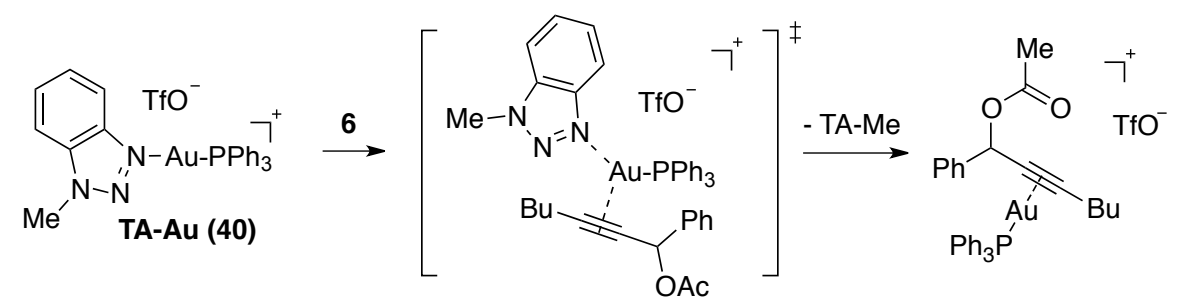

Scheme 9-3. Associative ligand substitution through transient 3-coordinate cationic gold(I) complex.

At this point, it is unclear whether the 3-coordinate cationic gold(I) is stable enough to be observed. Another piece of evidence to support this mechanism came from the inhibition of the reaction by external amount of added N-Methyl-benzotriazole. Again we were unable to determine the exact order of [41] due to the extremely slow reaction rates. But we can anticipate a negative kinetic order.
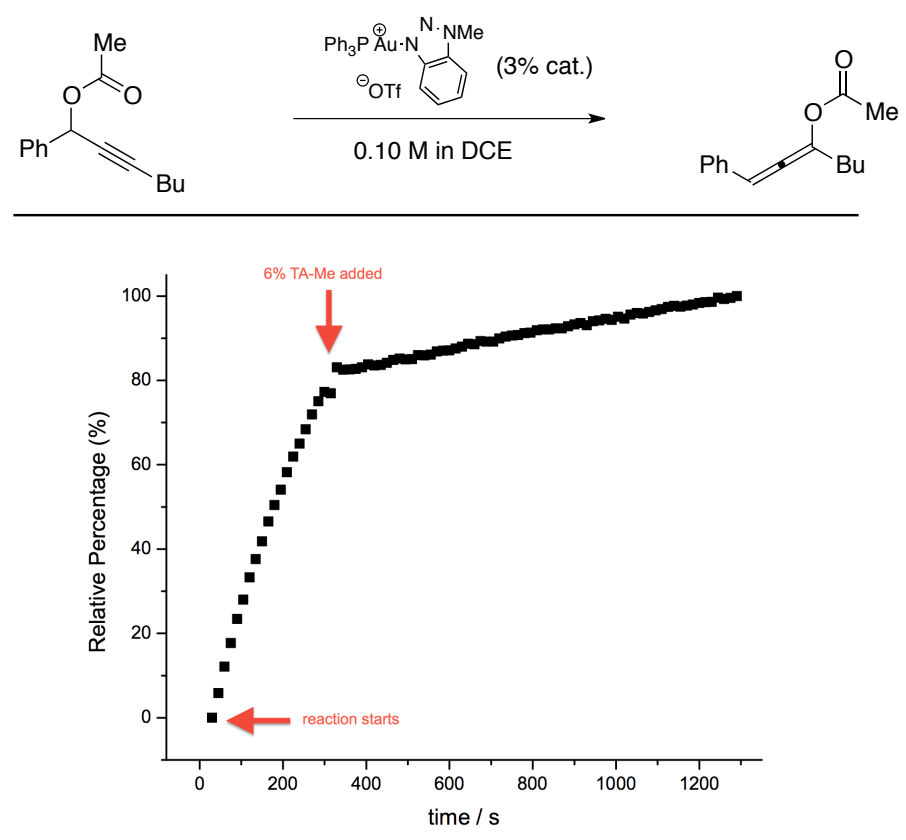

Figure 9-6. Inhibition by external N-Methyl-benzotriazole 


\subsection{Hammett Studies}

Another advantage of TA-Au catalyst is its easy preparation. In order to gain further insight, we prepared various TA-Au catalysts with different substituted triazole to investigate the impact of the electronic nature of the TA-Au catalysts. ${ }^{49}$ The ${ }^{31} \mathrm{P}$ NMR chemical shifts provide direct information of the electronic nature of gold canter. As expected, more electronwithdrawing group gives more upfield ${ }^{31} \mathrm{P}$ shift, suggesting the more cationic gold. The reaction kinetics is illustrated in Figure 9-7.
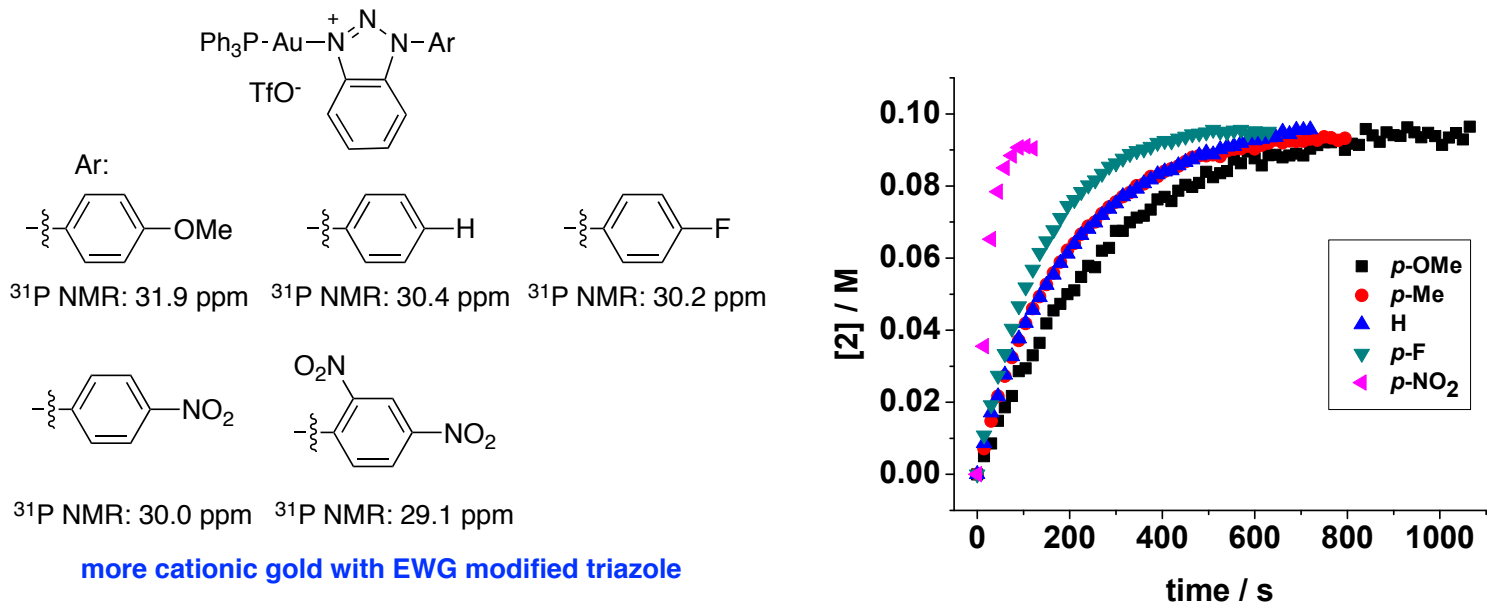

Figure 9-7. Kinetics profile using various TA-Au catalysts. Reaction conditions: 6 (0.10 M in DCE, $1.2 \mathrm{~mL})$, TA-Au (0.003 $\mathrm{M}$ in DCE), $26^{\circ} \mathrm{C}$.

Clearly, the more cationic gold(I) led to faster reaction rate. The slowest reaction was observed with 4-methoxyphenyl substituted TA-Au, still faster than the reaction catalyzed by 40, suggesting the inherent electron-withdrawing nature of the phenyl group attached to benzotriazole. The linear free energy relationship was established by plotting $\log \left(k / k_{\mathrm{H}}\right) \mathrm{vs.} \sigma_{\text {para }}$, giving a $\rho$ value of 0.74 (Figure 9-8). 


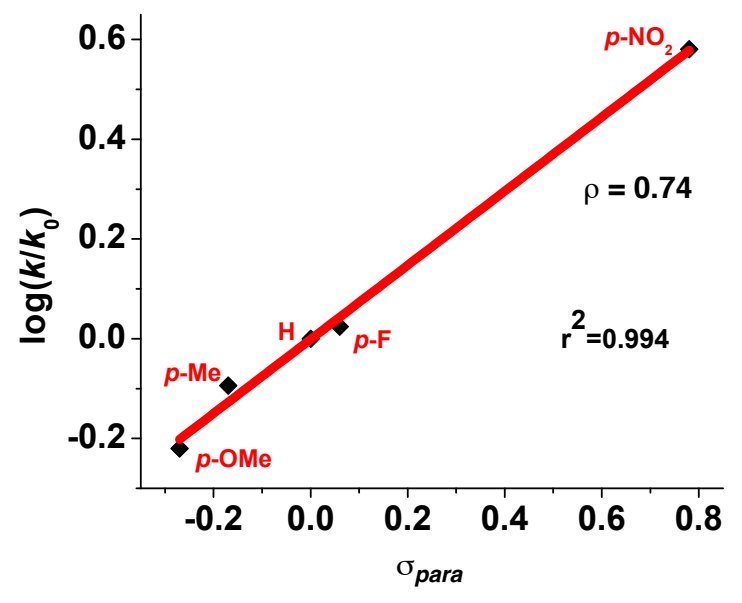

Figure 9-8. Hammett plot of substituted TA-Au catalysts

The positive $\rho$ value suggested partial positive charge building up in the transition state, which is consistent with the associative ligand substitution being the turnover-limiting step. The more electron-deficient triazole undergoes ligand exchange more rapidly, which is accounted for the faster reaction rate. This result also highlights the tunability of TA-Au catalyst.

It was also discovered that the chemoselectivity would not hold anymore if 2,4dinitrophenyl substituted $\mathrm{TA}-\mathrm{Au}$ catalyst was used. The reaction progress was nicely demonstrated below as a perfect model for consecutive reactions. Estimating the relative rate constant of two steps gives a ratio higher than 10 for $\mathrm{k}_{1} / \mathrm{k}_{2}$. Therefore this explains the chemoselectivity associated with the TA-Au. 

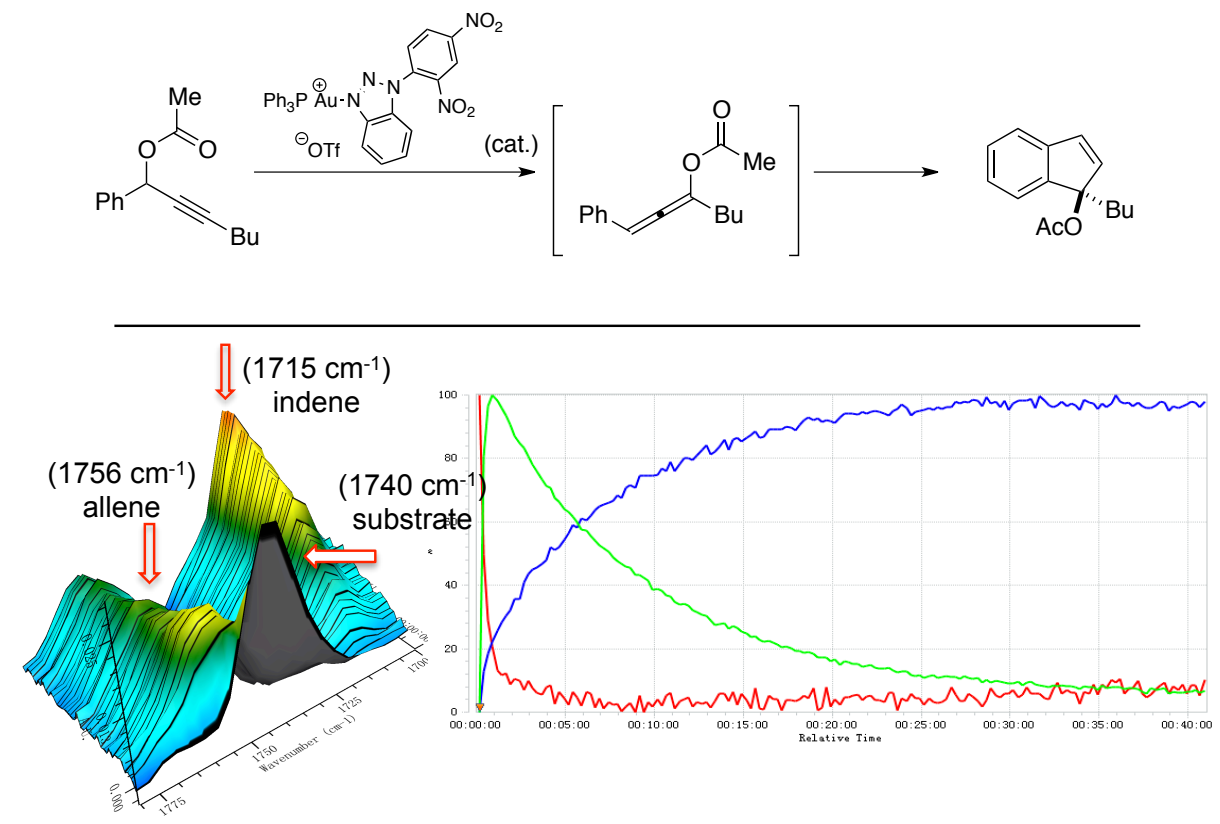

Figure 9-9. Kinetics with 2,4-dinitrophenyl substituted TA-Au

\subsection{Theoretical Discussion}

Finally, DFT calculation was used to explain the origin of chemoselectivity of the TA$\mathrm{Au}$ catalysts (activation of alkyne over allene). ${ }^{50}$ DFT calculation revealed the HOMO of propargyl ester 6 is $20 \mathrm{kcal} / \mathrm{mol}$ higher than the HOMO of allene 7. Thus, the ligand exchange is much slower between allene and TA-Au, which supports the observed selective alkyne activation. 


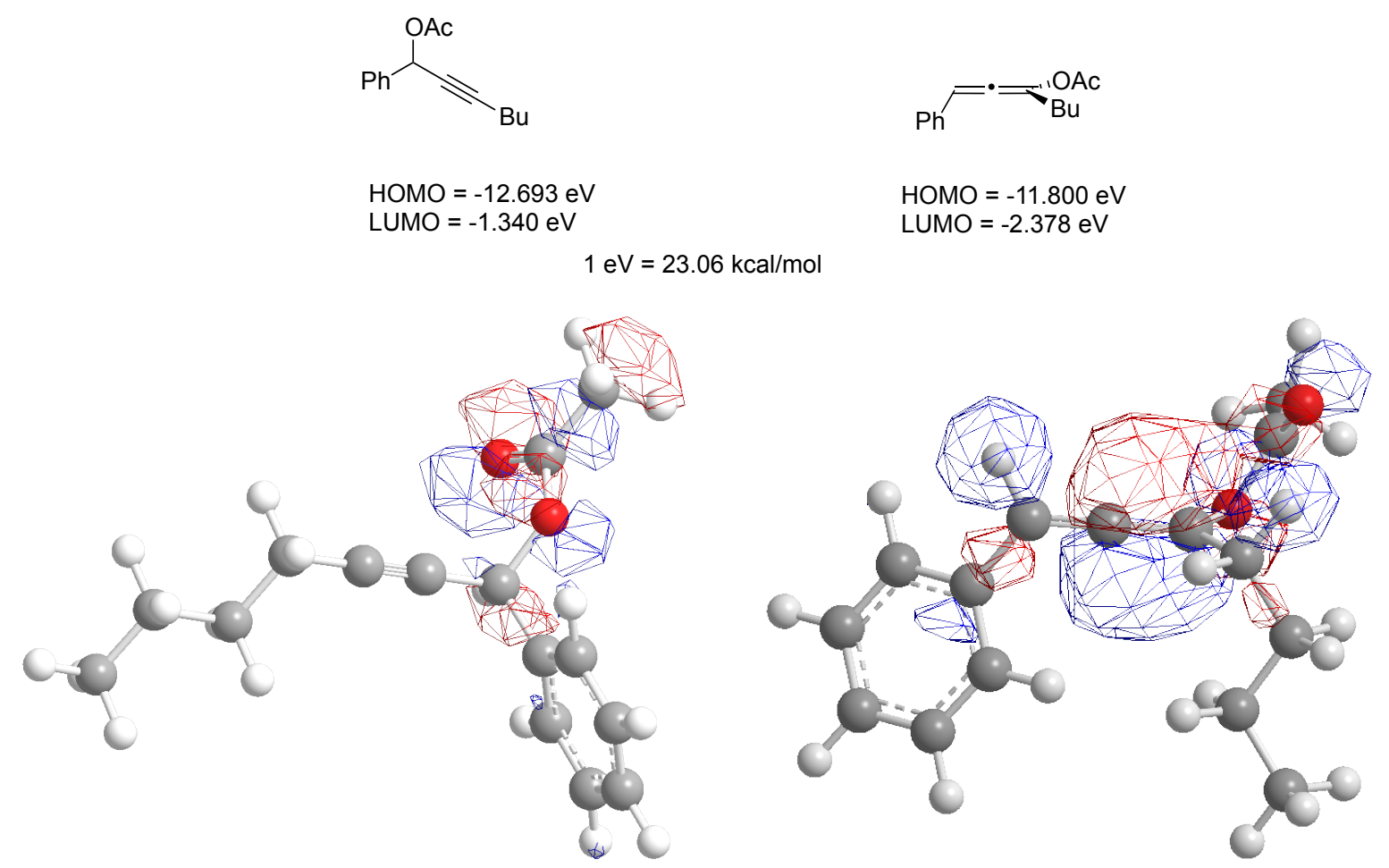

Figure 9-10. DFT calculation

\subsection{Implication for Triazole-Gold/Lewis Acid System}

In general, the gold catalysis community accepts that the protodeauration is turnoverlimiting in a variety of reactions. However, a series of experiments described in this Chapter reveals that the turnover-limiting step in TA-Au catalysis is the associative ligand exchange. This switch in turnover-limiting step may have some implication for future study.

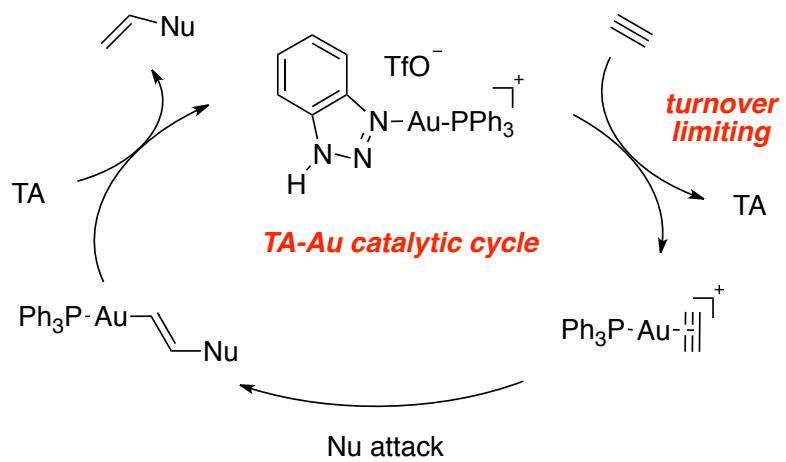

Scheme 9-4. General mechanism for TA-Au catalysis 
For example, as previously investigated in depth, the triazole-gold/Lewis acid system can be explained with this result. A dual catalysis can be invoked to explain the superior catalytic activity for the bimetallic system.

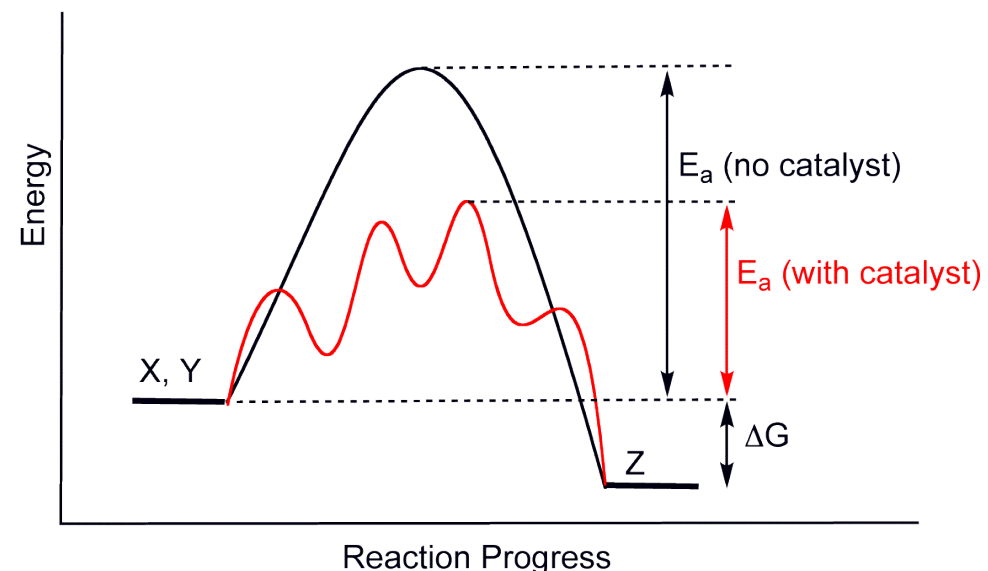

Figure 9-11. Energy diagram for catalysis

The role of Lewis acid may involve facilitating the turnover-limiting ligand exchange by weakening the coordination of triazole with gold cation. The mechanism may include the pre-coordination of Lewis on $\mathrm{N} 2$ position of benzotriazole, followed by alkyne approaching. This process is kinetically and thermodynamically favoured because gallium triflate lowers the activation barrier and the system gains a net stabilization of binding affinity of gallium triflate with triazole. 


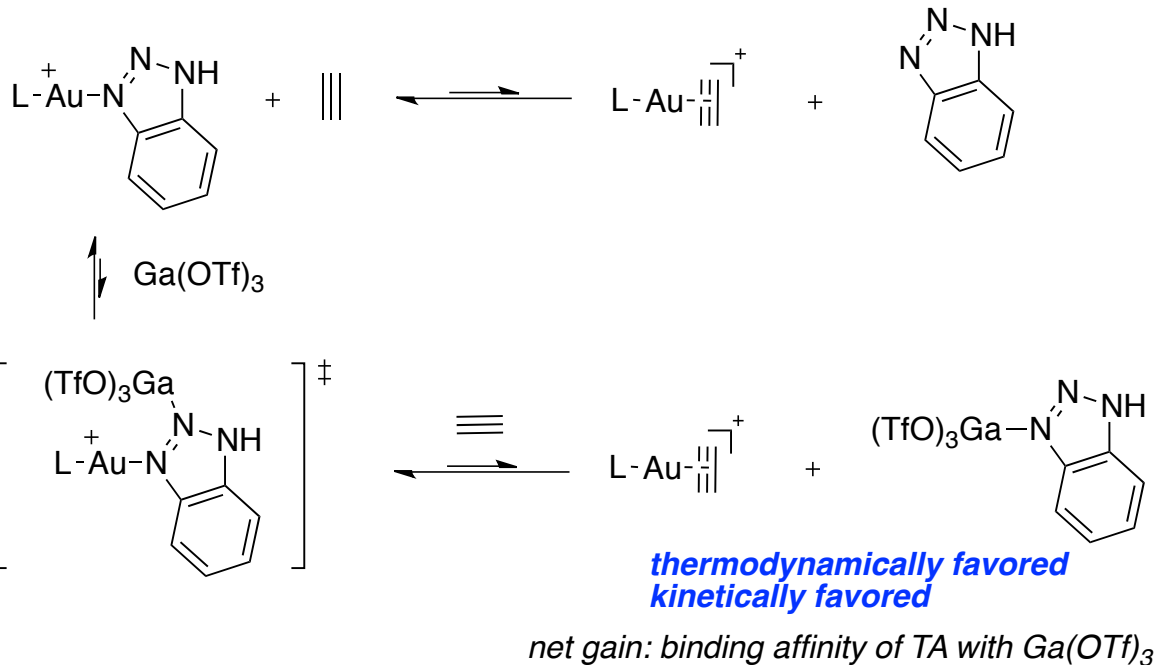

Scheme 9-5. Rationale for Lewis acid induced rate acceleration

Further physical organic investigation of such a process is under investigation. 


\section{Chapter 10. Reference}

$1 \mathrm{http} / / /$ www.nobelprize.org/nobel_prizes/chemistry/

2 Ito, Y.; Sawamura, M.; Hayashi, T. J. Am. Chem. Soc. 1986, 108, 6405

3 Teles, J. H.; Brode, S.; Chabanas, M. Angew. Chem., Int. Ed. 1998, 37, 1415

4 Trost, B. M.; Dong, G. Nature 2008, 456, 485.

5 Gorin, D. J.; Toste, F. D. Nature 2007, 446, 395.

6 (a) Modern Gold Catalyzed Synthesis; Hashmi, A. S. K.; Toste, F. D., Ed.; Wiley-VCH: Weinheim, 2012; (b) Hashmi, A. S. K.; Rudolph, M. Chem. Soc. Rev. 2012, 41, 2448; (c) Gorin, D. J.; Sherry, B. D.; Toste, F. D. Chem. Rev. 2008, 108, 3351; (d) Arcadi, A. Chem. Rev. 2008, 108, 3266; (e) Jiménez-Núñez, E.; Echavarren, A. M. Chem. Rev. 2008, 108, 3326; (f) Widenhoefer, R. A. Chem. Eur. J. 2008, 14, 5382; (g) Hashmi, A. S. K. Chem. Rev. 2007, 107, 3180; (h) Fürstner, A.; Davies, P. W. Angew. Chem. Int. Ed. 2007, 46, 3410; (i) Zhang, L.; Sun, J.; Kozmin, S. A. Adv. Synth. Catal. 2006, 348, 2271; (j) Hashmi, A. S. K.; Hutchings, G. J. Angew. Chem. Int. Ed. 2006, 45, 7896.

7 Shapiro, N. D.; Toste, F. D. Proc. Nat. Acad. Sci. U.S.A. 2008, 105, 2779.

8 Liu, L.-P.; Xu, B.; Mashuta, M. S.; Hammond, G. B. J. Am. Chem. Soc. 2008, 130,17642

9 Akana, J. A.; Bhattachayya, K. X.; Müller, P.; Sadighi, J. P. J. Am. Chem. Soc. 2007, 129, 7736.

10 Kumar, M.; Jasinski, J.; Hammond, G. B.; Xu, B. Chem. Eur. J. 2014, 20, 3113.

11 Oliver-Meseguer, J.; Cabrero-Antonino, J. R.; Domínguez, I.; Leyva-Pérez, A.; Corma, A. Science 2012, 338, 1452.

12 J. Oliver-Meseguer, A. Leyva-Pérez and A. Corma, ChemCatChem, 2013, 5, 3509.

13 (a) Weber, D; Gagné, M. R. Org. Lett., 2009, 11, 4962; (b) Wang, D.; Cai, R.; Sharma, S.; Jirak, J.; Thummanapelli, S. K.; Akhmedov, N. G.; Zhang, H.; Liu, X.; Petersen, J. L.; Shi, X. J. Am. Chem. Soc. 2012, 134, 9012.

14 (a) Brown, T. J.; Weber, D.; Gagné, D.; Widenhoefer, R. A. J. Am. Chem. Soc. 2012, 134, 9134; (b) Weber, D.; Tarselli, M. A.; Gagné, M. R. Angew. Chem. Int. Ed. 2009, 48, 5733.

15 Zhang, L. Acc. Chem. Res., Article ASAP.

16 Yan, W.; Liao, T.; Tuguldur, O.; Zhong, C.; Petersen, J. L.; Shi, X. Chem. Asian. J. 2011, 6, 2720-2724.

17 Yan, W.; Ye, X.; Weise, K.; Petersen, J. L.; Shi, X. Chem. Commun. 2012, 48, 3521.

18 Liu, Y.; Yan, W.; Chen, Y.; Petersen, J. L.; Shi, X. Org. Lett. 2008, 10, 5389-5392. 
19 Duan, H.; Sengupta, S.; Petersen, J. L.; Akhmedov, N.; Shi, X. J. Am. Chem. Soc. 2009, 131, 12100.

20 Wang, D.; Ye, X.; Shi, X. Org. Lett. 2010,12, 2088-2091.

21 Wang, D.; Gautam, L. N. S.; Bollinger, C.; Harris, A.; Li, M.; Shi, X. Org. Lett. 2011, 13, 2618.

22 Wang, Q.; Aparaj, S.; Akhmedov, N. G.; Petersen, J. L.; Shi, X. Org. Lett. 2012, 14, 1334.

23 Wang, D.; Cai, R.; Sharma, S.; Jirak, J.; Thummanapelli, S. K.; Akhmedov, N. G.; Zhang, H.; Liu, X.; Petersen, J. L.; Shi, X. J. Am. Chem. Soc. 2012, 134, 9012.

24 (a) Weber, S. G.; Rominger, F.; Straub, B. F. Eur. J. Inorg. Chem., 2012, 2863; (b) Zhu, Y.;

Day, C. S.; Zhang, L.; Hauser, K. J.; Jones, A. C. Chem. Eur. J., 2013, 19, 12264.

25 Homs, A.; Escofet, I.; Echavarren, A. M. Org. Lett., 2013, 15, 5782. References cited therein.

26 (a) Kennedy-Smith, J. J.; Staben, S. T.; Toste, F. D. J. Am. Chem. Soc. 2004, 126, 4526; (b) Staben, S. T.; Kennedy-Smith, J. J.; Toste, F. D. Angew. Chem. Int. Ed. 2004, 43, 5350.

27 (a) Nakamura, M.; Endo, K.; Nakamura, E. J. Am. Chem. Soc. 2003, 125, 13002; (b) Endo, K.; Hatakeyama, T.; Nakamura, M.; Nakamura, E. J. Am. Chem. Soc. 2007, 129, 5264; an enantioseletive version has been reported: (c) Fujimoto, T.; Endo, K.; Tsuji, H.; Nakamura, M.; Nakamura, E. J. Am. Chem. Soc. 2008, 130, 4492.

28 Allen, A. E.; MacMillan, D. W. C. Chem. Sci. 2012, 3, 633.

29 Although gallium(III) halides $(\mathrm{Cl}, \mathrm{Br}$ and $\mathrm{I})$ can serve as $\pi$-acid in promoting alkyneparticipating transformations, there have been no reports using $\mathrm{Ga}(\mathrm{OTf})_{3}$ as $\pi$-acid toward alkyne activation. Gandon reported a $\mathrm{GaCl} 3$-catalyzed cycloisomerization/Friedel-Crafts tandem reaction: Li, H.-J.; Guillot, R.; Gandon, V. J. Org. Chem. 2010, 75, 8435. However, this reaction cannot be catalyzed $\mathrm{Ga}(\mathrm{OTf})_{3}$. For a recent review on $\mathrm{Ga}(\mathrm{OTf})_{3}$, see: Prakash, $\mathrm{G}$. K. S.; Mathew, T.; Olah, G. A. Acc. Chem. Res. 2012, 45, 565.

30 Luzung, M. R.; Markham, J. P.; Toste, F. D. J. Am. Chem. Soc. 2004, 126, 10858.

31 Marion, N.; Díez-Gonzalez, S.; Fremont, P.; Noble, A. R.; Nolan, S. P. Angew. Chem. Int. Ed., 2006, 45, 3647.

32 Oliver-Meseguer, J.; Cabrero-Antonino, J. R.; Domínguez, I.; Leyva-Pérez, A.; Corma, A. Science 2012, 338, 1452.

33 (a) Mizushima, E.; Sato, K.; Hayashi, T.; Tanaka, M. Angew. Chem. Int. Ed. 2002, 41, 4563-4565; (b) Leyva, A.; Corma, A. J. Org. Chem. 2009, 74, 2067-2074; (c) Marion, N.; Ramón, R. S.; Nolan, S. P. J. Am. Chem. Soc. 2009, 131, 448-449; (d) Krauter, C. M.; Hashmi, 
A. S. K.; Pernpointner, M. ChemCatChem 2010, 2, 1226-1230; (e) Corma, A.; Ruiz, V. R.; Leyva-Pérez, A.; Sabater, M. J. Adv. Synth. Catal. 2010, 352, 1701-1710.

34 a) Vigalok, A. C-X Bond Formation, Springer, Heidelberg, 2010; b) Yudin, A. K. Catalyzed Carbon-Heteroatom Bond Formation, Wiley-VCH, Weinheim, 2012; c) Liu, H.; Jiang, X. Chem. Asian J. 2013, 8, 2546.

35 a) Morita, N.; Krause, N. Angew. Chem. Int. Ed. 2006, 45, 1897; b) Nakamura, I.; Sato, T.; Yamamoto, Y. Angew. Chem. Int. Ed. 2006, 45, 4473-4475; c) Davies, P. W.; Albrecht, S. J. C. Chem. Commun. 2008, 238; d) Nakamura, I.; Sato, T.; Terada, M.; Yamamoto, Y. Org. Lett. 2008, 10, 2649; e) Santos, L. L.; Ruiz, V. R.; Sabater, M. J.; Corma, A. Tetrahedron 2008, 64, 7902; f) Aponick, A.; Li, C.-Y.; Malinge, J.; Marques, E. F. Org. Lett. 2009, 11, 4624; g) Zhao, X.; Zhong, Z.; Peng, L.; Zhang, W.; Wang, J. Chem. Commun. 2009, 2535; h) Davies, P. W.; Albrecht, S. J. C. Angew. Chem. Int. Ed. 2009, 48, 8372; i) Jean, M.; Renault, J.; van de Weghe, P.; Asao, N. Tetrahedron Lett. 2010, 51, 378; j) Mudd, R. J.; Young, P. C.; Jordan-Hore, J. A.; Rosair, G. M.; Lee, A.-L. J. Org. Chem. 2012, 77, 7633; k) Corma, A.; Leyva-Pérez, A.; Sabater, M. J. Chem. Rev. 2011, 111, 1657.

36 Young, P. C.; Green, S. L. J.; Rosair, G. M.; Lee A.-L. Dalton Trans. 2013, 42, 9645.

37 a) Chary, B. C.; Kim, S. J. Org. Chem. 2010, 75, 7928; b) Luo, T.; Dai, M.; Zheng, S.-L.; Schreiber, S. L. Org. Lett. 2011, 13, 2834; c) Kuram, M. R.; Bhanuchandra, M.; Sahoo, A. K. J. Org. Chem. 2010, 75, 2247; d) Lee, P. H.; Kim, S.; Park, A.; Chary, B. C.; Kim, S. Angew. Chem. Int. Ed. 2010, 49, 6806; sulfonic acids are also successful substrates for such addition, see: d) Cui, D-M.; Meng, Q.; Zheng, J.-Z.; Zhang, C. Chem. Commun. 2009, 1577.

38 a) Nair, V.; Augustine, A.; Suja, T. D. Synthesis 2002, 2259; b) Meadows, D. C.; GervayHague, J. Med. Res. Rev. 2006, 26, 793; c) Qian H.; Huang, X. Synlett 2001, 1913; d) Huang, X.; Duan, D.; Zheng, W. J. Org. Chem. 2003, 68, 1958; e) Xu, W. M.; Tang, E.; Huang, X. Synthesis 2004, 2094; f) Cacchi, S.; Fabrizi, G.; Goggiamani, A.; Parisi, L. M.; Bernini, R. J. Org. Chem. 2004, 69, 5608; g) Díez, D.; García, P.; Marcos, I. S.; Garrido, N. M.; Basabe, P.; Broughton, H. B.; Urones, J. G. Tetrahedron 2005, 61, 699; h) Guan, Z.-H.; Zuo, W.; Zhao, L.B.; Ren, Z.-H.; Liang, Y.-M. Synthesis, 2007, 1465; i) Signore, G.; Malanga, C.; Menicagli, R. Tetrahedron 2008, 64, 11218; j) Das, B.; Lingaiah, M.; Damodar, K.; Bhunia, N. Synthesis, 2011, 2941; k) Liang, S.; Zhang, R.-Y.; Wang, G.; Chen, S.-Y.; Yu, X.-Q. Eur. J. Org. Chem. 2013, 7050.

39 a) Baskin, J. M.; Wang, Z. Org. Lett. 2002, 4, 4423; b) Nair, V.; Augustine, A.; George, T. G.; Nair, L. G. Tetrahedron Lett. 2001, 42, 6763; c) Cacchi, S.; Fabrizi, G.; Goggiamani, A.; 
Parisi, L. M.; Bernini, R. J. Org. Chem., 2004, 69, 5608; d) Battace, A.; Zair, T.; Doucet, H.; Santelli, M. Synthesis, 2006, 3495; e) Huang, F.; Batey, R. A. Tetrahedron 2007, 63, 7667; e) Bian, M.; Xu, F.; Ma, C. Synthesis 2007, 2951; f) Reeves, D. C.; Rodriguez, S.; Lee, H.; Hahhad, N.; Krishnamurthy, D.; Senanayake, C. H. Tetrahedron Lett., 2009, 50, 2870; g) Xu, Q.-L.; Dai, L.-X.; You, S.-L. Org. Lett. 2010, 12, 800; h) Taniguchi, N. Synlett 2011, 1308; i) Taniguchi, N. Synlett 2012, 124; i) Lu, Q.; Zhang, J.; Zhao, G.; Qi, Y.; Wang, H.; Lei, A. J. Am. Chem. Soc. 2013, 135, 11481; j) Chawla, R.; Kapoor, R.; Singh, A. K.; Yadav, L. D. S. Green Chem. 2012, 14, 1308; k) Lee, J. W.; Lee, C.-W.; Jung, J. H.; Oh, D. Y. Synth. Commun. 2000, 30, 2897; 1) Inomata, K.; Sasaoka, S.-i.; Kobayashi, T.; Tanaka, Y.; Igarashi, S.; Ohtani, T.; Kinoshita, H.; Kotake, H. Bull. Chem. Soc. Jpn. 1987, 60, 1767; m) Inomata, K.; Kobayashi, T.; Sasaoka, S.-i.; Kinoshita, H.; Kotake, H. Chem. Lett. 1986, 15, 289; n) Hendrickson, J. B.; Palumbo, P. S. Tetrahedron Lett. 1985, 26, 2849; o) Hsiao, C-N.; Shechter, H. Tetrahedron Lett. 1982, 23, 3455; p) Back, T. G.; Collins, S. J. Org. Chem. 1981, 46, 3249; q) Kotake, H.; Inomata, K.; Sumita, M. Chem. Lett. 1978, 7, 717; r) Chodroff, S.; Whitmore, W. J. Am. Chem. Soc. 1950, 72. 1073.

40 a) Backvall, J.-E.; Juntunen, S. K. J. Am. Chem. Soc. 1987, 109, 66; b) Chou, T.-S.; Hung, S.-C. J. Org. Chem. 1988, 53, 3020; c) de la Pradilla, R. F.; Montero, C.; Tortosa, M.; Viso, A. Chem. Eur. J. 2005, 11, 5136.

41 a) Palmer, J. T.; Rasnick, D.; Klaus, J. L.; Bromme, D. J. Med. Chem. 1995, 38, 3193; b) Santos, M. M. M.; Moreira, R. Mini Rev. Med. Chem. 2007, 7, 1040; c) Kerr, I. D.; Lee, J. H.; Farady, C. J.; Marion, R.; Rickert, M.; Kailash, M. S.; Pandey, C.; Caffrey, C. R.; Legac, J. ; Hansell, E.; McKerrow, J. H.; Craik, C. S.; Rosenthal, P. J.; Brinen, L. S. J. Biol. Chem. 2009, 284, 25697; d) Kisselev, A. F.; van der Linden, W. A.; Overkleeft, H. S. Chem. Biol. 2012, 19, 99; e) Ni, L.; Zheng, X. S.; Somers, P. K.; Hoong, L. K.; Hill, R. R.; Marino, E. M.; Suen, K.L.; Saxena, U.; Meng, C. Q. Bioorg. Med. Chem. Lett. 2003, 13, 745.

[41] a) Morales-Sanfrutos, J.; Lopez-Jaramillo, J.; Ortega-Munoz, M.; Megia-Fernandez, A.; Perez-Balderas, F.; Hernandez-Mateo, F.; Santoyo-Gonzalez, F. Org. Biomol. Chem. 2010, 8, 667; b) Lopez-Jaramillo, F. J.; Hernandez-Mateo, F.; Santoyo-Gonzalez, F. Vinyl Sulfone: A Multi-Purpose Function in Proteomics, Integrative Proteomics, H.-C. Leung (Ed.), 2012, InTech, DOI: 10.5772/29682.

42 Back, T. G.; Parvez, M.; Zhai, H. J. Org. Chem. 2003, 68, 9389. 
43 (a) Brown, T. J.; Dickens, M. G., Widenhoefer, R. A. J. Am. Chem. Soc., 2009, 131, 6350; (b) Brown, T. J.; Sugie, A.; Leed, M. G. D.; Widenhoefer, R. A. Chem. Eur. J., 2012, 18, 6959; (c) Brooner, R. E. M.; Brown, T. J.; Widenhoefer, R. A. Chem. Eur. J., 2013, 19, 8276.

44 Marion, N.; Díez-Gonzalez, S.; Fremont, P.; Noble, A. R.; Nolan, S. P. Angew. Chem. Int. Ed., 2006, 45, 3647.

45 (a) Wang, D.; Gautam, L. N. S.; Bollinger, C.; Harris, A.; Li, M.; Shi, X. Org. Lett., 2011, 13, 2618; (b) Wang, D.; Ye, X.; Shi, X. Org. Lett., 2010, 12, 2088-2091.

46 (a) He, C.; Ke, J.; Xu, H.; Lei, A. Angew. Chem. Int. Ed., 2013, 52, 1527; (b) Huang, Z.; Jin, L.; Han, H.; Lei, A. Org. Biomol. Chem., 2013, 11, 1810; (c) Li, J.; Jin, L.; Liu, C.; Lei, A. Chem. Commun., 2013, 49, 9615

47 Nun, P.; Gaillard, S.; Slawin, A. M. Z.; Nolan, S. P. Chem. Commun., 2010, 46, 9113.

48 Nieto-Oberhuber, C.; López, S.; Muñoz, M. P.; Cárdenas, D. J.; Buñuel, E.; Nevado, C.; Echavarren, A. M. Angew. Chem. Int. Ed., 2005, 44, 6146.

49 Wang, K.; Chen, M.; Wang, Q.; Shi, X.; Lee, J. K. J. Org. Chem., 2013, 78, 7249.

50 DFT calculation was performed on Gaussian 03 program at the B3LYP/6-311G level of theory. 